UNIVERSIDADE DE SÃO PAULO

ESCOLA POLITÉCNICA

DORIEDSON ALVES GALDINO DE OLIVEIRA

Roteamento com múltiplas métricas em redes de sensores sem fio definidas por software 


\title{
Roteamento com múltiplas métricas em redes de sensores sem fio definidas por software
}

\author{
Versão Corrigida \\ (Versão original encontra-se na unidade que aloja o Programa de Pós-graduação) \\ Dissertação apresentada à Escola Politécnica da Universi- \\ dade de São Paulo para obtenção do Título de Mestre em \\ Ciências.
}

Área de Concentração: Engenharia de Computação

Orientadora:

$\operatorname{Prof}^{a}$. Dr ${ }^{a}$. Cíntia Borges Margi 
Autorizo a reprodução e divulgação total ou parcial deste trabalho, por qualquer meio convencional ou eletrônico, para fins de estudo e pesquisa, desde que citada a fonte.

Este exemplar foi revisado e corrigido em relação à versão original, sob responsabilidade única do autor e com a anuência de seu orientador.

São Paulo, de de

Assinatura do autor:

Assinatura do orientador:

\section{Catalogação-na-publicação}

Oliveira, Doriedson Alves Galdino de

Roteamento com múltiplas métricas em redes de sensores sem fio definidas por software / D. A. G. Oliveira -- versão corr. -- São Paulo, 2020. $88 \mathrm{p}$.

Dissertação (Mestrado) - Escola Politécnica da Universidade de São Paulo. Departamento de Engenharia de Computação e Sistemas Digitais.

1.Wireless 2.Redes de sensores 3.Roteamento 4.Combinação de métricas I.Universidade de São Paulo. Escola Politécnica. Departamento de Engenharia de Computação e Sistemas Digitais II.t. 


\section{AGRADECIMENTOS}

A minha orientadora profa. Cíntia Borges Margi pela paciência, compreensão nos momentos difíceis, confiança, orientações que sem elas eu não poderia realizar este trabalho e ensinamentos valiosos que levarei para toda a vida.

A profa. Anna Helena Reali Costa pelas reuniões que nortearam a lógica da combinação das métricas.

A minha esposa Regilene Alves Galdino de Oliveira, com amor, admiração e gratidão por sua compreensão, carinho, presença e incansável apoio ao longo do período de elaboração deste trabalho.

A minha filha Isabelly Alves Galdino de Oliveira, por sua adaptação à minha rotina, por sua compreensão inocente nos momentos que eu não podia brincar e pelo seu amor incondicional.

Aos colegas do laboratório SEMBEI (Security and Embedded Systems Engineering group) que me ajudaram na ambientação sobre redes de sensores sem fio e às pausas aleatórias para reuniões de assuntos diversos e compartilhamento de conhecimento. 


\section{RESUMO}

As redes de sensores sem fio (RSSF) são formadas por dispositivos (nós) interconectados com capacidade de sensoriamento, atuação, processamento e comunicação. Muitas aplicações requerem o uso destes dispositivos em lugares remotos, dificultando o acesso físico e consequentemente a troca de baterias e reprogramação. O paradigma de redes definidas por software tem sido aplicado às RSSFs com o objetivo de trazer flexibilidade e melhorar o gerenciamento da rede permitindo a configuração dos nós de forma centralizada, sendo conhecido como SDWSN (do inglês Software-Defined Wireless Sensor Networks). O roteamento desempenha um importante papel no consumo de energia. Trabalhos prévios mostram que o uso da qualidade do link (ETX) como métrica na definição de rotas usualmente reduz a latência, e o uso da energia remanescente do nó como métrica deve balancear o consumo de energia na rede aumentando o tempo de vida da mesma. Dada a lacuna na literatura sobre combinações de métricas na definição de rotas em SDWSN, esta pesquisa tem como objetivo propor estratégias de uso de múltiplas métricas no algoritmo de definição de rotas em SDWSN e avaliar o impacto que o uso destas combinações causam. Na literatura, o ETX e a energia remanescente do nó são métricas bastante utilizadas em protocolos de roteamento para redes de sensores sem fio. Desta forma, escolhemos utilizar estas duas métricas para avaliar as propostas de combinações de métricas. Definimos duas estratégias principais como abordagem para as combinações das métricas. A primeira estratégia consiste no uso de uma fórmula de média ponderada na qual podemos atribuir pesos para as métricas. A segunda estratégia consiste em usar a lógica difusa na combinação das métricas abordando dois métodos de defuzificação: centroide e média dos máximos. Ambas estratégias são utilizadas na literatura para combinação das métricas em protocolos de roteamento distribuído. Primeiro, analisamos a correlação entre o ETX e a energia remanescente e concluímos que não há correlação entre as duas métricas, corroborando a premissa que a combinação alavanca as propriedades das métricas. Depois analisamos dois algoritmos de roteamento (menor caminho e menor caminho mais largo) com duas diferentes sensibilidades $(0,5$ e 1,0$)$ para cada métrica. Concluímos que o algoritmo de menor caminho obteve melhores resultados com ambas as sensibilidades. Depois analisamos as estratégias de combinação de métricas. As estratégias definidas pela equação de média ponderada e pela lógica difusa apresentaram resultados melhores que o uso das métricas individuais. Por fim, analisamos a escalabilidade da proposta com os seguintes tamanhos de rede: $25,49,81,121,169,225$ e 289 nós. O uso da equação de média ponderada como estratégia de combinação de métrica apresentou o melhor resultado na avaliação de escalabilidade, apresentando assim uma boa estratégia de combinação de métricas para uso no algoritmo de definição de rotas.

Palavras-chave: Redes de sensores sem fio definidas por software (SDWSN). Métrica de roteamento. Lógica difusa. Energia remanescente. Número esperado de transmissões (ETX). 


\begin{abstract}
Wireless sensors networks (WSN) are composed by interconnected devices (nodes) with capability to sense, actuate, process and communicate. Many applications deploy the devices at a remote location making it difficult to replace batteries and reprogram the node. The software-defined networking paradigm has been applied to WSN with the goal to achieve flexibility and improve network management enabling centralized configuration of nodes, approach known as SDWSN (Software-Defined Wireless Sensor Networks). Routing plays an important role in energy consumption. Previous work shows that the use of link quality (ETX) as a routing metric usually decreases latency and the use of remaining energy as a metric should balance the network energy consumption increasing network lifetime. Given the gap in the literature about metric combination in SDWSN routing definition, in this research we propose strategies to use multiple metrics in SDWSN routing algorithm and assess the impact from these combinations on network. In the literature, ETX and remaining energy are often used as metrics in WSNs routing protocols. Thus, we choose to use these two metrics to evaluate our metric combination strategy. We defined two strategies for metric combination. The first strategy is to use the weighted average equation where we can assign weights to the metrics. The second strategy is to use the fuzzy logic to combine the metrics by addressing two methods of defuzzification: centroid and mean of maximum. Both strategies are used in the literature to combine metrics in distributed routing protocols. First we analyze the correlation between ETX and the remaining energy, and conclude that there is no correlation between the two metrics, corroborating the premise that the combination leverages the properties of the metrics. Then we analyze two routing algorithms (shortest path and widest shortest path) with two different sensitivity values (0.5 and 1.0) for each metric. We conclude that the shortest path algorithm yields better results with both sensitivity values. Then we analyze the metric combination strategies. The strategies defined by the weighted average equation and the fuzzy logic present better results than the use of individual metrics. Finally, we analyze the scalability of the proposal with the following network sizes: 25, 49, 81, 121, 169, 225 and 289 nodes. The use of the weighted average equation as a metric combination strategy presents the best result in the scalability evaluation, thus presenting a good metric combination strategy for use in the route definition algorithm.
\end{abstract}

Keywords: Software defined wireless sensor networks (SDWSN). Routing metric. Fuzzy logic. Remaining energy. Expected transmission count (ETX). 


\section{LISTA DE FIGURAS}

1 Exemplo do conceito de redes definidas por software em comparação às redes tradicionais. . . . . . . . . . . . . . . . . . . . . . . 22

2 Exemplos de gráficos de dispersão. . . . . . . . . . . . . . . . . . 28

3 Funções de pertinência para fuzificação das variáveis de entrada (ETX e energia remanescente). . . . . . . . . . . . . . . 31

$4 \quad$ Função de pertinência para variável de saída (métrica). . . . . . . . . 31

5 Gráficos de dispersão para análise de correlação entre as métricas ETX e energia remanescente. . . . . . . . . . . . . . . . 36

6 Seleção de rotas alternativas de acordo com algoritmo usado através do uso da energia remanescente como peso da aresta. . . . . . . . . . 38

$7 \quad$ Funções de pertinência para fuzificação das variáveis de entrada. . . . . 40

8 Função de pertinência para defuzificação da métrica. . . . . . . . . . . 42

9 Superfície 3D demonstrando a relação entre os valores das métricas de entrada e os valores da métrica resultante da combinação que cada método de defuzificação provê. As cores da superfície são meramente ilustrativas não representando informação relevante. . . . . . . . . . .

10 Topologia em grade (9x9) com controlador no centro (\#41) e sorvedouro no centro superior (\#37). O círculo verde representa o alcance do rádio, limitado aos nós adjacentes.

11 Tempo médio de vida da rede por cenário com seus respectivos intervalos de confiança. . . . . . . . . . . . . . . . . . .

12 Taxa média de entrega de dados por cenário com seus respectivos intervalos de confiança. . . . . . . . . . . . . . . . . . . 48

13 Média das sobrecargas de controle por cenário com seus respectivos intervalos de confiança. . . . . . . . . . . . . . . . . . . 
14 Média do número de alterações de rotas por cenário com seus respectivos intervalos de confiança. . . . . . . . . . . . . . . 50

15 Consumo médio de energia da rede por cenário com seus respectivos intervalos de confiança. . . . . . . . . . . . . . . 51

16 Consumo médio de energia por pacote de dados entregue por cenário com seus respectivos intervalos de confiança. . . . . . . . . . . 52

17 Probabilidade acumulada de atraso fim a fim para os pacotes de dados de 10 simulações por cenário com percentil em 95\% . . . . . . . . . 53

18 Tempo médio de vida da rede por cenário com seus respectivos intervalos de confiança. . . . . . . . . . . . . . . . . . . 59

19 Taxa média de entrega de dados por cenário com seus respectivos intervalos de confiança. . . . . . . . . . . . . . . . . . 60

20 Média das sobrecargas de controle por cenário com seus respectivos intervalos de confiança. . . . . . . . . . . . . . . . . . 60

21 Média do número de alterações de rotas por cenário com seus respectivos intervalos de confiança. . . . . . . . . . . . . . . . 61

22 Consumo médio de energia da rede por cenário com seus respectivos intervalos de confiança. . . . . . . . . . . . . . . . 62

23 Consumo médio de energia por pacote de dados entregue por cenário com seus respectivos intervalos de confiança. . . . . . . . . . . 62

24 Probabilidade acumulada de atraso fim a fim para pacote de dados de 10 simulações por cenário com percentil em 95\% . . . . . . . . . . 63

25 Topologia em grade $(7 \times 7)$ com controlador no centro (\#25) e sorvedouro no centro superior $(\# 22) \ldots \ldots \ldots$

26 Tempo médio de vida da rede por cenário com seus respectivos intervalos de confiança. . . . . . . . . . . . . . . . . . . . 69

27 Taxa média de entrega de dados por cenário com seus respectivos intervalos de confiança. . . . . . . . . . . . . . . . 70

28 Média das sobrecargas de controle por cenário com seus respectivos intervalo de confiança. . . . . . . . . . . . . . . . 70 
29 Média do número de alterações de rotas por hora/nó por cenário com seus respectivos intervalos de confiança. . . . . . . . . . . . 71

30 Consumo médio de energia da rede por cenário com seus respectivos intervalos de confiança. . . . . . . . . . . . . . . 72

31 Consumo médio de energia por pacote de dados entregue por cenário com seus respectivos intervalos de confiança. . . . . . . . . . . 73

32 Probabilidade acumulada de atraso fim a fim para os pacotes de dados de 10 simulações por cenário com percentil em 95\% para o CENÁRIO ETX/ENERGIA $(0,5) \ldots \ldots \ldots \ldots \ldots$

33 Probabilidade acumulada de atraso fim a fim para os pacotes de dados de 10 simulações por cenário com percentil em 95\% para o CENÁRIO CENTROIDE $(0,5) \ldots \ldots \ldots \ldots \ldots \ldots \ldots$

34 Probabilidade acumulada de atraso fim a fim para os pacotes de dados de 10 simulações por cenário com percentil em 95\% para o CENÁRIO

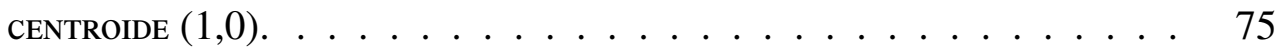

35 Probabilidade acumulada de atraso fim a fim para os pacotes de dados de 10 simulações por cenário com percentil em 95\% para o CENÁRIO

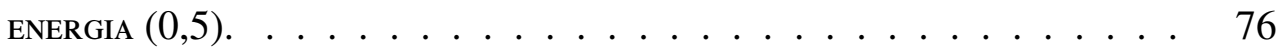

36 Superfície 3D demonstrando a relação entre os valores das métricas de entrada e os valores da métrica resultante da combinação que cada método de defuzificação provê. As cores da superfície são meramente ilustrativas não representando informação relevante. . . . . . . . . . . 


\section{LISTA DE TABELAS}

1 Implementação, algoritmo de definição de rotas e métrica de roteamento dos arcabouços descritos acima para o desenvolvimento de aplicações para SDWSN encontrados na literatura. . . . . . . . . . . 27

2 Coeficientes de Pearson e Spearman demonstrando a diferença no cálculo de correlação entre duas métricas. . . . . . . . . . . . . . . . 29

3 Fuzificação da variável ETX com valor $25 \ldots 32$

4 Fuzificação da variável EnRem com valor 75 . . . . . . . . . . . 32

5 Base de regras para inferência $\ldots \ldots \ldots 32$

6 Aplicação das regras de inferência . . . . . . . . . . . . . 33

7 Coeficientes de Spearman para análise de correlação entre duas métricas em três cenários distintos. . . . . . . . . . . . . . . . 37

8 Regras base para o cálculo da métrica fuzificada de saída. . . . . . . . 40

9 Cenários elaborados através das combinações entre os algoritmos de definição de rotas, valores de sensibilidade e métricas . . . . . . . . . 45

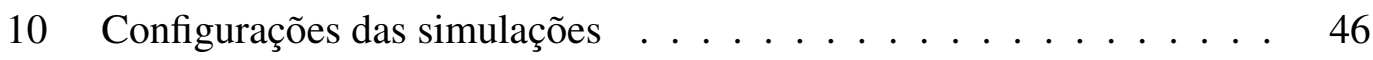

11 Mapas de média da energia remanescente dos nós da rede por cenário para análise da distribuição no consumo de energia entre os nós. . . .

12 Classificação e ordenação dos cenários para a métrica tempo médio de vida da rede. . . . . . . . . . . . . . . . . . . . .

13 Classificação geral dos cenários ordenados pela pontuação obtida através da soma das classificações das métricas avaliadas. . . . . . . . . 56

14 Nomenclatura dos cenários e seus principais parâmetros. . . . . . . . 58

15 Mapas de média da energia remanescente dos nós da rede por cenário para análise da distribuição no consumo de energia entre os nós. . . .

16 Classificação geral dos cenários ordenados pela pontuação obtida através da soma das classificações das métricas avaliadas. . . . . . . . . 65 
17 Configurações das simulações. . . . . . . . . . . . . . . . . . 68

18 Atraso fim a fim ordenado do menor para o maior por tamanho de rede para definição do melhor cenário. . . . . . . . . . . . . . . . . . 77

19 Mapas de média da energia remanescente dos nós da rede por cenário para análise da distribuição no consumo de energia entre os nós. . . . 78

20 Classificação dos cenários. . . . . . . . . . . . . . . . . . . . . . . 79

21 Classificação dos cenários com aplicação de pesos priorizando a redução no atraso fim a fim. . . . . . . . . . . . . . . . . . . . . . 80

22 Classificação dos cenários com aplicação de pesos priorizando o aumento no tempo de vida da rede. . . . . . . . . . . . . . . . . . 81 


\section{LISTA DE SIGLAS}

\begin{tabular}{|c|c|}
\hline $\mathrm{ACO}$ & Ant Colony Optimization \\
\hline COOJA & Contiki Operating System Java Simulator \\
\hline CTP & Collection Tree Protocol \\
\hline DAG & Directed Acyclic Graph \\
\hline DIO & DODAG Information Object \\
\hline DODAG & Destination Oriented DAG \\
\hline ETX & Expected Transmission Count \\
\hline IEEE & Institute of Electrical and Electronics Engineers \\
\hline IETF & Internet Engineering Task Force \\
\hline IP & Internet Protocol \\
\hline IPv6 & Internet Protocol version 6 \\
\hline IT-SDN & Improved TinySDN \\
\hline MAC & Media Access Control \\
\hline MES & Multi-dimensional Energy Space \\
\hline MOM & Mean of Maximum \\
\hline NWPSO & Non-linear Weight Particle Swarm Optimization \\
\hline OJIOT & Open Journal of Internet Of Things \\
\hline PROMELA & Process or Protocol Meta Language \\
\hline PDR & Packet Delivery Rate \\
\hline PSO & Particle Swarm Optimization \\
\hline RPL & Routing Protocol for Low Power and Lossy Networks \\
\hline RSSF & Redes de Sensores Sem Fio \\
\hline RSSI & Received Signal Strength Indicator \\
\hline
\end{tabular}


SDN

SDN-WISE

SDWSN

SP

SPIN

TCP

UDGM

WSN

WSP

WS3N
Software defined networking

SDN solution for WIreless SEnsor networks

Software-Defined Wireless Sensor Networks

Shortest Path

Simple PROMELA Interpreter

Transmission Control Protocol

Unit Disk Graph Medium

Wireles sensor networks

Widest Shortest Path

Wireless Secure SDN-Based Communication for Sensor Networks 


\section{SUMÁRIO}

1 Introdução $\quad 15$

1.1 Motivação . . . . . . . . . . . . . . . . . . 16

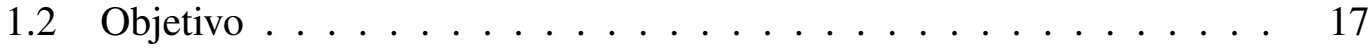

1.3 Método ......................... 17

1.4 Publicações e contribuições originais . . . . . . . . . . . . . 18

1.5 Organização do documento . . . . . . . . . . . . . . . 20

2 Estado da Arte: Definições de rotas em SDWSN 21

2.1 Redes de sensores sem fio definidas por software (SDWSN) . . . . . 21

2.2 Protocolos de roteamento . . . . . . . . . . . . . . . . . 22

2.3 Roteamento em arcabouços de SDWSN . . . . . . . . . . . . . 24

2.4 Sumário . . . . . . . . . . . . . . . . . . . . 27

3 Fundamentos estatísticos e de automatização 28

3.1 Correlação das métricas . . . . . . . . . . . . . . . . . 28

3.2 Lógica difusa na combinação das métricas . . . . . . . . . . . 30

$3.2 .1 \quad$ Fuzificação . . . . . . . . . . . . . . . . . 30

3.2 .2 Inferência . . . . . . . . . . . . . 32

3.2 .3 Defuzificação . . . . . . . . . . . . . . . . 32

4 Proposta de uso de múltiplas métricas no algoritmo de definição de rotas 34

$4.1 \quad$ Proposta . . . . . . . . . . . . . . . . . . 35

5 Avaliação experimental e análise dos resultados: seleção do algoritmo, estratégias de combinações e escalabilidade

5.1 Seleção do algoritmo de definição de rotas . . . . . . . . . . . . . . 44

5.1.1 Cenários e configurações dos experimentos . . . . . . . 45

5.1 .2 Resultados e análise . . . . . . . . . . . . . . 47

5.1 .3 Considerações . . . . . . . . . . . . . . . . 55

5.2 Estratégias de combinação de métricas . . . . . . . . . . . . . 57 
5.2.1 Cenários e configurações dos experimentos . . . . . . . . 57

5.2 .2 Resultados e análise . . . . . . . . . . . . . . 59

5.2 .3 Considerações . . . . . . . . . . . . . . . 66

5.3 Análise de escalabilidade das estratégias . . . . . . . . . . . . . 67

5.3.1 Cenários e configurações dos experimentos . . . . . . . . 67

5.3.2 Análise dos resultados ............... 68

5.3 .3 Considerações . . . . . . . . . . . . . . . . . 79

5.4 Impacto dos pesos de métricas para seleção de estratégias . . . . . . . 80

6 Conclusão $\quad 82$

$\begin{array}{lr}\text { Referências } & 85\end{array}$ 


\section{INTRODUÇÃO}

As redes de sensores sem fio (RSSF ou Wireless Sensor Networks (WSN)) vem sendo usadas em diversos tipos de aplicações como: detecção e rastreamento, monitoramento de ambiente e da indústria, suporte e monitoramento da saúde (OLIVEIRA; ALVES; MARGI, 2015). Uma RSSF é formada por pequenos dispositivos interconectados com capacidade de sensoreamento, atuação, processamento e comunicação. Estes dispositivos possuem recursos limitados com baixo poder de processamento, pouca memória, alcance limitado do rádio, baixa taxa de transferência de dados e energia limitada, provida por baterias (CULLER; ESTRIN; SRIVASTAVA, 2004). Tais dispositivos são referenciados como nós no jargão da área de redes de sensores sem fio e a partir daqui, para facilitar a leitura e compreensão, iremos referenciar esses dispositivos como sensores ou nós.

Uma vez em uso, os nós geralmente se tornam inacessíveis ao usuário por estarem em lugares remotos e de difícil acesso, impossibilitando a troca de baterias e a reprogramação dos mesmos. Para contornar este problema é possível aplicar o conceito de redes programáveis. As redes programáveis foram inicialmente propostas para redes cabeadas de forma a facilitar o gerenciamento e a manutenção colaborando para a evolução da rede. A aplicação dessa ideia proporcionou o surgimento de um novo paradigma nomeado Redes Definidas por Software (SDN, do inglês - Software Defined Networking), no qual o principal objetivo é separar o plano de controle do plano de dados. Assim, o plano de controle é logicamente centralizado sendo processado por equipamentos mais robustos, enquanto os switches e roteadores ficam responsáveis somente pelo encaminhamento de pacotes de acordo com as regras impostas pelo plano de controle.

Após o advento do paradigma SDN em redes cabeadas, este tem sido aplicado às redes de sensores sem fio com objetivo de permitir a definição de rotas nos nós e reprogramação do firmware sem a necessidade de acesso físico aos mesmos, formando 
assim as redes de sensores sem fio definidas por software (SDWSN, do inglês SoftwareDefined Wireless Sensor Networks) (MODIEGINYANE et al., 2017). A SDWSN viabiliza o gerenciamento da rede através de um ponto logicamente centralizado, ideia principal da SDN. Apesar da SDWSN reduzir a complexidade da configuração e gerenciamento da rede, ainda devemos manter em foco o uso eficiente da energia no intuito de prolongar o tempo de vida dos nós, e por consequência o tempo de vida da rede como um todo.

A comunicação é a principal causa do consumo de energia no nó. Na literatura podemos encontrar diversas abordagens em relação à redução no consumo de energia através de protocolos de roteamento em redes de sensores sem fio (CHANG et al., 2013; GHAFFARI, 2014; WENXING; MUQING; YUEWEI, 2016). Alguns trabalhos utilizam uma única métrica no algoritmo de definição de rotas e outros usam combinações de métricas. Porém, os trabalhos que usam combinações de métricas os fazem em protocolos de roteamento distribuído (no qual cada nó é parcialmente responsável pelas definições de rotas). Para o roteamento centralizado é comum usar uma única métrica, como qualidade do enlace ou energia remanescente. Dada a lacuna na literatura sobre combinações de métricas na definição de rotas em SDWSN, esta pesquisa tem como objetivo propor o uso de múltiplas métricas, incluindo a energia remanescente, no protocolo de definição de rotas em SDWSN e avaliar o impacto que estas combinações causam na rede. A avaliação considera mensuração do tempo de vida da rede, taxa de entrega de dados, sobrecarga de controle, mudanças de rotas, consumo de energia, atraso fim a fim e distribuição do consumo de energia.

\subsection{Motivação}

O consumo de energia tem sido foco de muitas pesquisas em redes de sensores sem fio (CHANG et al., 2013; GHAFFARI, 2014; JUNLI; YAWEN; HAIBIN, 2017). As pesquisas mais recentes focam nos protocolos de roteamento que são responsáveis pela transmissão de dados através do rádio, sendo o rádio um grande consumidor de energia do nó. Usar a energia remanescente do nó como métrica na definição de rotas (CAMILO et al., 2006; WENXING; MUQING; YUEWEI, 2016) tem demonstrado eficácia no balanceamento do consumo de energia e no aumento do tempo de vida da rede. $\mathrm{O}$ uso da energia remanescente tem sido aplicado em abordagens de roteamento distribuído (cada nó da rede é responsável por calcular suas rotas e repassar as infor- 
mações) e centralizado (um nó central é responsável por receber as informações da rede, calcular e definir as rotas). Alguns trabalhos (CHANG et al., 2013; GHAFFARI, 2014) propõem a combinação de múltiplas métricas (por exemplo, número de saltos, qualidade do link e energia remanescente) para alavancar as propriedades de cada métrica na definição de rotas. Estes trabalhos avaliam as combinações em abordagens de roteamento distribuído e apresentam bons resultados referente à redução no consumo de energia, balanceamento do consumo, tempo de vida da rede e redução da latência na entrega de dados.

A lacuna na literatura sobre combinações de métricas na definição de rotas em abordagens de roteamento centralizado (SDWSN) nos motivou a avaliar o impacto que estas combinações causam em SDWSN. Por essa razão, buscar uma estratégia dinâmica através de equações ou técnicas de inteligência artificial para combinar métricas em resposta a necessidade atual da rede, abordando o paradigma SDN, onde o controlador não possui restrição energética e nem de processamento, demonstra ser uma abordagem promissora para automatização das redes de sensores sem fio.

\subsection{Objetivo}

O objetivo principal desta pesquisa é aplicar e avaliar estratégias de combinações de métricas no algoritmo de definição de rotas em SDWSN, incluindo a energia remanescente dos nós, e avaliar o impacto no tempo de vida da rede, taxa de entrega de dados, sobrecarga de controle, mudanças de rotas, consumo de energia, atraso fim a fim e distribuição do consumo de energia.

Como objetivo complementar, analisamos a correlação das métricas com a finalidade de verificar se não há relação entre elas, assim possibilitando alavancar as propriedades da combinação.

\subsection{Método}

Após uma revisão detalhada da literatura, selecionamos as duas métricas mais utilizadas nos protocolos de roteamento para redes de sensores sem fio. São elas o número esperado de transmissões (ETX, do inglês Expected Transmission Count) (COUTO et al., 2005), e a energia remanescente que representa o nível atual de bateria do nó. 
Primeiramente analisamos dois algoritmos de definição de rotas e duas sensibilidades no cálculo de rotas aplicando as métricas ETX e energia remanescente de forma individual. Após selecionar o melhor algoritmo de definição de rotas, analisamos duas estratégias de combinações de métricas junto com o uso individual de cada métrica. Uma estratégia é definida através de uma equação de média ponderada, ao qual são aplicados pesos às métricas ETX e energia remanescente. Essa abordagem traz maior flexibilidade, permitindo avaliar o impacto no desempenho da rede através da seleção de diferentes pesos aplicados às métricas. A segunda estratégia é definida através do uso da lógica difusa, inspirada na literatura da lógica difusa e seu crescente uso e disseminação. Para a estratégia da lógica difusa abordamos dois métodos de defuzificação: (i) centroide e (ii) média dos máximos.

Devido a rede de sensores sem fio ser composta por pequenos dispositivos e de baixo custo isto contribui para formação de redes densas, com muitos nós. A escalabilidade é um problema em SDWSN, no qual o aumento no tamanho da rede pode ocasionar gargalos na comunicação em pontos de centralização como o controlador e o sorvedouro. Com isto, para finalizar nosso trabalho, realizamos uma análise de escalabilidade para verificar se as estratégias propostas mantêm suas propriedades com o aumento do números de nós na rede.

A análise e validação de nossa proposta é realizada através de simulações no COOJA (OSTERLIND et al., 2006), um simulador de RSSF e emulador de dispositivos capaz de rodar código nativo de diferentes plataformas. As estratégias de combinação de métricas são implementadas no arcabouço IT-SDN (ALVES et al., 2017), um arcabouço para elaboração e uso de aplicações para SDWSN. A plataforma selecionada para os experimentos foi o TelosB (MOTEIV. .., 2006), um dispositivo frequentemente usado em redes de sensores sem fio e referenciado na literatura.

A análise do desempenho de nossa proposta é feita através da observação do tempo de vida da rede, taxa de entrega de dados, sobrecarga de controle, mudanças de rotas, consumo de energia, atraso fim a fim e distribuição do consumo de energia.

\subsection{Publicações e contribuições originais}

Os seguintes trabalhos foram conduzidos em colaboração com a orientadora e apresentam resultados preliminares desta pesquisa: 
a) Roteamento ciente de energia em redes de sensores sem fio definidas por software: Este trabalho foi publicado no XXXV Simpósio Brasileiro de Telecomunicações e Processamento de Sinais, 2017. Este trabalho propôs demonstrar que a combinação das métricas ETX e energia melhoram a taxa de entrega de dados e o tempo de vida da rede. A proposta foi implementada no arcabouço TinySDN.

b) Combining metrics for route selection in SDWSN: static and dynamic approaches evaluation: Este trabalho foi publicado no IEEE Latin-American Conference on Communications, 2018. Este trabalho propôs avaliar o impacto no roteamento em SDWSN através de combinações de métricas usando abordagens estática e dinâmica em um tamanho de rede fixo.

Os trabalhos a seguir foram conduzidos em colaboração com a orientadora e colegas de laboratório, e ajudaram na ambientação e desenvolvimento desta pesquisa:

a) ITSDN: Improved architecture for SDWSN: O artigo foi apresentado no "Salão de Ferramentas"do XXXV Simpósio Brasileiro de Redes de Computadores e Sistemas Distribuídos, 2017. Foi escrito por Renan C. A. Alves, Doriedson A. G. Oliveira, Gustavo A. Núñez e Cíntia B. Margi. Este trabalho descreve o IT-SDN, uma ferramenta aberta para SDWSN ao qual se empenha em resolver muitos problemas relacionados a abordagens anteriores para SDWSN.

b) Software-defined wireless sensor networks approach: Southbound protocol and its performance evaluation: O artigo foi publicado em Open Journal of Internet Of Things (OJIOT), 2018. Foi escrito por Cíntia B. Margi, Renan C. A. Alves, Gustavo A. Núñez e Doriedson A. G. Oliveira. Dado a falta de uma análise mais profunda em protocolos de Southbound em SDWSN, este trabalho apresenta um análise de performance mais completa para SDWSN através do uso do arcabouço IT-SDN além de revisar suas características e apontar os tradeoffs em comparação com o protocolo de roteamento IETF RPL.

c) WS3N: Wireless Secure SDN-Based Communication for Sensor Networks: O artigo foi publicado em Security and Communication Networks, 2018. Foi escrito por Renan C. A. Alves, Doriedson A. G. Oliveira, Geovandro C. C. F. Pereira, Bruno C. Albertini e Cíntia B. Margi. Este é um dos primeiros trabalhos na literatura a propor, especificar, implementar e avaliar serviços de segurança para arcabouços baseados em SDN para WSN. O trabalho engloba admissão segura 
de nó e distribuição de chave fim a fim para comunicação segura entre os nós, serviços considerados chaves para uma arcabouço prover. Os resultados indicam que o objetivo foi alcançado com sobrecarga aceitável para redes de tamanho médio.

d) The Cost of Software-Defining Things: A Scalability Study of Software-Defined Sensor Networks: O artigo foi publicado no Journal IEEE Access, 2019. Foi escrito por Renan C. A. Alves, Doriedson A. G. Oliveira, Gustavo A. Núñez e Cíntia B. Margi. Este trabalho avalia o desempenho do paradigma de redes definidas por software, especificamente o arcabouço IT-SDN, aplicado a redes de sensores sem fio explorando a performance de métricas cruciais como entrega de dados, atraso, sobrecarga de controle e consumo de energia, além de avaliar a escalabilidade através de simulações e experimentos em testbeds.

\subsection{Organização do documento}

O restante deste trabalho é organizado como segue. O Capítulo 2 apresenta os fundamentos de redes de sensores sem fio definidas por software, arcabouços para SDWSN e o estado da arte em roteamento SDWSN. O Capítulo 3 introduz o conceito de avaliação estatística usada para analisar a correlação das métricas e a lógica difusa usada para combinação das métricas. O Capítulo 4 apresenta a proposta para o uso de múltiplas métricas no algoritmo de definição de rotas. O Capítulo 5 detalha a implementação, experimentos e resultados para a proposta de combinação de métricas. $\mathrm{O}$ Capítulo 6 conclui o documento com as considerações finais e trabalhos futuros. 


\section{ESTADO DA ARTE: DEFINIÇÕES DE ROTAS EM SDWSN}

Este capítulo apresenta uma visão geral sobre redes de sensores sem fio, a aplicação do paradigma de redes definidas por software e os protocolos de roteamento com abordagens distribuídas e centralizadas. Exibe uma visão geral sobre os arcabouços encontrados para o desenvolvimento de aplicações em SDWSN e o estado da arte em roteamento para SDWSN.

\subsection{Redes de sensores sem fio definidas por software (SDWSN)}

Com a evolução da tecnologia permitindo construir dispositivos cada vez menores, tornou-se possível construir pequenos dispositivos com rádio, processador e sensores a preços baixos. Estes dispositivos possibilitam seu uso em um amplo espaço físico permitindo um denso sensoriamento de fenômenos físicos, processamento e comunicação da informação. Tais dispositivos possuem limitações de recursos como baixo processamento, baixo poder de comunicação por rádio, pouca memória e alimentação por baterias (CULLER; ESTRIN; SRIVASTAVA, 2004).

Configurar manualmente grandes redes de pequenos dispositivos é algo impraticável. O ideal é os nós se auto-organizarem e fornecerem um meio de programação e gerenciamento como um grupo ao invés da administração individual. Pensando nisso, aplicou-se uso do paradigma SDN (do inglês Software Defined Networking) às redes de sensores sem fio, assim definindo um ponto centralizado de coordenação da rede permitindo a programação e o gerenciamento da rede através de um único lugar. $\mathrm{Na}$ Figura 1 podemos visualizar a diferença entre o paradigma SDN e uma rede tradicional.

O ponto chave desta abordagem é o uso de um protocolo responsável por defi- 

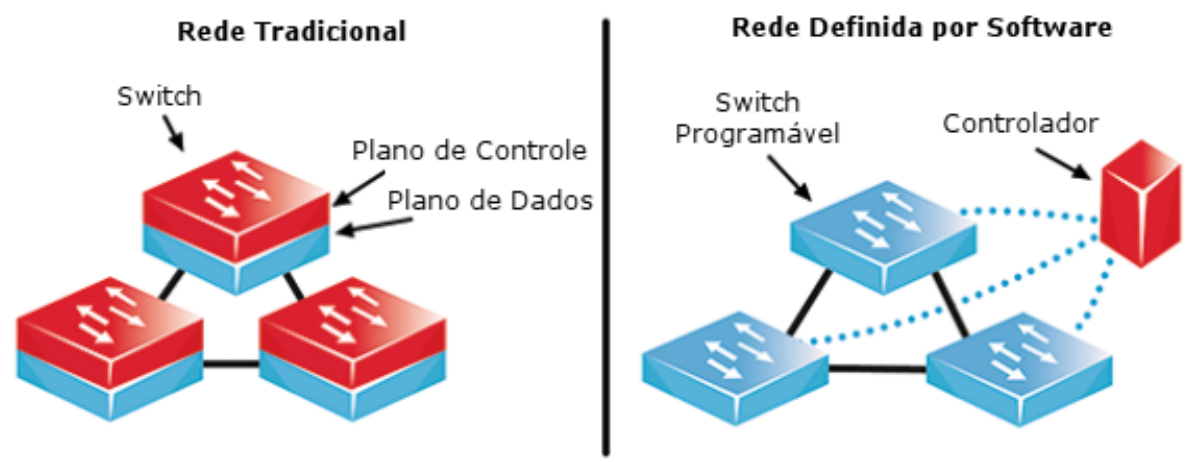

Figura 1 - Exemplo do conceito de redes definidas por software em comparação às redes tradicionais.

Fonte: https://www.commsbusiness.co.uk/wp-content/uploads/2016/05/traditionalsoftware-defined-590x245.png

nir e gerenciar as regras do roteamento na rede. Este protocolo é conhecido como Southbound sendo responsável por habilitar a comunicação entre o controlador e a rede. Para complemento de informação, existe o protocolo Northbound, responsável pela comunicação entre a aplicação e o controlador, e o protocolo East-Westbound, responsável pela comunicação entre os controladores. Os protocolos Northbound e East-Westbound não são abordados nesta pesquisa.

\subsection{Protocolos de roteamento}

Espera-se que a rede opere por longos períodos de tempo, e por serem dispositivos de comunicação sem fio, as baterias limitam sua capacidade operacional. Para reduzir o consumo de energia, a maioria dos componentes incluindo o rádio devem ser desligados na maior parte do tempo.

Os sistemas operacionais TinyOS (LEVIS et al., 2005) e Contiki (DUNKELS; GRONVALL; VOIGT, 2004), desenvolvidos para facilitar a programação destes dispositivos, abordam este problema e disponibilizam opções de controlar a atividade de cada componente tais como níveis de operações do processador e ativação e desativação dos sensores. O rádio é considerado um dos maiores consumidores de energia no dispositivo e existem trabalhos na literatura com objetivo de reduzir este consumo. Como exemplo, podemos mencionar o protocolo ContikiMAC (DUNKELS, 2011) responsável por controlar o ciclo de trabalho do rádio ligando e desligando o mesmo.

Os protocolos de roteamento desempenham um importante fator relacionado ao 
consumo de energia. Há trabalhos na literatura que propõem protocolos de roteamento para redes de sensores sem fio com ênfase no estudo da aplicação de diferentes métricas. Estes protocolos têm como objetivo aumentar o tempo de vida da rede, aumentar a taxa de entrega de dados e reduzir o atraso fim a fim, por exemplo.

O RPL (do inglês Routing Protocol for Low Power and Lossy Networks) é um protocolo de roteamento IPv6 para redes de baixo consumo e com perdas, definido através da RFC6550 (WINTER P. THUBERT, 2012) elaborado pela Internet Engineering Task Force (IETF). Este é um protocolo de roteamento distribuído e tem como base de funcionamento uma topologia formada por um grafo acíclico direcionado (DAG, do inglês directed acyclic graph) para a criação de um ou mais destinos orientados (DODAGs, do inglês Destination Oriented DAGs). A topologia inicia-se com um nó raiz enviando uma mensagem de controle com objeto de informação DODAG (DIO, do inglês $D O$ DAG Information Object) e os nós ao alcance checam o valor de rank atual dentro desta mensagem para seleção de seu pai. Os nós calculam seus próprios ranks e encaminham através de mensagens DIOs para seus vizinhos. O cálculo do ranking é definido através de uma função objetivo que é formulada para priorizar alguma característica ou métrica. Podemos encontrar trabalhos na literatura que empenham esforços em aplicar diferentes métricas na função objetivo do RPL para melhorar o desempenho da rede, incluindo o consumo de energia. Chang et al. (2013) avaliam a combinação do ETX e a energia remanescente na função objetivo do RPL e demonstram um melhor equilíbrio no consumo de energia entre os nós, aumentando o tempo de vida da rede. Lee, Xie and Chang (2014) avaliam o uso do indicador de intensidade do sinal recebido (RSSI, do inglês Received Signal Strength Indicator) como métrica na função objetivo do RPL, e concluem que a métrica proposta baseada em RSSI melhora o atraso fim a fim comparando com o uso da métrica ETX na função objetivo. Lamaazi and Benamar (2017) avaliam as métricas ETX e consumo de energia combinadas através de lógica difusa na função objetivo do RPL, e concluem que a nova métrica melhora a taxa de entrega de dados em comparação com o uso da métrica ETX além de equalizar a distribuição no consumo de energia entre todos os nós.

Outros trabalhos elaboram novos protocolos de roteamento com aplicações de diferentes métricas. Camilo et al. (2006) propõem um protocolo de roteamento distribuído implementando o algoritmo de otimização de colônia de formigas (ACO, do inglês Ant Colony Optimization). Com o algoritmo ACO, em intervalos regulares, cada nó na rede envia um pacote formiga com a missão de encontrar um caminho até o sor- 
vedouro. O pacote formiga armazena em sua memória os últimos dois nós e o restante da informação é armazenada nos nós por onde o pacote passou. Cada nó contém uma tabela com rotas definidas por trilhas de feromônios. A escolha de uma rota é dada por uma fórmula que combina a quantidade de feromônios com a visibilidade da trilha que é dada por equação usando a energia remanescente do próximo salto da rota.

Xiang, Wang and Zhou (2016) elaboram um protocolo de roteamento centralizado usando a lógica do algoritmo de otimização por enxame de partículas (PSO, do inglês particle swarm optimization) e propõem um método para melhorar a procura local do algoritmo o nomeando como NWPSO (do inglês Non-linear Weight Particle Swarm Optimization. A ideia principal é usar o algoritmo NWPSO para a seleção de nós controladores responsáveis pela coleta de dados locais e encaminhamento ao controlador. O algoritmo proposto implementa uma função fitness através do uso da energia remanescente com objetivo de prolongar o tempo de vida da rede.

Wenxing, Muqing and Yuewei (2016) propõem um protocolo de roteamento centralizado elaborando um algoritmo baseado em espaços de energia multi-dimensional (MES, do inglês Multi-dimensional Energy Space). Os nós são divididos em dimensões de acordo com seus níveis de energia remanescente. Os nós em dimensões com mais energia não encaminham pacotes para nós em dimensões com menos energia. Os nós em dimensões com menos energia encaminham pacotes para vizinhos da mesma dimensão ou para nós em dimensões com mais energia.

\subsection{Roteamento em arcabouços de SDWSN}

Após o advento da utilização do paradigma SDN em WSN, surgiram diversos trabalhos na literatura dispostos a elaborar arcabouços para aplicações SDWSN no intuito de solucionar os problemas com roteamento desacoplando o plano de controle do plano de dados.

O Flow-sensor (MAHMUD; RAHMANI, 2011) foi um dos primeiros esforços em aplicar o paradigma SDN em WSN usando as premissas do OpenFlow. O arcabouço aborda o uso de tabelas de fluxos para encaminhamento de pacotes. Os autores denominam em sua proposta um "otimizador de rotas"que combina o número de saltos e o custo da rota, pré-fixado, para decidir o melhor caminho. Através do uso combinado de duas ferramentas de modelagem e verificação lógica, PROMELA e SPIN, os autores 
especificam, modelam e avaliam a proposta validando o principal objetivo, estabelecer um fluxo de dados.

O Sensor OpenFlow (LUO; TAN; QUEK, 2012) foi outro dos primeiros esforços em abordar o paradigma SDN em WSN. Os autores propõem uma tabela de fluxos baseada no OpenFlow com ajustes para redes de sensores sem fio. Um dos principais ajustes é comportar endereços compactos de redes como o endereçamento de rede de 16bits do dispositivo ZigBee, ou ampliar as WSNs com endereçamento IP. Desta forma, o algoritmo de definição de rotas fica centralizado no controlador sendo responsável pela definição e manutenção das rotas nas tabelas de fluxos dos nós. O principal objetivo da proposta foi despertar interesse e provocar discussões na comunidade de pesquisadores no intuito de ver uma nova geração de redes de sensores sem fio mais versátil, flexível e fácil de gerenciar.

Galluccio et al. (2015) propõem o arcabouço SDN-WISE com o objetivo principal de reduzir a quantidade de informação trocada entre os nós sensores e o controlador, e tornar os nós sensores programáveis como máquina de estados. O arcabouço aborda o uso de tabelas de fluxo para encaminhar pacotes entre os nós. Na ausência de regra para um pacote específico o nó solicita a regra ao controlador. Para o nó contactar o controlador é necessário um regra indicando o próximo salto em direção ao controlador. Esta regra é diferente das outras por que ela não é configurada através do controlador, mas através de um protocolo de descoberta de topologia de forma distribuída. A regra para o controlador é calculada através de pacotes de descoberta de topologia que contém informações sobre nível da bateria, nível de sinal do rádio e número de saltos até o controlador mais próximo. Os experimentos foram executados através de simulações e em uma testbed física. De acordo com os resultados, os autores concluem que o SDN-WISE é uma abordagem promissora para a realização de WSNs programáveis.

O TinySDN (OLIVEIRA; MARGI, 2016) foi inicialmente apresentado como habilitador de múltiplos controladores para SDWSN e posteriormente apresentado como um arcabouço completo desenvolvido sob o sistema operacional TinyOS (HILL et al., 2000) para desenvolvimento de aplicações para SDWSN. O arcabouço usa tabelas de fluxos para o encaminhamento de pacotes. A regra para alcançar o controlador é definida através do Collection Tree Protocol (CTP), um protocolo de descoberta de topologia de forma distribuída. Devido o foco do arcabouço ter sido os protocolos Southbound e descoberta de vizinhos, o controlador foi simplificado abordando um algoritmo de definição de rotas simples com regras que verifica se o endereço de destino 
é menor ou maior que o endereço do nó solicitante, e então subtrai ou soma um ao endereço do nó solicitante para estabelecer o endereço do próximo salto. Este algoritmo de definição de rotas permite somente topologia em linha com endereçamento sequencial. Os resultados demonstram que o arcabouço proposto não adiciona atraso considerável no encaminhamento de pacotes de dados como acontece no protocolo CTP.

O IT-SDN (ALVES et al., 2017) é um arcabouço desenvolvido com a proposição de separação entre os protocolos usados para alcançar a comunicação Southbound, a descoberta de vizinhos e a descoberta do controlador. A proposta de separação entre os protocolos possibilita o uso de protocolos elaborados e desenvolvidos por terceiros permitindo a avaliação e comparação entre eles. O arcabouço implementa tabelas de fluxos nos nós para encaminhamento de pacotes ficando o algoritmo de definição de rotas centralizada no controlador. A regra para o controlador é definida através do próprio controlador que inicia o protocolo de descoberta de vizinhos e começa configurando a regra em seus vizinhos. O cálculo de rotas é realizado através do algoritmo de Dijkstra que calcula o menor caminho através do uso de uma métrica a ser definida. Alves et al. (2019) exploram a performance das métricas avaliando redes simuladas com até 289 nós além de avaliar redes reais através de testbed. Também exploram importantes parâmetros para SDWSNs como posicionamento do controlador, ciclo de trabalho do rádio, número de sorvedouros e mensagens de controle roteadas pela origem. Os resultados indicam que redes definidas por software são possíveis e praticáveis em WSNs apresentando taxa de entrega de dados competitivas enquanto reduz o consumo de energia em comparação com o RPL. Na Tabela 1 podemos conferir os arcabouços citados e suas principais características.

Margi and Oliveira (2017) apresentam os primeiros resultados do desenvolvimento desta pesquisa abordando a combinação do ETX com a energia remanescente em um esforço inicial de combinação de métricas em algoritmo de definição de rotas em SDWSN. Nossa abordagem foi implementada no arcabouço TinySDN e os resultados demonstraram melhoras na taxa de entrega de dados e aumento no tempo de vida da rede comparando com o uso de métricas individuais. Nosso segundo resultado preliminar (Oliveira; Margi, 2018) abordou a combinação de métricas usando uma estratégia de média ponderada e uma segunda estratégia através do uso de lógica difusa. As duas estratégias foram implementadas no arcabouço IT-SDN e os resultados apresentaram melhora na taxa de entrega de dados, tempo de vida da rede e balanceamento 


\begin{tabular}{lll}
\hline Arcabouço & Implementação & Algoritmo / Métrica de roteamento \\
\hline Flow-sensor & Teórico / Modelagem & não especificado / número de saltos \\
\hline Sensor Oen-Flow & Teórico & não especificado \\
\hline SDN-WISE & Código próprio & não especificado \\
\hline TinySDN & TinyOS & If-else / endereço do vizinho \\
\hline IT-SDN & Contiki & Dijkstra / ETX \\
\hline
\end{tabular}

Tabela 1 - Implementação, algoritmo de definição de rotas e métrica de roteamento dos arcabouços descritos acima para o desenvolvimento de aplicações para SDWSN encontrados na literatura.

Fonte: autor.

no consumo de energia entre os nós.

\subsection{Sumário}

A revisão da literatura apresentou que a combinação de métricas na definição de rotas em redes de sensores sem fio alavancam as propriedades das métricas para a rede. Estas combinações são avaliadas em protocolos de roteamento distribuído, porém para algoritmos de definição de rotas em SDWSN somente há avaliações através do uso de métricas individuais. Assim, dada esta lacuna na literatura, é interessante propor e avaliar estratégias de combinações de métrica para SDWSN com propósito de alavancar as propriedades da rede, uma vez que essas redes apresentam problemas como o gargalo da comunicação em pontos de tráfego centralizado como o controlador e o sorvedouro. 


\section{FUNDAMENTOS ESTATÍSTICOS E DE AUTOMATIZAÇÃO}

Neste capítulo explicamos os conceitos relacionados a avaliação estatística usada para as métricas do algoritmo de seleção de rotas. Em seguida explanamos a lógica difusa usada nesta pesquisa como uma estratégia de combinação de métricas.

\subsection{Correlação das métricas}

Avaliar a correlação entre as métricas ajuda a entender o problema e direcionar a possíveis soluções (BOSLAUGH, 2012). Quando duas métricas são fortemente correlacionadas implica que as mudanças em uma métrica devem influenciar diretamente a outra. Para avaliarmos a correlação entre duas métricas, primeiramente geramos um gráfico de dispersão e analisamos visualmente como e quanto estão correlacionadas.

Para exemplo, temos três gráficos de dispersão exibidos na Figura 2. A Figura 2a apresenta uma forte correlação linear, a Figura $2 b$ apresenta uma forte correlação não linear e a Figura 2c mostra que não há correlação aparente entre as variáveis.

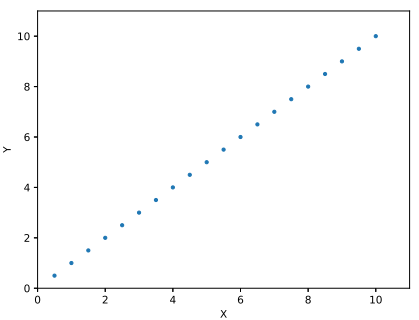

(a) linear

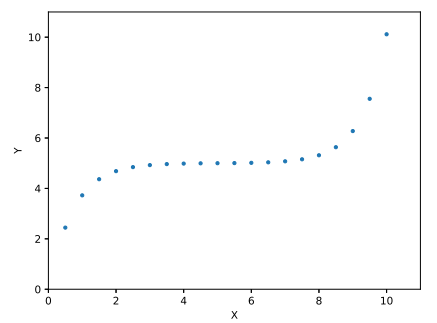

(b) não linear

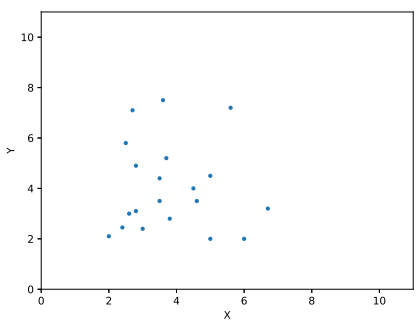

(c) disperso

Figura 2 - Exemplos de gráficos de dispersão.

Fonte: autor.

Após análise do gráfico de dispersão, podemos medir o grau de associação entre as métricas através do coeficiente de correlação. Os coeficientes mais usados são os de 
Pearson e Spearman.

O coeficiente de correlação de Pearson mede o grau da correlação linear entre duas métricas assumindo os valores entre -1 e 1 . O valor -1 indica uma forte correlação negativa, ou seja, se uma métrica aumenta a outra sempre diminui. $\mathrm{O}$ valor 1 indica uma forte correlação positiva, enquanto que o valor 0 indica que não há correlação linear entre as métricas.

O coeficiente de correlação de postos de Spearman avalia a intensidade que a relação entre duas métricas pode ser descrita por uma função monótona. Os valores também variam entre -1 e 1, sendo que os extremos indicam forte relação e 0 nenhuma relação.

Enquanto a correlação de Pearson avalia relações lineares, a correlação de Spearman avalia relações monótonas. A correlação de Spearman entre duas métricas é equivalente à correlação de Pearson entre os valores de postos daquelas duas métricas. Na Tabela 2 podemos conferir o coeficiente de correlação de Pearson e Spearman para cada gráfico apresentado na Figura 2.

\begin{tabular}{ccc}
\hline & \multicolumn{2}{c}{ Coeficiente } \\
Figura & Pearson & Spearman \\
\hline $2 \mathrm{a}$ & 1,0000 & 1,0000 \\
\hline $2 \mathrm{~b}$ & 0,7762 & 1,0000 \\
\hline $2 \mathrm{c}$ & $-0,0372$ & 0,0052 \\
\hline
\end{tabular}

Tabela 2 - Coeficientes de Pearson e Spearman demonstrando a diferença no cálculo de correlação entre duas métricas.

Fonte: autor.

A Figura $2 b$ apresenta uma correlação não linear e o coeficiente de correlação de Spearman apresenta valor 1,0000 indicando uma perfeita correlação. Embora o coeficiente de correlação de Pearson indique uma forte correlação através do valor 0,7762 , ele não consegue medir com tanta precisão quanto o coeficiente de correlação de Spearman. 


\subsection{Lógica difusa na combinação das métricas}

A primeira publicação sobre lógica difusa e a introdução do conceito foi realizada em 1965 pelo autor Lotfi Asker Zadeh (DERNONCOURT, 2013). Na lógica booleana admite-se apenas valores verdadeiro ou falso, enquanto na lógica difusa admite-se valores dentro do intervalo 0 e 1 . O conceito de lógica difusa surgiu da observação e necessidade de solucionar problemas em que não é possível simplesmente responder sim ou não (SANDRI; CORREA, 1999).

A aplicação da lógica difusa permite tratar estados indeterminados através de dispositivos de controle. Deste modo é possível analisar conceitos não quantificáveis como a qualidade de uma métrica: muito ruim, ruim, média, boa e muito boa. Desta forma, a lógica difusa é uma técnica que nos permite representar modelos que contenham certo grau de incerteza ou imprecisão.

O método de Mamdani é um dos mais populares (IANCU, 2012), e é baseado em uma estrutura simples de operações min-max, envolvendo regras de inferência do tipo: Se ETX é pequeno e Energia é alta Então a métrica é muito-boa, sendo pequeno, alta e muito-boa conjuntos difusos.

Para realizar uma decisão usando lógica difusa é necessário seguir os seguintes passos:
a) fuzificação;
b) inferência;
c) defuzificação.

\subsubsection{Fuzificação}

A fuzificação de um valor consiste em transformar um valor de entrada em um grau de pertinência através de uma função de pertinência elaborada por variáveis linguísticas. Para exemplificar, usaremos nossa proposta de combinação de métricas através do uso da lógica difusa aplicando as métricas ETX e energia remanescente como variáveis de entrada para obtermos a métrica de saída.

Primeiro elaboramos as funções de pertinência para a métrica ETX através das variáveis linguísticas: pequeno, médio e grande; e para a métrica energia remanescente 
através das variáveis linguísticas: baixa, média e alta, conforme ilustrado na Figura 3.
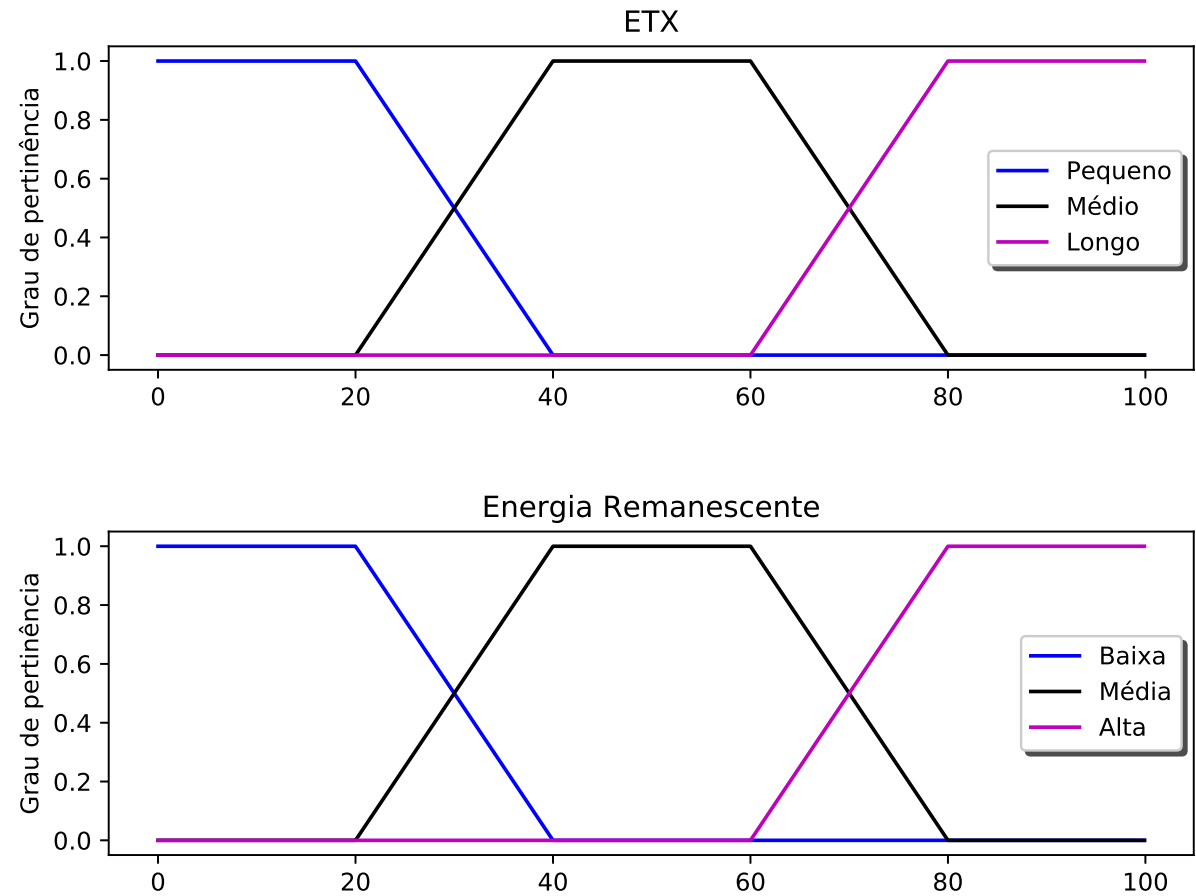

Figura 3 - Funções de pertinência para fuzificação das variáveis de entrada (ETX e energia remanescente).

Fonte: autor.

Depois elaboramos a função de pertinência para a métrica de saída através das variáveis linguísticas: muito-ruim, ruim, média, boa e muito-boa, conforme visualizado na Figura 4.

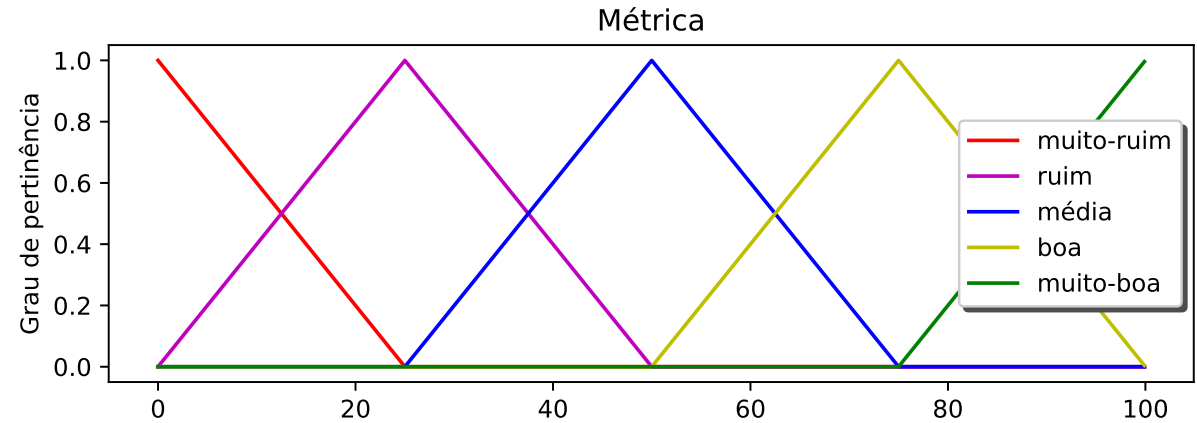

Figura 4 - Função de pertinência para variável de saída (métrica).

Fonte: autor.

Para realizarmos o cálculo da combinação de métricas definimos a métrica ETX com valor 25 e a métrica energia remanescente (EnRem) com valor 75. As Tabelas 3 e 4 exibem os valores fuzificados através das funções de pertinência apresentadas na Figura 3. 


\begin{tabular}{cccc}
\hline & pequeno & médio & longo \\
\hline ETX & 0,75 & 0,25 & 0,00 \\
\hline
\end{tabular}

Tabela 3 - Fuzificação da variável ETX com valor 25

Fonte: autor.

\begin{tabular}{cccc}
\hline & baixa & média & alta \\
\hline EnRem & 0,00 & 0,25 & 0,75 \\
\hline
\end{tabular}

Tabela 4 - Fuzificação da variável EnRem com valor 75

Fonte: autor.

\subsubsection{Inferência}

Após a fuzificação dos valores de entrada, realizamos a inferência através das regras elaboradas por nossa expertise. A Tabela 5 exibe as regras a serem aplicadas.

\begin{tabular}{ll}
\hline Regra 1 & Se ETX é grande e EnRem é baixa Então a métrica é muito-ruim \\
\hline Regra 2 & $\begin{array}{l}\text { Se ETX é médio e EnRem é baixa ou Se ETX é grande e EnRem é } \\
\text { média Então a métrica é ruim }\end{array}$ \\
\hline Regra 3 & $\begin{array}{l}\text { Se ETX é pequeno e EnRem é baixa ou Se ETX é médio e EnRem é } \\
\text { média ou Se ETX é grande e EnRem é alta Então a métrica é média }\end{array}$ \\
\hline Regra 4 & $\begin{array}{l}\text { Se ETX é pequeno e EnRem é média ou Se ETX é médio e EnRem é } \\
\text { alta Então a métrica é boa }\end{array}$ \\
\hline Regra 5 & Se ETX é pequeno e EnRem é alta Então a métrica é muito-boa \\
\hline
\end{tabular}

Tabela 5 - Base de regras para inferência

Fonte: autor.

A Tabela 6 exibe os valores fuzificados aplicados às regras de inferência. Conforme observado, as regras 3, 4 e 5 foram ativadas.

\subsubsection{Defuzificação}

No processo de defuzificação selecionamos os valores de saída das regras de inferência ativadas, e aplicamos a média dos máximos (usado no modelo de Mamdani). A regra 3 ativou a função de pertinência métrica média que possui média 50. A regra 4 ativou a função de pertinência métrica boa que possui média 75 . A regra 5 ativou 


\begin{tabular}{ll}
\hline Regra 1 & Se 0,00 e 0,00 Então 0,00 \\
\hline Regra 2 & Se 0,25 e 0,00 ou Se 0,00 e 0,25 Então 0,00 \\
\hline Regra 3 & Se 0,75 e 0,00 ou Se 0,25 e 0,25 ou Se 0,00 e 0,75 Então 0,25 (média) \\
\hline Regra 4 & Se 0,75 e 0,25 ou Se 0,25 e 0,75 Então 0,25 (boa) \\
\hline Regra 5 & Se 0,75 e 0,75 Então 0,75 (muito-boa) \\
\hline
\end{tabular}

Tabela 6 - Aplicação das regras de inferência

Fonte: autor.

a função de pertinência métrica muito-boa que possui média 100. Extraindo a média para a soma dos três valores das funções de saídas ativadas obtemos como resultado o valor 75 para a métrica final conforme Equação 3.1.

$$
\text { métrica }=\frac{50+75+100}{3}=75
$$

Desta forma, obtemos uma métrica com valor 75 resultante da combinação de duas outras métricas. Esta métrica resultante poderá ser usada em algoritmos de definição de rotas que utilizam apenas uma métrica como o algoritmo de Dijkstra. 


\section{PROPOSTA DE USO DE MÚLTIPLAS MÉTRICAS NO ALGORITMO DE DEFINIÇÃO DE ROTAS}

As redes de sensores sem fio tem sido foco de muitas pesquisas dada a sua larga possibilidade de aplicações e baixo custo dos sensores. Destas pesquisas podemos observar duas principais vertentes com relação a definição de rotas:

a) Roteamento distribuído, onde cada nó é responsável por decidir e definir as regras de encaminhamento de pacotes. Na literatura, um dos protocolos mais citados é o RPL (do inglês, IPv6 Routing Protocol for Low Power and Lossy Networks), que é um protocolo de encaminhamento IPv6 para redes de sensores sem fio. O RPL é definido e padronizado na RFC6550 pelo IETF (do inglês, Internet Engineering Task Force).

b) Roteamento centralizado, no qual existe uma unidade logicamente centralizada responsável por decidir e definir as regras de encaminhamento de pacotes em cada nó na rede. Na literatura podemos encontrar diferentes abordagens para o emprego de roteamento em SDWSN, como por exemplo o método de torneio alternando entre a fase de coleta de informação da rede e definição das rotas e a fase de coleta de dados dos sensores (XIANG; WANG; ZHOU, 2016).

Existem diversos artigos abordando combinações de métricas em roteamento distribuído para alavancar as propriedades das redes de sensores sem fio como o aumento do tempo de vida da rede, redução no atraso fim a fim e aumento na taxa de entrega de dados (CHANG et al., 2013; QASEM et al., 2016; LAMAAZI; BENAMAR, 2017). Porém, existe uma lacuna na literatura sobre combinações de métricas em protocolos de roteamento em SDWSN. Dada esta lacuna, esta pesquisa tem como objetivo propor e avaliar o uso de combinações de métricas no algoritmo de definição de rotas em SDWSN, e avaliar a escalabilidade da melhor abordagem. 


\subsection{Proposta}

Neste trabalho, propomos e avaliamos o uso da combinação de métricas no algoritmo de definição de rotas em SDWSN. Assim, esta seção aborda as métricas utilizadas, os algoritmos considerados para o cálculo de rotas, as estratégias de combinação das métricas e os aspectos da implementação.

Devido alguns arcabouços na literatura serem mais teóricos, e outros não possuírem implementação completa, reunimos um grupo de pesquisadores com interesse em comum de pesquisa em SDWSN para especificação e implementação de um arcabouço baseado no TinySDN, nomeando-o IT-SDN. Alves et al. (2019) demonstram a partir do arcabouço IT-SDN que a aplicação do paradigma SDN em WSN obtém um desempenho tão bom quanto o RPL, um protocolo de roteamento distribuído e padronizado para a internet das coisas. Ainda, o arcabouço apresenta o uso de menos energia entregando o mesmo número da pacote de dados. Com isso, para a implementação e avaliação de nossa proposta escolhemos usar o arcabouço IT-SDN, uma ferramenta open source projetada e disponibilizada para a elaboração e desenvolvimento de aplicações completas para SDWSN.

O ETX é uma métrica que tem sido bastante abordada na literatura para definição de rotas em redes de sensores sem fio, representando a probabilidade do número esperado de transmissões para entregar um pacote com sucesso ao destino (COUTO et al., 2005). O ETX é definido através da equação $E T X=\frac{1}{d_{f} \times d_{r}}$, ao qual $d_{f}$ é a probabilidade de um pacote ser entregue com sucesso e $d_{r}$ é a probabilidade de um pacote ACK ser recebido com sucesso.

Dada a preocupação com o consumo de energia dos nós também podemos encontrar trabalhos abordando o uso da energia remanescente do nó como métrica de roteamento em redes de sensores sem fio. A energia remanescente é configura inicialmente com um valor definido através da capacidade da bateria em uso e é definida através da equação EnRem $=$ EnIni - EnCons, ao qual EnIni representa a energia inicial e EnCons representa a energia consumida. O consumo de energia é definido através da equação $\operatorname{EnCons}(m J)=($ TransmT $\times 17,4 m A+$ Recep $T \times 19,7 m A+C P U T \times 2,33 m A+$ $L P M T \times 0,18 m A) \times 3 V / 32768$, ao qual TransmT representa o tempo de transmissão do rádio, RecepT representa o tempo de recepção do rádio, $C P U T$ representa o tempo de processamento da CPU e LPMT representa o tempo que o dispositivo fica no estado de Low Power Mode. O tempo no dispositivo é contabilizado em ticks (número de ciclos 
do processador) e então convertido para segundos através da divisão pelo valor 32768 que é o clock do processador. Na equação observamos a multiplicação por $3 \mathrm{~V}$, que é a tensão resultante das baterias usadas, para obtenção da energia consumida em mJ. Os valores em $m A$ representam as correntes de consumo de seus respectivos dispositivos adquiridos através do datasheet do dispositivo TelosB (MOTEIV. .., 2006).

Em protocolos de roteamento distribuído, como o RPL, podemos encontrar na literatura trabalhos que combinam o ETX e a energia remanescente com o objetivo de alavancar as propriedades das duas métricas. Dado o uso frequente na literatura das métricas mencionadas, escolhemos abordá-las neste trabalho.

Avaliar e analisar a correlação entre as variáveis é um fator importante para entender o problema e elaborar possíveis soluções. A correlação mede o relacionamento entre duas variáveis e o coeficiente descreve a força e a direção do relacionamento. A correlação de Pearson avalia a relação linear entre duas variáveis contínuas, enquanto a correlação de Spearman avalia a relação monotônica entre duas variáveis contínuas ou ordinais. Podemos avaliar a relação entre duas variáveis através de um gráfico de dispersão. Com isso, elaboramos três gráficos de dispersão através de três cenários simulados. Um cenário usa a métrica ETX no algoritmo de definição de rotas, outro cenário usa a métrica energia remanescente e o outro cenário usa a combinação das duas métricas através da Equação 4.1 abordada a frente. Incluímos um cenário com combinação de métricas para analisar se há relação entre o uso da métrica no algoritmo de definição de rotas e a correlação das métricas. A Figura 5 exibe os gráficos de dispersão. Cada gráfico representa a quantificação das variáveis extraídas de dez simulações. Através da análise visual dos três gráficos concluímos que as variáveis não possuem relação linear e também não possuem relação monotônica.

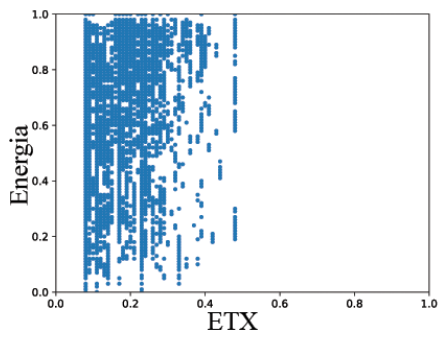

(a) ETX

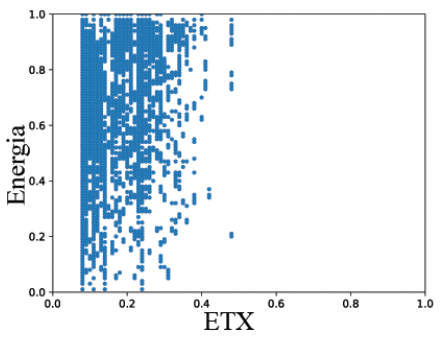

(b) ETX/energia remanescente

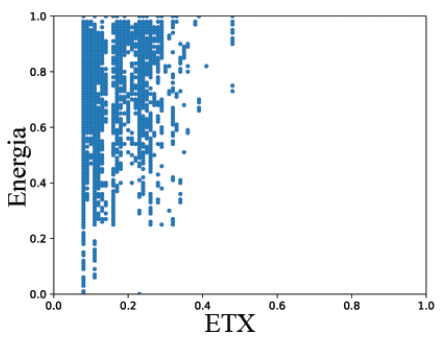

(c) energia remanescente

Figura 5 - Gráficos de dispersão para análise de correlação entre as métricas ETX e energia remanescente.

Fonte: autor. 
Calculando o coeficiente de Spearman podemos confirmar que não há correlação entre as métricas ETX e energia remanescente conforme visualizado na Tabela 7. Desta forma, podemos usar a combinação das duas métricas no algoritmo de definição de rotas e analisar seu impacto na rede.

\begin{tabular}{cc}
\hline Figura & Coeficiente \\
\hline $5 \mathrm{a}$ & $-0,052237395252301748$ \\
\hline $5 \mathrm{~b}$ & 0,0023625283565737202 \\
\hline $5 \mathrm{c}$ & $-0,03093396761447248$ \\
\hline
\end{tabular}

Tabela 7 - Coeficientes de Spearman para análise de correlação entre duas métricas em três cenários distintos.

Fonte: autor.

Na literatura é comum citarem o uso do algoritmo de Dijkstra na definição de rotas através do cálculo do menor caminho, enquanto outros trabalhos não citam o algoritmo usado. O algoritmo de menor caminho prioriza um caminho através da menor soma das arestas em um grafo acíclico. Na Figura 6 podemos observar um grafo com oito nós, sendo o nó s4 um sensor que coleta dados e encaminha através de seus vizinhos até o sorvedouro identificado como s1. Neste grafo o nó s4 possui duas rotas alternativas até o sorvedouro: a Rota A (s4 > s3 > s2 > s1) e a Rota B (s4 > s5 > s6>s7 > s8 > s1). O peso das arestas é definido como o valor do nível de bateria do nó. O algoritmo de menor caminho irá selecionar a Rota A com peso total 100 dado pela soma das arestas $\left(25_{s 3}+25_{s 4}+50_{s 1}=100\right)$ enquanto a Rota B tem peso total 250 através da soma das arestas $\left(50_{s 5}+50_{s 6}+50_{s 7}+50_{s 8}+50_{s 1}=250\right)$. Dado que este grafo usa a energia remanescente do nó como métrica de roteamento talvez seja interessante priorizar um caminho com mais energia nos nós ao invés de um menor caminho através da soma das energias. Para este cálculo podemos usar o algoritmo de menor caminho mais largo que, em nosso problema, irá priorizar um caminho com arestas com mais energia. $\mathrm{O}$ algoritmo de menor caminho mais largo irá selecionar a Rota B que possui a aresta de menor peso com valor 50 ao invés da Rota A que possui a aresta de menor peso com valor 25. Dado a nossa seleção de uso das métricas ETX e energia remanescente nesta pesquisa propomos analisar o algoritmo de Dijkstra, menor caminho (SP, do inglês Shortest Path) já implementado no IT-SDN, e sua variação, menor caminho mais largo (WSP, do inglês Widest Shortest Path) implementado no IT-SDN para análise de nossa proposta. 


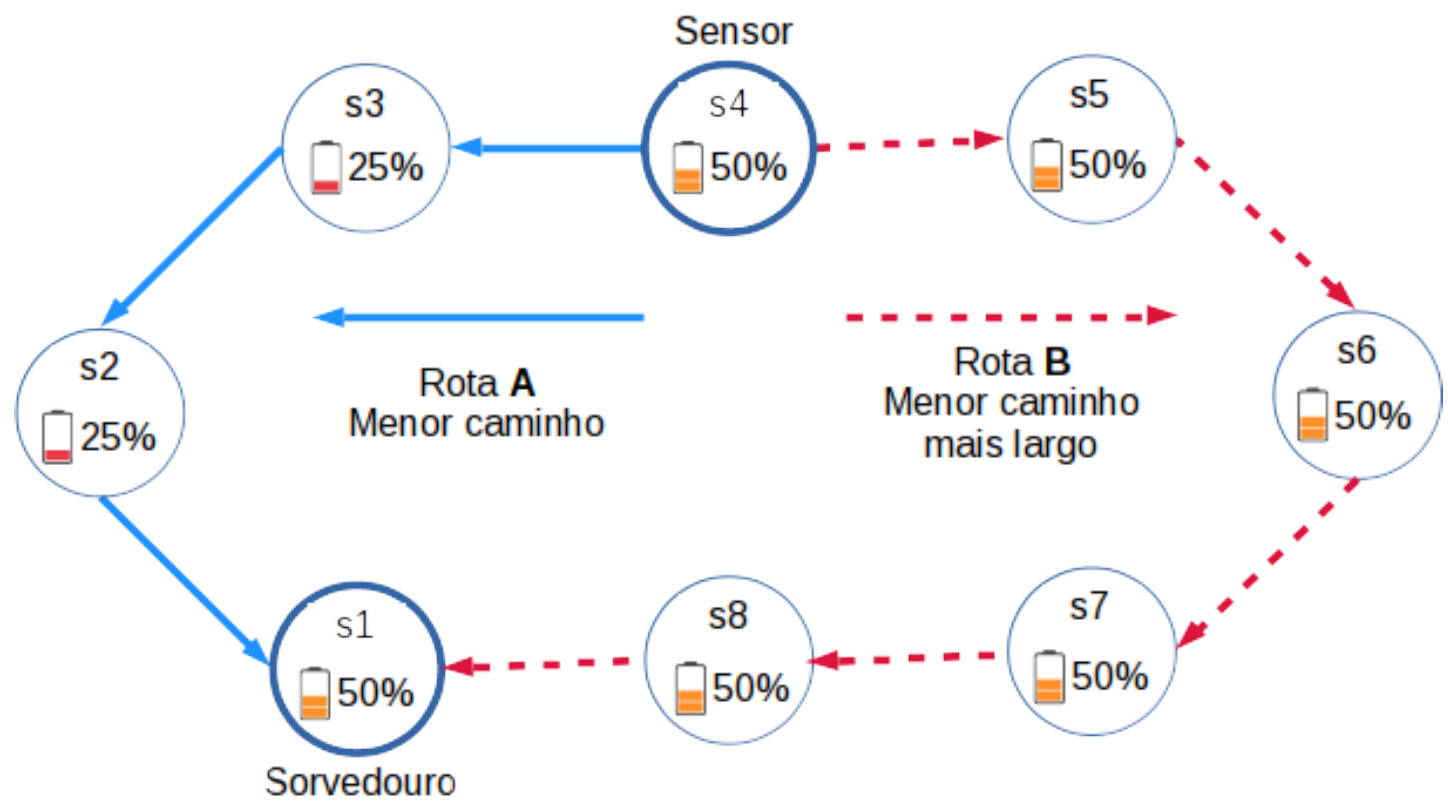

Figura 6 - Seleção de rotas alternativas de acordo com algoritmo usado através do uso da energia remanescente como peso da aresta.

Fonte: autor.

No arcabouço IT-SDN, o algoritmo de definição de rotas utiliza um valor nomeado sensibilidade para determinar quando uma rota deve ser reconfigurada. Este valor evita que qualquer alteração mínima da métrica acarrete em alterações de rota e consequentemente no aumento do tráfego de pacotes de controle na rede. Quanto maior for o valor configurado para sensibilidade menor será o número de alterações de rotas conforme o Algoritmo 1.

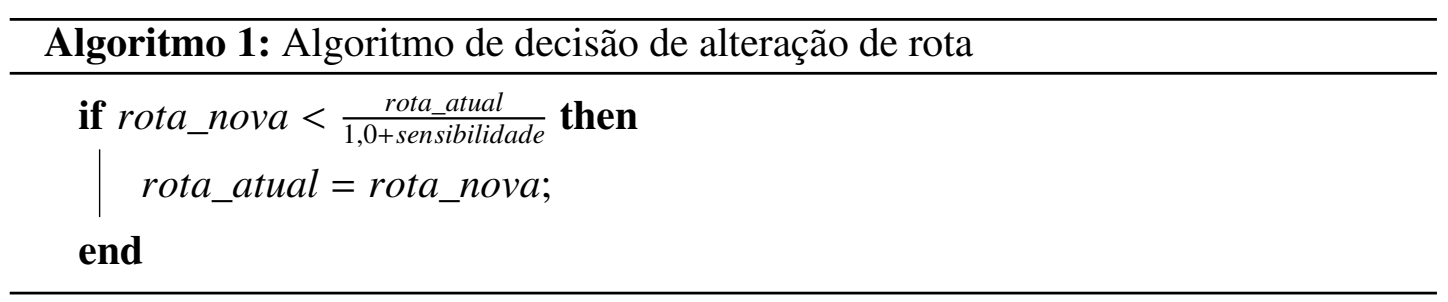

Dada a existência desta variável, escolhemos avaliar dois valores em nossa proposta. Além do valor 0,5 que é definido como padrão no IT-SDN, escolhemos o valor 1,0 para análise de uma menor sensibilidade no intuito de gerar menos tráfego de pacotes de controle causados pelas alterações de rotas e, assim, avaliar o seu impacto na rede.

Escolhemos implementar e avaliar duas estratégias de combinações de métricas utilizadas na literatura em protocolos de roteamento distribuído para redes de sensores sem fio: 
a) equação de média ponderada;

b) lógica difusa.

A equação de média ponderada é formulada para combinar a energia remanescente e o ETX resultando em uma nova métrica para ser usada no algoritmo de definição de rotas. Esta é definida pela Equação 4.1, onde $m$ é a métrica obtida e $\alpha$ um peso aplicado às métricas ETX e EnRem com valor definido em um intervalo fechado [0,1] . Os valores de ETX e da EnRem são normalizadas em um intervalo fechado [0,100], assim, a métrica resultante estará em um intervalo fechado $[0,100]$.

$$
m=(\alpha \times E T X)+[(1-\alpha) \times(100-\text { EnRem })]
$$

Esta estratégia é similar ao conceito proposto por Chang et al. (2013), onde os autores realizam a combinação de métricas através da equação de média ponderada aplicada à função objetiva para o protocolo de roteamento RPL.

A possibilidade de variar o peso das métricas traz maior flexibilidade, permitindo através da seleção dos pesos a análise do impacto no desempenho da rede. Note que o (100 - EnRem) na Equação 4.1 é um ajuste para que o valor zero (menor valor) seja o melhor valor em ambas as métricas.

Em uma análise prévia (MARGI; OLIVEIRA, 2017) utilizando o arcabouço TinySDN avaliamos diferentes valores para $\alpha$ e dado que os melhores resultados se concentraram com $\alpha=0,5$, fixamos $\alpha=0,5$ e desta forma ambas as métricas ganham pesos iguais e a equação se comporta como uma equação de média aritmética podendo ser substituída pela equação $m=\frac{E T X+(100-E n R e m)}{2}$.

Na lógica difusa, a combinação ocorre através da conversão das métricas em valores linguísticos e depois em uma métrica de saída através do processo de defuzificação. Para a estratégia da lógica difusa escolhemos aplicar o modelo fuzzy de Mamdani por ser um dos métodos mais populares (IANCU, 2012). Este modelo permite converter um conjunto de variáveis de entrada (EnRem e ETX) em uma variável de saída (métrica) através dos processos de fuzificação, inferência e defuzificação. Para a fuzificação das variáveis de entrada são usadas funções de pertinência (conjunto de variáveis linguísticas) para determinar o grau de pertinência. As variáveis linguísticas usadas para representar o valor de entrada ETX são definidas como pequeno, médio e longo, e para representar o valor de entrada EnRem são definidas como baixa, média e alta. A 
Figura 7 exibe a relação entre essas variáveis linguísticas, onde a melhor métrica está relacionada com o maior valor para EnRem e o menor valor para ETX, enquanto o inverso provê uma métrica péssima. Note que não precisamos fazer o ajuste nos valores da energia remanescente como foi feito na equação de média ponderada uma vez que a lógica difusa permite combinar valores de intervalos e ordens diferentes. Na Tabela 8 podemos observar o relacionamento entre as duas variáveis linguísticas de entrada para a obtenção da variável de saída. Se obtemos um ETX pequeno e uma EnRem alta, então teremos uma métrica de saída muito-boa.
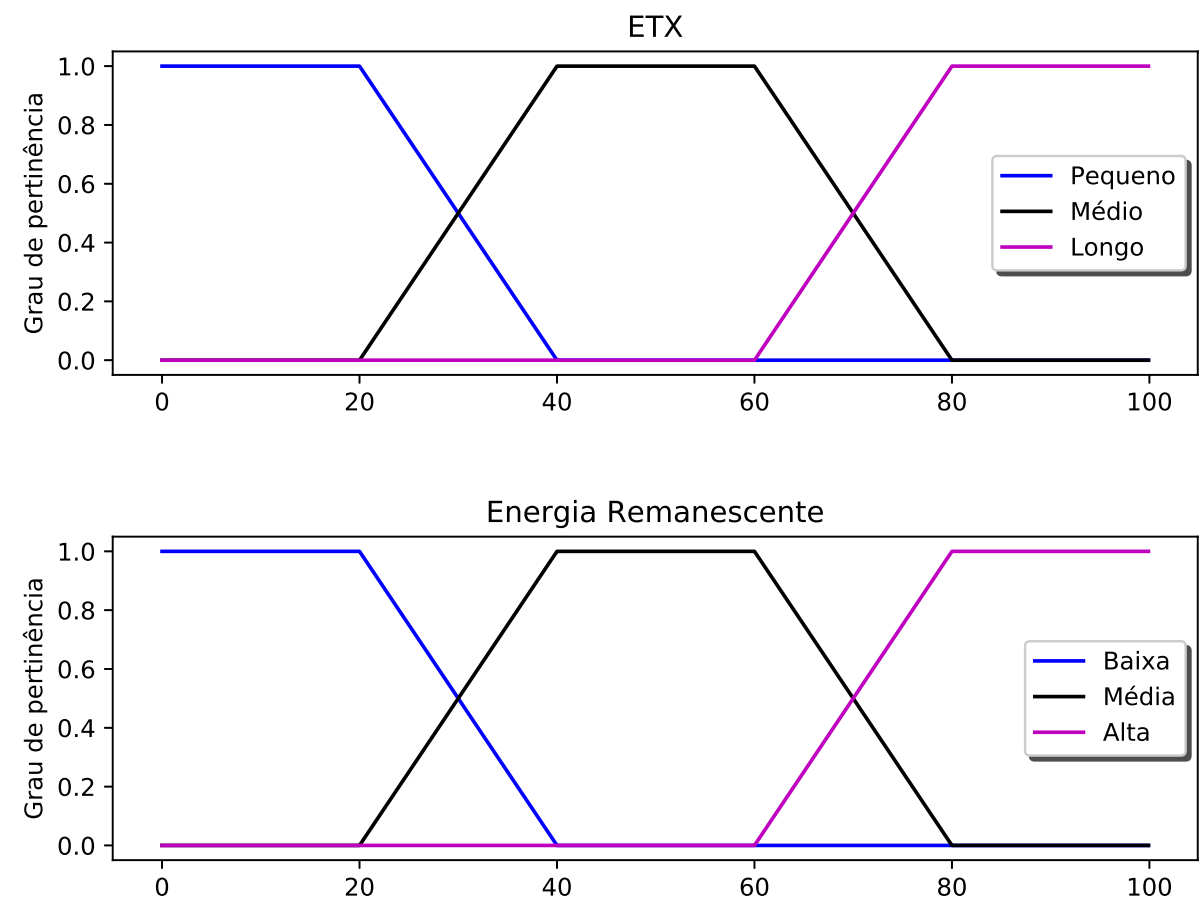

Figura 7 - Funções de pertinência para fuzificação das variáveis de entrada. Fonte: autor.

\begin{tabular}{cccc}
\hline & baixa & média & alta \\
\hline pequeno & média & boa & muito-boa \\
\hline médio & ruim & média & boa \\
\hline longo & muito-ruim & ruim & média \\
\hline
\end{tabular}

Tabela 8 - Regras base para o cálculo da métrica fuzificada de saída.

Fonte: autor.

O modelo fuzzy de Mamdani usa o método de inferência max-min. A função de composição usa o operador min enquanto a função de agregação usa o operador max. 
As Equações 4.2, 4.3, 4.4, 4.5 e 4.6 foram extraídas da Tabela 8 e são usadas para calcular a qualidade das métricas de acordo com os valores fuzificados de entrada.

$$
\mu(\text { muito-ruim })=\max \left(\begin{array}{c}
\min (\text { longo }(\text { ETX }), \text { baixa }(\text { EnRes })) \\
0
\end{array}\right)
$$

$$
\mu(\text { ruim })=\max \left(\begin{array}{c}
\min (\text { médio }(\text { ETX }), \text { baixa }(\text { EnRes })) \\
\min (\text { longo }(\text { ETX }), \text { média }(\text { EnRes }))
\end{array}\right)
$$

$$
\mu(\text { média })=\max \left(\begin{array}{c}
\min (\text { pequeno(ETX }), \text { baixa(EnRes })) \\
\min (\text { médio(ETX }), \text { média }(\text { EnRes })) \\
\min (\text { longo(ETX }), \operatorname{alta}(\text { EnRes }))
\end{array}\right)
$$

$$
\mu(\text { boa })=\max \left(\begin{array}{c}
\min (\text { pequeno }(\text { ETX }), \text { média }(\text { EnRes })) \\
\min (\text { médio(ETX }), \text { alta }(\text { EnRes }))
\end{array}\right)
$$

$$
\mu(\text { muito-boa })=\max \left(\begin{array}{c}
\min (\text { pequeno }(\text { ETX }), \operatorname{alta}(\text { EnRes })) \\
0
\end{array}\right)
$$

No processo de inferência obtemos cinco valores de qualidade, cada um com um grau de pertinência: muito-ruim, ruim, média, boa e muito-boa. Estes valores e seus respectivos graus de pertinência são usados no processo de defuzificação através da função de pertinência exibida na Figura 8.

Para o processo de defuzificação abordamos dois métodos:

a) a média dos máximos (MOM, do inglês, Mean of Maximum) é abordado no 


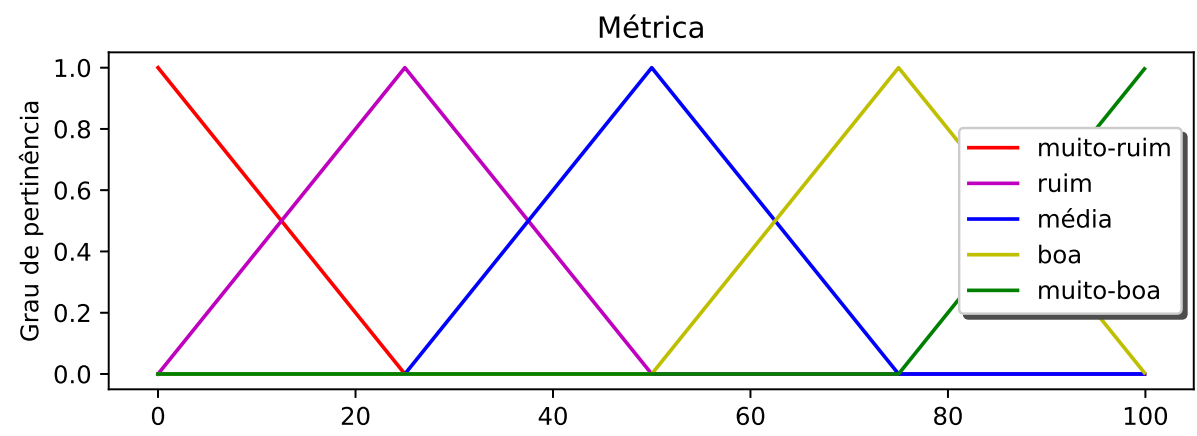

Figura 8 - Função de pertinência para defuzificação da métrica.

Fonte: autor.

modelo fuzzy de Mamdani para calcular a média de todos os valores centrais máximos ativados pelas regras de inferência caso haja mais de uma;

b) o centroide, que calcula o centro de gravidade ou de massa do polígono formado através dos valores obtidos pelas regras de inferência e obtém uma média mais precisa (KAMGUEU; NATAF; DJOTIO, 2015).

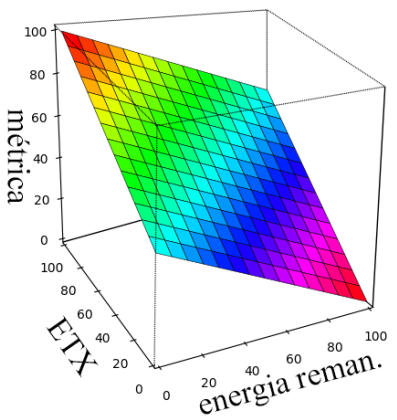

(a) MÉDIA PONDERADA $(\alpha=0,5)$

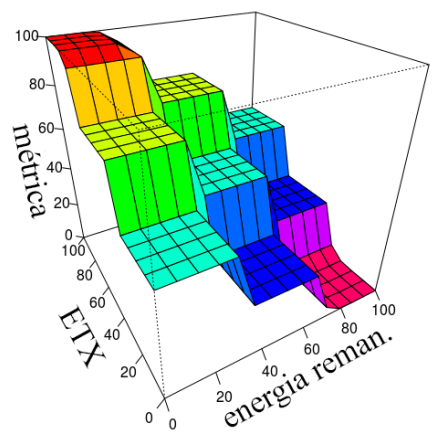

(b) MÉDIA DOS MÁXIMOS

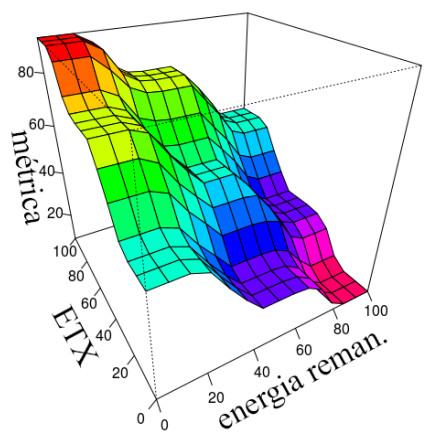

(c) CENTROIDE

Figura 9 - Superfície 3D demonstrando a relação entre os valores das métricas de entrada e os valores da métrica resultante da combinação que cada método de defuzificação provê. As cores da superfície são meramente ilustrativas não representando informação relevante.

Fonte: autor.

Na Figura 9 podemos conferir a superfície gerada através da relação entre os valores de entrada e os valores de saída que cada método provê.

No cálculo do método MOM usamos a Equação 4.7, onde $m$ é a métrica resultante, $x_{i}$ é o centro do polígono gerado pela regra ativada e $n$ é o número de polígonos (regras 
ativadas).

$$
m=\frac{\sum_{i=1}^{n} x_{i}}{n}
$$

No cálculo do método centroide usamos a Equação 4.8, onde $m$ é a métrica resultante, $x_{i}$ é o centro de área do polígono dada pela regra ativada, $\mu c\left(x_{i}\right)$ é a massa do polígono e $n$ é o número de polígonos (regras ativadas).

$$
m=\frac{\sum_{i=1}^{n} x_{i} \cdot \mu c\left(x_{i}\right)}{\sum_{i=1}^{n} \mu c\left(x_{i}\right)}
$$

Assim, para analisar o impacto que a combinação de métricas causa na abordagem de roteamento centralizado em SDWSN, este trabalho avalia dois algoritmos de definição de rotas, duas sensibilidades para o recálculo de rotas, duas estratégias de combinação de métricas além de prover uma análise de escalabilidade para as melhores estratégias. 


\section{AVALIAÇÃO EXPERIMENTAL E ANÁLISE DOS RESULTADOS: SELEÇÃO DO ALGORITMO, ESTRATÉGIAS DE COMBINAÇÕES E ESCALABILIDADE}

Neste capítulo apresentamos a avaliação de dois algoritmos de definição de rotas com duas sensibilidades diferentes. Após a seleção do melhor algoritmo de definição de rotas apresentamos a proposta e avaliação das estratégias de combinação de métricas e apresentamos a avaliação do impacto que a escalabilidade causa nas melhores estratégias.

\subsection{Seleção do algoritmo de definição de rotas}

Para realizar a análise sobre o algoritmo de definição de rotas escolhemos o algoritmo de menor caminho (SP, shortest path) e o algoritmo de menor caminho mais largo (WSP, widest shortest path). Desta forma podemos identificar e selecionar qual algoritmo apresenta maior tempo de vida da rede, maior taxa de entrega de dados, menor sobrecarga de controle, melhor aproveitamento de energia da rede (consumo da energia total da rede), menor consumo de energia por pacote de dados, menor atraso fim a fim e melhor balanceamento no consumo de energia.

Além da configuração do algoritmo de definição de rotas também analisamos outros dois aspectos:

a) valores da sensibilidade do algoritmo de definição de rotas;

b) uso individual das métricas. 


\subsubsection{Cenários e configurações dos experimentos}

A Tabela 9 exibe os cenários elaborados através das combinações entre os algoritmos de definição de rotas, os valores de sensibilidade e as métricas escolhidas.

\begin{tabular}{lccc}
\hline \multicolumn{1}{c}{ Cenário } & Algoritmo & Métrica & Sensibilidade \\
\hline CENÁRIO ETX (sP) 0,5 & SP & ETX & 0,5 \\
\hline CENÁRIO ETX (SP) 1,0 & SP & ETX & 1,0 \\
\hline CENÁRIO ETX (WSP) 0,5 & WSP & ETX & 0,5 \\
\hline CENÁRIO ETX (WSP) 1,0 & WSP & ETX & 1,0 \\
\hline CENÁRIO ENERGIA (SP) 0,5 & SP & Energia & 0,5 \\
\hline CENÁRIO ENERGIA (SP) 1,0 & SP & Energia & 1,0 \\
\hline CENÁRIO ENERGIA (WSP) 0,5 & WSP & Energia & 0,5 \\
\hline CENÁRIO ENERGIA (WSP) 1,0 & WSP & Energia & 1,0 \\
\hline
\end{tabular}

Tabela 9 - Cenários elaborados através das combinações entre os algoritmos de definição de rotas, valores de sensibilidade e métricas

Fonte: autor.

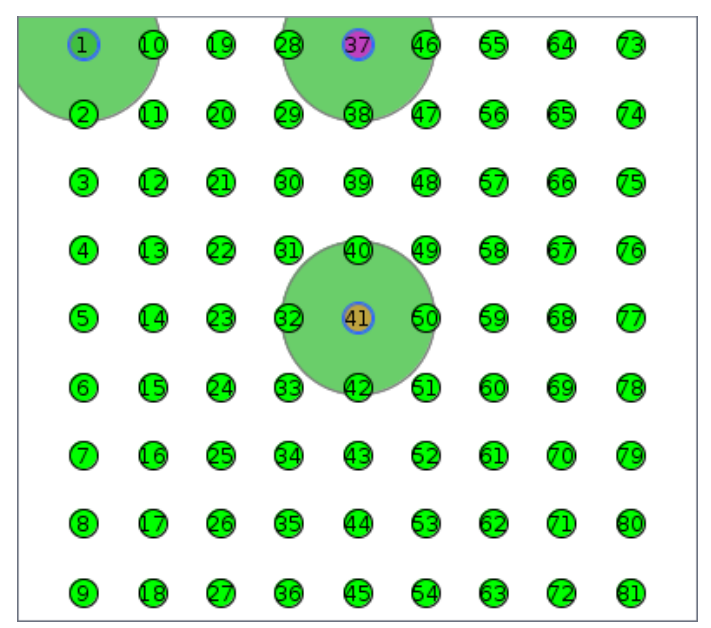

Figura 10 - Topologia em grade (9x9) com controlador no centro (\#41) e sorvedouro no centro superior (\#37). O círculo verde representa o alcance do rádio, limitado aos nós adjacentes.

Fonte: autor.

Dado os cenários, a análise é feita sobre os resultados obtidos através de simulações executadas no COOJA (simulador de redes de sensores sem fio e emulador de nós sensores). As configurações usadas nas simulações são exibidas na Tabela 10 e a 
topologia e disposição dos nós são exibidos na Figura 10. As simulações foram configuradas para finalizarem ao identificar o primeiro nó sem energia na rede. Na literatura não há um consenso universal na definição de tempo de vida da rede, geralmente é definida quando o primeiro sensor esgota sua energia. Em outros casos é definida quando metade dos sensores da rede esgotam suas bateria ou até quando a rede inteira se desliga (Pantazis; Nikolidakis; Vergados, 2013). Desta forma, definimos o tempo de vida da rede igual a tempo do primeiro sensor sem energia e, assim, o tempo da simulação passa a ser o tempo de vida da rede. Os resultados apresentados exibem intervalo de confiança de 95\% considerando a distribuição t de Student (HAVERKORT; WILEY, 1998) para a média de 10 simulações por cenário. As simulações são configuradas com sementes aleatórias responsáveis por determinar a ativação dos sensores permitindo uma certa aleatoriedade no sistema para aproximação de sistemas reais.

\begin{tabular}{ll}
\hline Topologia & grade 9x9 (81 nós) \\
\hline Controlador & centro \\
\hline Sorvedouro & centro superior \\
\hline Nós sensores & 79 \\
\hline Anúncio de vizinhos & frequência máxima: 1 pacote por minuto \\
\hline Algoritmo de definição de rotas & SP / WSP \\
\hline Sensibilidade na definição de rotas & $0,5 / 1,0$ \\
\hline Sensoriamento de dados & a cada 1 minuto \\
\hline Ciclo de trabalho do rádio & 16 Hz \\
\hline Energia inicial & 62.000 mJ \\
\hline Tempo de simulação & primeiro nó sem energia \\
\hline Ambiente do rádio & UDGM (do inglês Unit Disk Graph Medium) \\
\hline Distância entre os nós & 45 metros vertical/horizontal \\
\hline Raio de alcance do rádio & 50 metros \\
\hline Raio de interferência & 50 metros \\
\hline
\end{tabular}

Tabela 10 - Configurações das simulações

Fonte: autor.

O controlador é composto por duas partes: o programa do controlador que é executado diretamente sobre o sistema operacional do computador, no nosso caso o sistema 
operacional Ubuntu, e a interface de comunicação com a rede de sensores sem fio que é executada dentro do simulador COOJA. A ligação entre o programa do controlador e sua interface com a rede de sensores sem fio ocorre através de um túnel configurado através do protocolo TCP/IP. Devido a restrições de hardware, como o processador, o simulador COOJA conta com uma marcação de tempo relativo a velocidade do processamento interno dos sensores ao qual não permite sincronismo com o tempo real. Desta forma, a contagem de tempo dentro da simulação do COOJA difere da contagem de tempo do controlador que ocorre em tempo real no computador. Para sincronizar o tempo entre o controlador e o simulador COOJA, o controlador possui um mecanismo para ajustar sua contagem de tempo, através da sua interface de comunicação, com o simulador COOJA assim permitindo a execução na mesma linha de tempo.

\subsubsection{Resultados e análise}

Para analisar o tempo de vida da rede extraímos o tempo final de cada simulação (definido como o tempo máximo que todos os nós sensores estão ativos) e elaboramos o gráfico apresentado na Figura 11. As barras do gráfico foram divididas entre cENÁRIo ETX e CENÁRIO ENERGIA com a finalidade de comparar as duas métricas dada a mesma configuração.

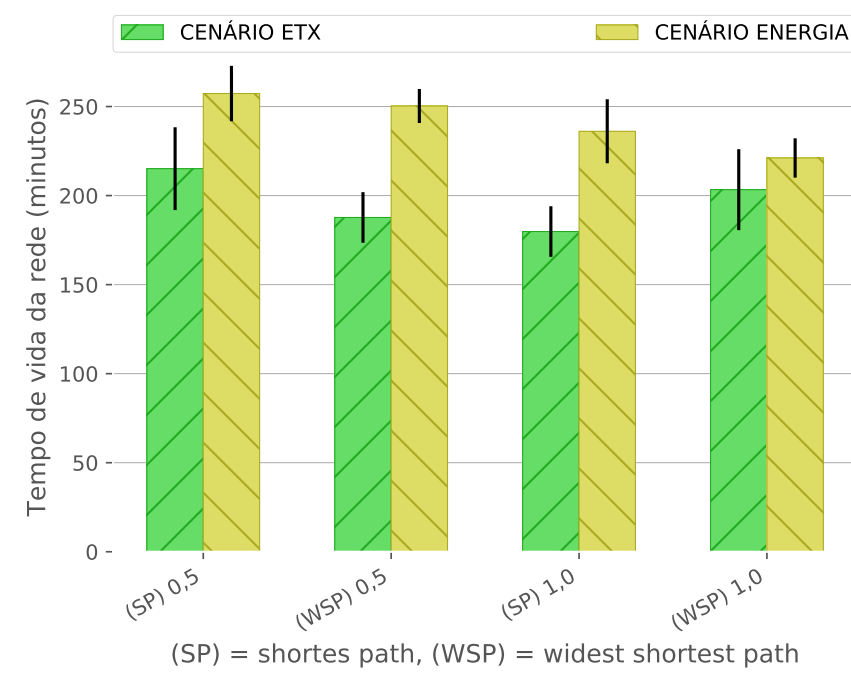

Figura 11 - Tempo médio de vida da rede por cenário com seus respectivos intervalos de confiança.

Fonte: autor.

O CENÁRIO ENERGIA (sP) 0,5 apresenta o maior tempo de vida da rede entre todos os cenários enquanto o CENÁRIO ETX (SP) 0,5 apresenta o maior tempo de vida da rede entre 
os cenários que utilizam a métrica ETX no algoritmo de definição de rotas.

Também observamos que o CENÁRIo ENERGIA (wSP) 1,0, apesar de apresentar o menor tempo de vida da rede entre os cenários que usam a energia remanescente como métrica, apresenta um tempo maior que todos os cenÁrios eTx. Com isto, podemos concluir que o uso da energia remanescente no algoritmo de definição de rotas contribui para o aumento do tempo de vida da rede.

O CENÁRIO ETX (SP) 0,5 apresenta o maior tempo de vida da rede entre os CENÁRIOS ETX, e o CENÁrIo ENERGia (sP) 0,5 apresenta o maior tempo de vida da rede entre os CENÁRIos energia. Podemos verificar que ambos os cenários usam o mesmo algoritmo de definição de rotas (SP) e o mesmo valor de sensibilidade $(0,5)$.

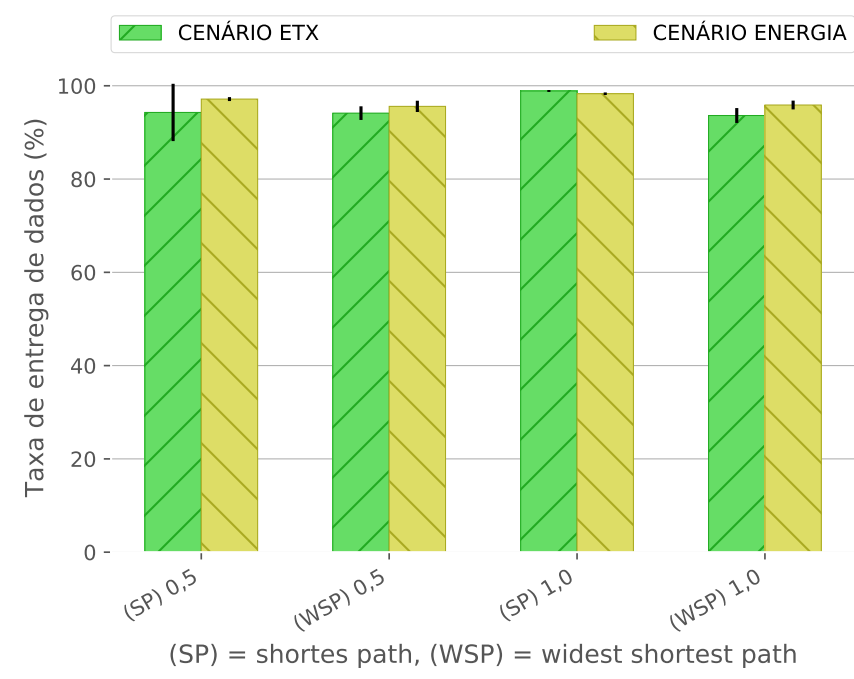

Figura 12 - Taxa média de entrega de dados por cenário com seus respectivos intervalos de confiança.

Fonte: autor.

Outra métrica importante a ser analisada é a taxa de entrega de dados, também conhecida como PDR (do inglês, packet delivery rate). O PDR é definido pela divisão do total de pacotes de dados recebidos pelo total de pacotes de dados enviados na rede $\left(P D R=\frac{\text { recebidos }}{\text { enviados }}\right)$. Na Figura 12 observamos que o CENÁRIO ETX (SP) 1,0 obtém a maior taxa média de entrega de dados entre todos os cenários enquanto o CENÁRIO ENERGIA (sP) 1,0 obtém a maior taxa média de entrega de dados entre os cenários que usam a energia remanescente como métrica. Desta forma, podemos concluir que o algoritmo de definição de rotas (SP) com a sensibilidade 1,0 contribui para uma melhor taxa de entrega de dados. De fato, quanto menos sensível for a mudança de rotas menos tráfego de controle será gerado, contribuindo para o aumento do PDR. Por outro lado, 
verificamos no resultado anterior que um algoritmo de rotas mais sensível contribui para o aumento no tempo de vida da rede.

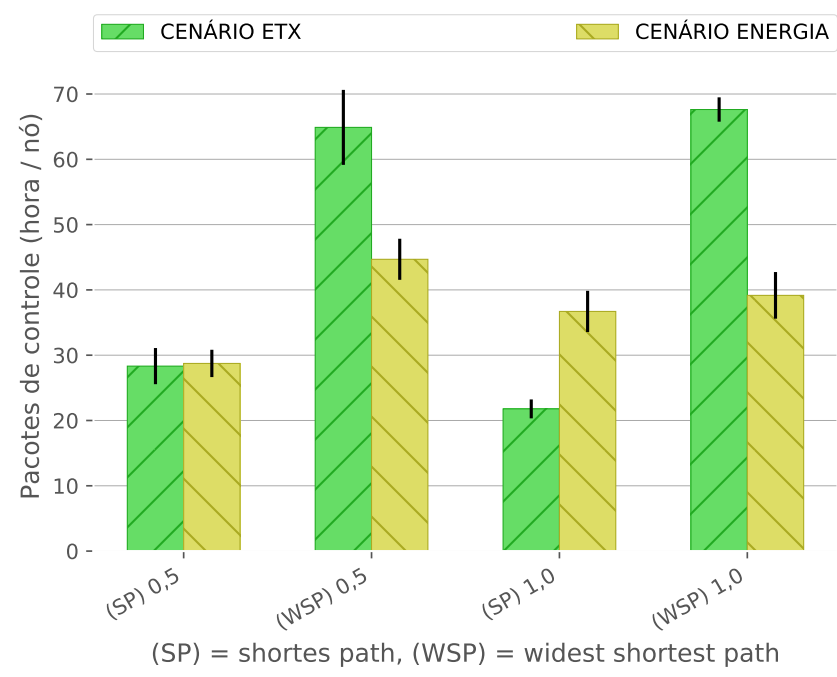

Figura 13 - Média das sobrecargas de controle por cenário com seus respectivos intervalos de confiança.

Fonte: autor.

A sobrecarga de controle é dada pela quantidade de pacotes necessários para configuração e manutenção da rede através da definição de rotas e gerenciamento dos nós sensores. Assim, quanto menor for o tráfego de pacotes de controle, maior será a banda para o tráfego de pacotes de dados uma vez que o tráfego de pacotes de dados e controle acontecem no mesmo enlace. Na Figura 13 observa-se a média de pacotes de controle enviados por hora/nó na rede. O cENÁRIO ETX (SP) 1,0 apresenta a menor média de sobrecarga de controle entre todos os cenários enquanto o CENÁRIO ENERGIA (sP) 0,5 apresenta a menor média de sobrecarga de controle entre os CENÁRIOS ENERGIA. Assim, conclui-se que o algoritmo de definição de rotas (SP) contribui para uma menor sobrecarga de controle.

A manutenção das rotas é um fator determinante para o balanceamento do tráfego e bom funcionamento da rede. Para isso, é necessário que o mecanismo de definição de rotas utilize valores relevantes que impactem de forma positiva o tráfego da rede. Muitas alterações de rotas em um curto período de tempo podem ocasionar em um aumento no tráfego de controle, reduzindo a taxa de entrega de dados. Também, podem ocasionar aumento do congestionamento e consequentemente aumento no consumo de energia e redução no tempo de vida da rede. Por outro lado, poucas alterações de rotas, em um longo período de tempo, podem resultar em rotas estáticas levando ao 


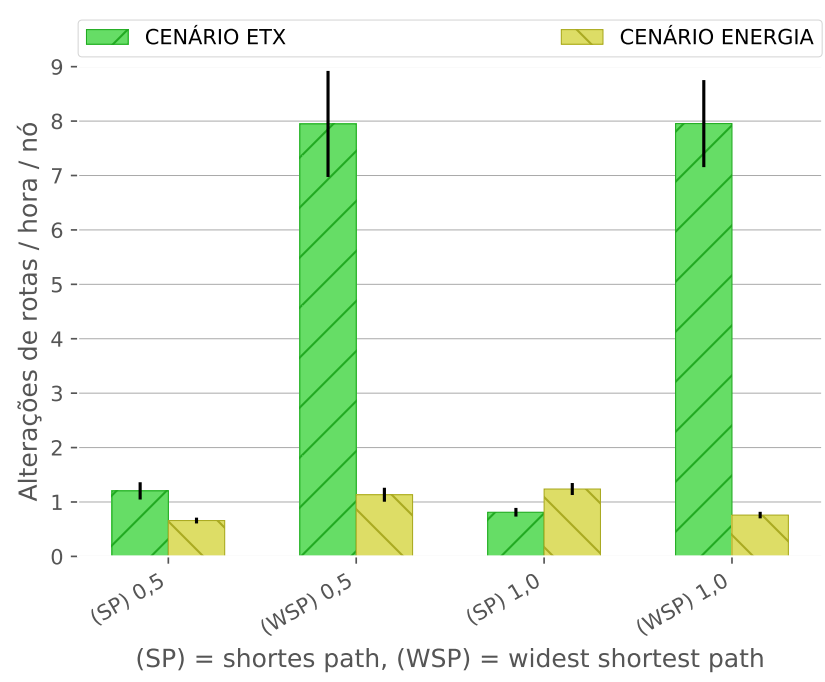

Figura 14 - Média do número de alterações de rotas por cenário com seus respectivos intervalos de confiança.

Fonte: autor.

esgotamento prematuro de alguns nós e ao particionamento da rede. Para analisar as alterações de rotas, extraímos o número de rotas calculadas e configuradas pelo controlador dividido por hora e por nó. Assim, obtemos um gráfico da média de alterações de rotas por hora/nó, conforme exibido na Figura 14. Observamos que o CENÁRIO ETX (wSP) 0,5 e o CENÁRIO ETX (WSP) 1,0 obtêm as maiores médias de alterações de rotas e, como consequência, observamos um aumento na sobrecarga de controle exibida na Figura 13. Os outros cenários apresentam médias semelhantes de alterações de rotas com aproximadamente 1 alteração por hora/nó. O cenÁRIo ENERGIA (sP) 0,5 e o cENÁRIO ENERGIA (WSP) 1,0 apresentam as duas menores médias de alterações de rotas e demonstram que a métrica energia contribui para este fator.

O consumo de energia é um fator de grande importância em redes de sensores sem fio devido à limitação de energia e, muitas vezes, o difícil acesso para reposição das baterias. Com isso, uma rede energeticamente eficiente deve combinar o menor consumo de energia por pacote de dados entregue com o máximo de aproveitamento da energia disponível na rede enquanto completamente ativa (tempo de vida da rede). Na Figura 15 podemos observar a porcentagem média de energia consumida da rede enquanto completamente ativa (tempo de vida da rede). Podemos considerar a porcentagem de energia consumida como o nível de aproveitamento de energia da rede. A energia total da rede é composta pela soma da energia inicial de todos os nós da rede, excluindo o controlador que não possui restrição de alimentação por baterias. O cENÁRIO ENERGIA 


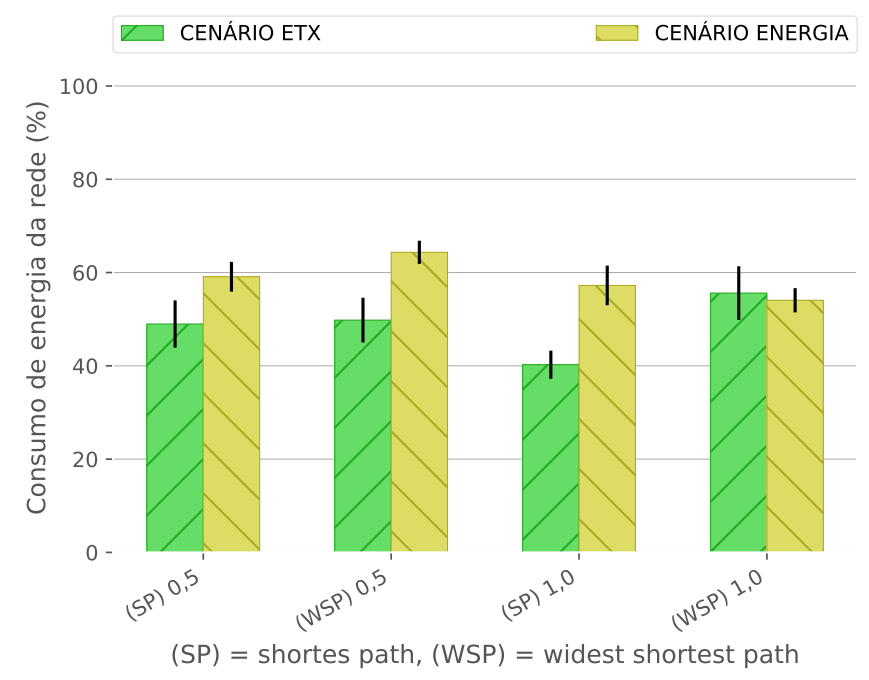

Figura 15 - Consumo médio de energia da rede por cenário com seus respectivos intervalos de confiança.

Fonte: autor.

(wSP) 0,5 apresenta o maior nível médio de aproveitamento (maior consumo), porém exibe uma sobrecarga de controle elevada impactando na taxa de entrega de dados e no tempo de vida da rede. O cENÁrio ETX (SP) 1,0 apresenta o menor nível médio de aproveitamento (menor consumo), e mesmo alcançando uma baixa sobrecarga de controle e uma boa taxa de entrega de dados apresenta um dos menores tempos de vida da rede devido a configuração de rotas estáticas. O CENÁRIO ENERGIA (SP) 0,5 apresenta o segundo maior consumo médio de energia, e analisando o consumo de energia isoladamente e considerando como melhor resultado os cenários que consomem mais energia (melhor aproveitamento de energia da rede), verificamos que a métrica energia remanescente e sensibilidade 0,5 contribuem para um melhor aproveitamento da energia total da rede.

Uma rede eficiente usará o máximo de energia disponível antes que o primeiro nó esgote sua bateria completamente. Porém, o consumo de energia por si só não comprova uma rede eficiente. Se uma rede consome muita energia, mas possui uma grande sobrecarga de controle e uma baixa taxa de entrega de dados, então essa rede não é tão eficiente quanto uma rede que consome o mesmo nível de energia com baixa sobrecarga de controle e alta taxa de entrega de dados. Desta forma, para analisar a eficiência no consumo de energia, dividimos o total de energia consumida na rede pelo total de pacotes de dados entregues e assim conseguimos extrair o consumo médio de energia por pacotes de dados entregue, ilustrado na Figura 16. O cENÁRIO ETX 


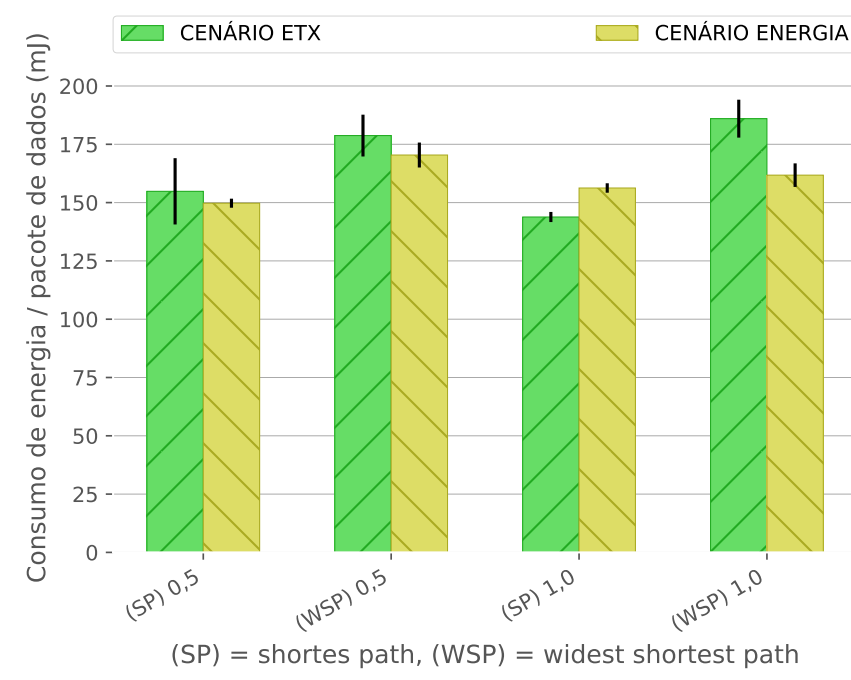

Figura 16 - Consumo médio de energia por pacote de dados entregue por cenário com seus respectivos intervalos de confiança.

Fonte: autor.

(sP) 1,0 apresenta o menor consumo médio de energia por pacote de dados entregue, aproximadamente $143 \mathrm{~mJ}$ por pacote, porém é o cenário que apresenta o menor nível de aproveitamento de energia da rede (Figura 15). Por outro lado, o CENÁRIo ENERGIA (sP) 0,5 apresenta o segundo menor consumo médio de energia por pacote de dados entregue, aproximadamente $149 \mathrm{~mJ}$ por pacote, o segundo melhor nível de aproveitamento de energia da rede (Figura 15), a terceira menor sobrecarga de controle (Figura 13), a terceira melhor taxa de entrega de dados (Figura 12) e o maior tempo de vida da rede (Figura 11). Observa-se que a métrica ETX apresenta o menor consumo médio de energia por pacote de dados usando um algoritmo de roteamento menos sensível, enquanto a métrica energia remanescente apresenta o menor consumo médio usando um algoritmo mais sensível. No entanto, os dois melhores cenários usam o algoritmo shortest path (SP).

Outro fator importante de mensurar em uma rede de sensores sem fio é o atraso fim a fim, definido através do tempo que um pacote de dados demora entre a origem e o destino. $\mathrm{O}$ atraso fim a fim pode variar, principalmente, com o congestionamento e com o processamento de encaminhamento de pacotes nos nós. A Figura 17 exibe a probabilidade acumulada do atraso fim a fim com percentil em 95\%. Definimos o percentil em $95 \%$ para ignorar o tempo inicial da rede, quando acontece a configuração da rede elevando assim o atraso fim a fim. O cENÁrio ETX (SP) 1,0 apresenta o menor atraso fim a fim com tempo médio de 1396 ms enquanto o CENÁRIO ENERGIA (WSP) 


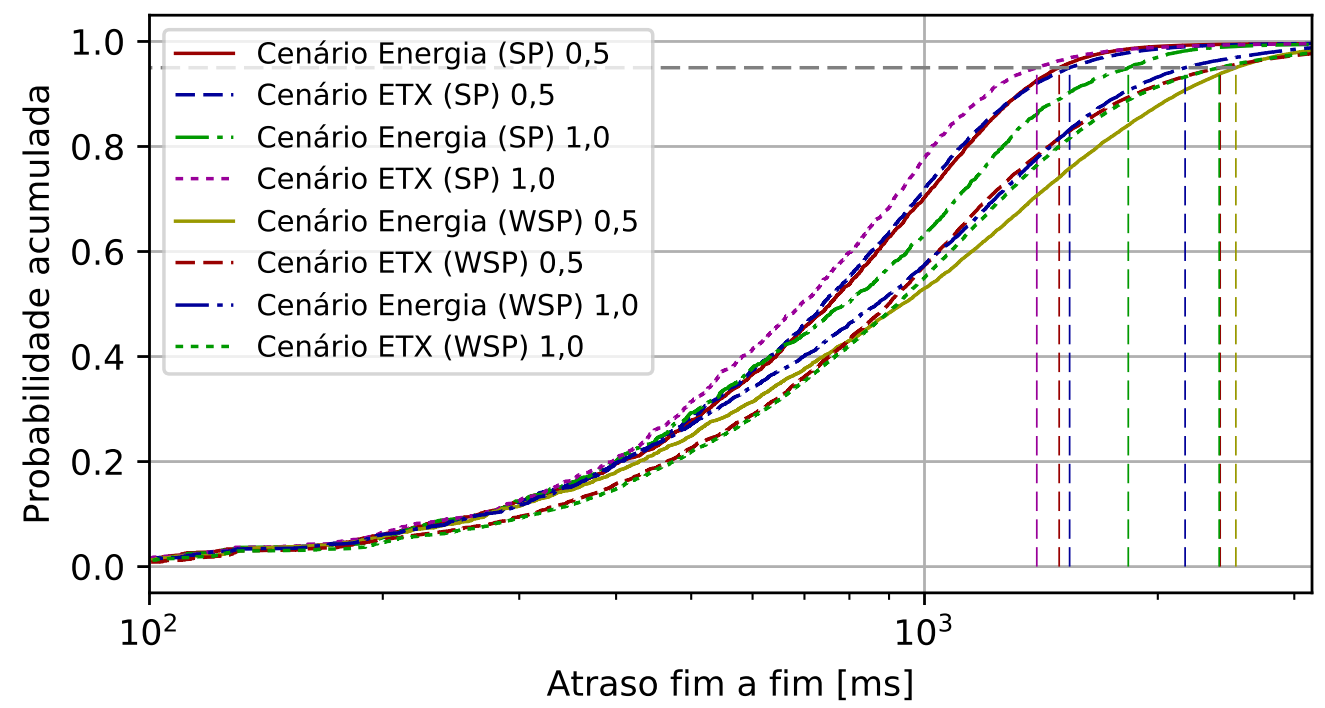

Figura 17 - Probabilidade acumulada de atraso fim a fim para os pacotes de dados de 10 simulações por cenário com percentil em $95 \%$.

Fonte: autor.

0,5 apresenta o maior atraso fim a fim com tempo médio de $2522 \mathrm{~ms}$. O cenário ENERGIA(sP) 0,5 apresenta o segundo menor atraso fim a fim. Assim, podemos concluir que o algoritmo SP contribui para um menor atraso aparecendo nos dois cenários com menor atraso fim a fim.

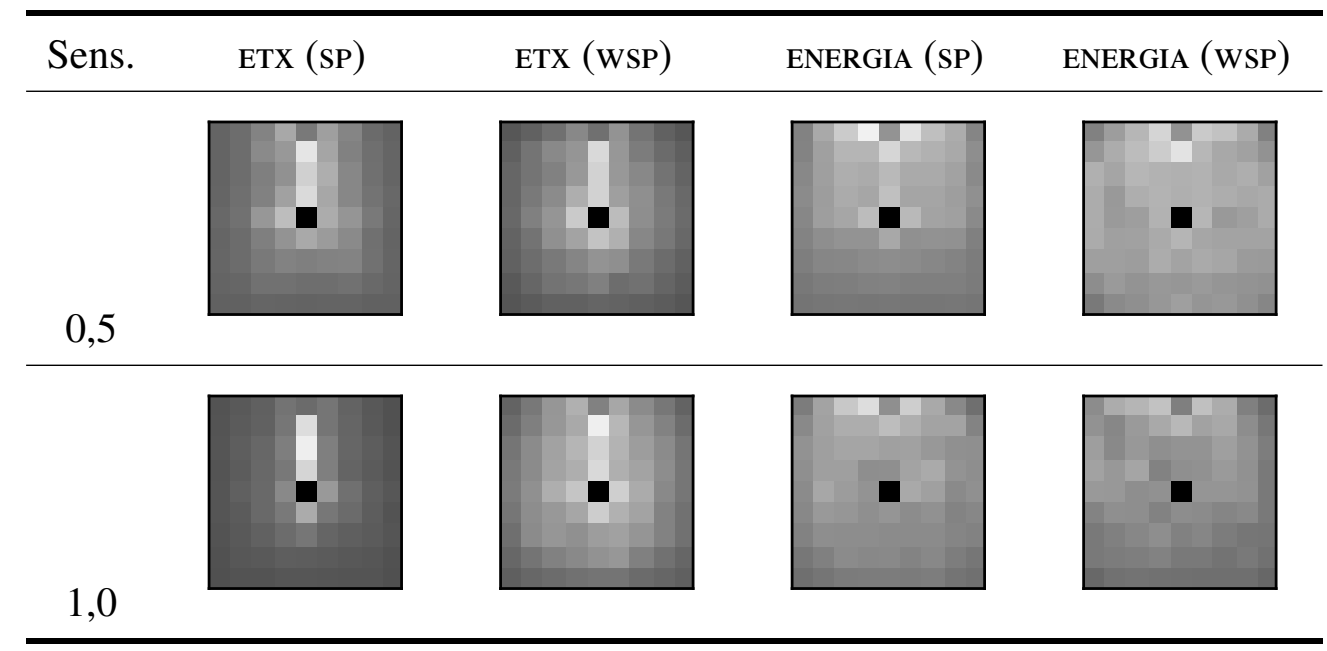

Tabela 11 - Mapas de média da energia remanescente dos nós da rede por cenário para análise da distribuição no consumo de energia entre os nós.

Fonte: Autor.

A fim de entender melhor o balanceamento no consumo de energia entre os nós na rede extraímos os mapas de energia ao fim de cada simulação. Cada ponto nos mapas de energia exibidos na Figura 11 representa um nó e sua respectiva posição na rede. $\mathrm{O}$ 
ponto central (preto) representa o controlador que não contabiliza consumo já que não possui limitação de energia. Quanto mais próximo de branco for o ponto, maior é o consumo de energia para aquele sensor.

Observamos que os cenários que usam a métrica ETX tendem a concentrar o consumo de energia em alguns nós direcionados ao sorvedouro e ao controlador, que são pontos de concentração de fluxo de pacotes identificado pela cor mais próxima de branco. Já os cenários que usam a energia remanescente como métrica apresentam um melhor balanceamento no consumo de energia. O CENÁRIO ENERGIA (WSP) 0,5 apresenta graficamente o melhor balanceamento no consumo de energia vinculado a um maior aproveitamento da energia total da rede (Figura 15), porém o consumo de energia por pacote de dados recebidos é o terceiro maior devido a uma elevada sobrecarga de controle (Figura 13). O CENÁRIO ENERGIA (SP) 1,0 apresenta graficamente a segunda melhor distribuição uniforme no consumo de energia, o terceiro melhor aproveitamento de energia da rede (Figura 15) e a quarta menor sobrecarga de controle (Figura 13). Os cenários que usam energia remanescente apresentam um maior consumo de energia conforme observado pela cor mais clara nos mapas em comparação aos cenários que usam ETX. Este maior consumo está relacionado a um maior tempo de vida da rede, conforme visto na Figura 11.

De acordo com os resultados analisados, observamos que não foi possível definir apenas um cenário com melhor desempenho para as métricas avaliadas. Desta forma, elaboramos uma classificação ordenando os cenários de acordo com os resultados apresentados para cada métrica avaliada. Para entender melhor a definição da classificação pegamos como exemplo a métrica tempo médio de vida da rede, exibida na Figura 11. Após a análise dos resultados observamos que o CENÁRIo (sP) 0,5 obteve o maior tempo médio de vida da rede apresentando a melhor classificação para esta métrica e, assim, obtendo a maior pontuação. A pontuação é determinada através do número de cenários avaliados. Desta forma, dado que nossa avaliação foi realizada através de 8 cenários então o cenário melhor classificado (CENÁRIo (sP) 0,5) recebe pontuação 8 e assim sucessivamente até o cenário pior classificado, recebendo pontuação 1 conforme exibido na Tabela 12.

Após realizar a classificação dos cenários para cada métrica avaliada elaboramos uma classificação geral dos cenários através da soma das pontuações obtidas em cada métrica. Desta forma, podemos observar um cenário melhor classificado através da combinação dos resultados das métricas, conforme exibido na Tabela 13. Para a clas- 


\begin{tabular}{lc}
\hline Cenário & Pontuação \\
\hline ENERGIA (sP) 0,5 & 8 \\
\hline ENERGIA (WSP) 0,5 & 7 \\
\hline ENERGIA (SP) 1,0 & 6 \\
\hline ENERGIA (WSP) 1,0 & 5 \\
\hline ETX (SP) 0,5 & 4 \\
\hline ETX (WSP) 1,0 & 3 \\
\hline ETX (WSP) 0,5 & 2 \\
\hline ETX (sP) 1,0 & 1 \\
\hline
\end{tabular}

Tabela 12 - Classificação e ordenação dos cenários para a métrica tempo médio de vida da rede.

sificação dos cenários consideramos que as métricas possuem a mesma importância e, desta forma, não realizamos atribuições de diferentes pesos para as métricas. $\mathrm{Na}$ Seção 5.4 realizamos uma análise de classificação dos cenário abordando diferentes pesos para as métricas de acordo com a prioridade do ambiente da rede. Dada a classificação geral observamos que o CENÁRIO ENERGIA (SP) 0,5 apresenta o maior tempo médio de vida da rede, o menor número médio de alterações de rotas, o segundo maior consumo médio de energia da rede, o segundo menor consumo médio de energia por pacote de dados, o segundo menor atraso fim a fim, a terceira melhor taxa média de entrega de dados e a terceira menor sobrecarga de controle. O CENÁRIO ETX (sP) 1,0 apresenta a melhor taxa média de entrega de dados, a menor sobrecarga de controle, o menor consumo médio de energia por pacote de dados, o menor atraso fim a fim, o terceiro menor número médio de alterações de rotas, porém apresenta o menor tempo médio de vida da rede e o menor consumo médio de energia da rede. Estes últimos dois piores resultados demonstraram relação com a métrica ETX, ao qual, apresenta uma definição de rotas mais estáticas e como consequência o esgotamento prematuro da energia de alguns nós reduzindo o tempo de vida da rede.

\subsubsection{Considerações}

Para realizar a análise de configuração avaliamos o mecanismo de definição de rotas através do uso de dois algoritmos: SP (shortest path) e WSP (widest shortest path). O algoritmo SP exibiu melhores resultados entre taxa de entrega de dados, 


\begin{tabular}{|c|c|c|c|c|c|c|c|c|}
\hline Cenário & 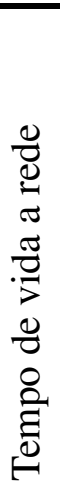 & 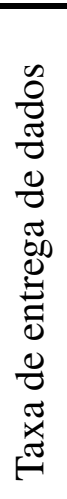 & 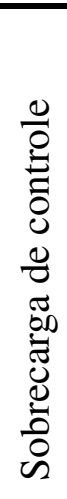 & 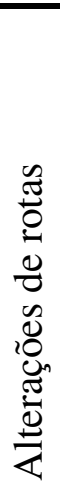 & 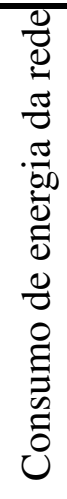 & 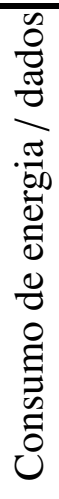 & 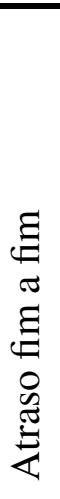 & 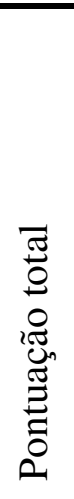 \\
\hline ENERGIA (SP) 0,5 & 8 & 6 & 6 & 8 & 7 & 7 & 7 & 49 \\
\hline ETX (SP) 1,0 & 1 & 8 & 8 & 6 & 1 & 8 & 8 & 40 \\
\hline ENERGIA (SP) 1,0 & 6 & 7 & 5 & 3 & 6 & 5 & 5 & 37 \\
\hline ENERGIA (WSP) 1,0 & 5 & 5 & 4 & 7 & 4 & 4 & 4 & 33 \\
\hline ETX (sP) 0,5 & 4 & 3 & 7 & 4 & 2 & 6 & 6 & 32 \\
\hline ENERGIA (WSP) 0,5 & 7 & 4 & 3 & 5 & 8 & 3 & 1 & 31 \\
\hline ETX (WSP) 0,5 & 2 & 2 & 2 & 2 & 3 & 2 & 2 & 15 \\
\hline ETX (WSP) 1,0 & 3 & 1 & 1 & 1 & 5 & 1 & 3 & 15 \\
\hline
\end{tabular}

Tabela 13 - Classificação geral dos cenários ordenados pela pontuação obtida através da soma das classificações das métricas avaliadas.

Fonte: autor.

sobrecarga de controle, consumo de energia por pacote de dados entregue e atraso fim a fim.

Avaliamos a sensibilidade para o algoritmo de definição de rotas através de dois valores: 0,5 e 1,0. De acordo com a Tabela 13, o valor 0,5 apresentou bons resultados quando vinculado com o uso da energia remanescente e algoritmo de definição de rotas SP enquanto o valor 1,0 apresentou bons resultados quando vinculado com a métrica ETX e o mesmo algoritmo de definição de rotas SP.

Avaliamos duas métricas para o algoritmo de definição de rotas: ETX e energia remanescente. $\mathrm{O}$ uso da energia remanescente apresentou melhor balanceamento no consumo de energia e maior tempo de vida da rede enquanto que o ETX apresentou menor sobrecarga de pacotes de controle quando vinculado ao uso do algoritmo de definição de rotas SP.

Os três cenários com melhores desempenhos foram o CENÁRIO ENERGIA (sP) 0,5, o 
CENÁRIO ETX (SP) 1,0 e o CENÁRIO ENERGIA (sP) 1,0. Ambos cenários usaram o algoritmo de definição de rotas SP, apontando ser um bom algoritmo de definição de rotas. O uso do ETX e da energia remanescente demonstraram possuir qualidades distintas para a melhoria no desempenho da rede, conforme verificado na correlação das métricas. A métrica ETX obteve melhor desempenho usando a sensibilidade de valor 1,0, o que condiz com a natureza da métrica que oscila de acordo com a qualidade do enlace entre os nós, e uma menor sensibilidade irá disparar menos recálculos de rotas. A métrica energia remanescente obteve o melhor desempenho usando a sensibilidade de valor 0,5 o que também condiz com a natureza da métrica que possui um sentido único, do valor máximo para o mínimo, então uma sensibilidade maior irá ajudar no balanceamento do tráfego da rede melhorando no balanceamento do consumo de energia e no aumento do tempo de vida da rede.

\subsection{Estratégias de combinação de métricas}

De acordo com os resultados da Seção 5.1, selecionamos os três cenários com melhores desempenhos: o CENÁRIO ENERGIA (SP) 0,5, o CENÁRIO ETX (SP) 1,0 e o CENÁRIO ENERGIA (SP) 1,0. Neste capítulo vamos analisar uma métrica resultante da combinação por equação de média ponderada e outra métrica resultante da combinação por lógica difusa e comparar seu desempenho com os melhores cenários selecionados na Seção 5.1.

\subsubsection{Cenários e configurações dos experimentos}

Para a combinação das métricas escolhemos usar duas estratégias, sendo uma por equação de média ponderada e a outra por uso da lógica difusa. No intuito de simplificar a identificação dos cenários para as simulações desta seção, abordamos a seguinte nomenclatura:

a) para os cenários da Seção 5.1, removemos o SP da nomenclatura, uma vez que todos os cenários usam o algoritmo de roteamento shortest path. Desta forma, o CENÁRIO ENERGIA (SP) 0,5 é nOm eado CENÁRIO ENERGIA (0,5), o CENÁRIO ETX (SP) 1,0 é nomeado CENÁRIO ETX $(1,0)$ e o CENÁRIO ENERGIA (SP) 1,0 é nomeado CENÁRIO ENERGIA $(1,0)$; 
b) para a estratégia por equação de média ponderada com $\alpha=0,5$ e sensibilidade 5 nomeamos CENÁRIo ETX/ENERGIA $(0,5)$, e para sensibilidade 1,0 nomeamos CENÁRIO ETX/ENERGIA $(1,0)$;

c) para a estratégia da lógica difusa com o método de defuzificação MOM nomeamos CENÁRIo MOM $(0,5)$ e cENÁRIo MOM $(1,0)$. E usando o método de defuzificação centroide nomeamos CENÁRIo CENTROIDE $(0,5)$ e CENÁRIO CENTROIDE $(1,0)$.

A Tabela 14 apresenta o sumário da nomenclatura dos cenários.

\begin{tabular}{llc}
\hline \multicolumn{1}{c}{ Cenário } & parâmetros & sensibilidade \\
\hline CENÁRIO ETX $(1,0)$ & $\alpha=1,0$ & 1,0 \\
\hline CENÁRIO ETX/ENERGIA $(0,5)$ & $\alpha=0,5$ & 0,5 \\
\hline CENÁRIO ETX/ENERGIA $(1,0)$ & $\alpha=0,5$ & 1,0 \\
\hline CENÁrIO MOM $(0,5)$ & método MOM & 0,5 \\
\hline CENÁRIO MOM $(1,0)$ & método MOM & 1,0 \\
\hline CENÁRIO CENTROIDE $(0,5)$ & método centroide & 0,5 \\
\hline CENÁRIO CENTROIDE $(1,0)$ & método centroide & 1,0 \\
\hline CENÁRIO ENERGIA $(0,5)$ & $\alpha=0$ & 0,5 \\
\hline CENÁRIO ENERGIA $(1,0)$ & $\alpha=0$ & 1,0 \\
\hline
\end{tabular}

Tabela 14 - Nomenclatura dos cenários e seus principais parâmetros.

Fonte: autor.

Dado os cenários, analisamos os resultados obtidos através de simulações executadas no COOJA. As configurações para as simulações são mantidas as mesmas definidas na Seção 5.1 conforme Tabela 10, excluindo o algoritmo de definição de rotas WSP.

As simulações foram configuradas para finalizarem ao identificar o primeiro nó sem energia remanescente na rede. Desta forma, o tempo da simulação passa a ser o tempo de vida da rede. Os resultados apresentados exibem intervalo de confiança de 95\% considerando a distribuição t de Student (HAVERKORT; WILEY, 1998) para a média de 10 simulações por cenário (com sementes aleatórias). 


\subsubsection{Resultados e análise}

Seguindo a mesma sequência de resultados da Seção 5.1, iniciaremos com a análise do tempo de vida da rede (lembrando que o tempo de vida da rede é o tempo em que a rede permaneceu com todos os nós ativos). A Figura 18 apresenta o tempo médio de vida da rede para cada cenário com seu respectivo intervalo de confiança.

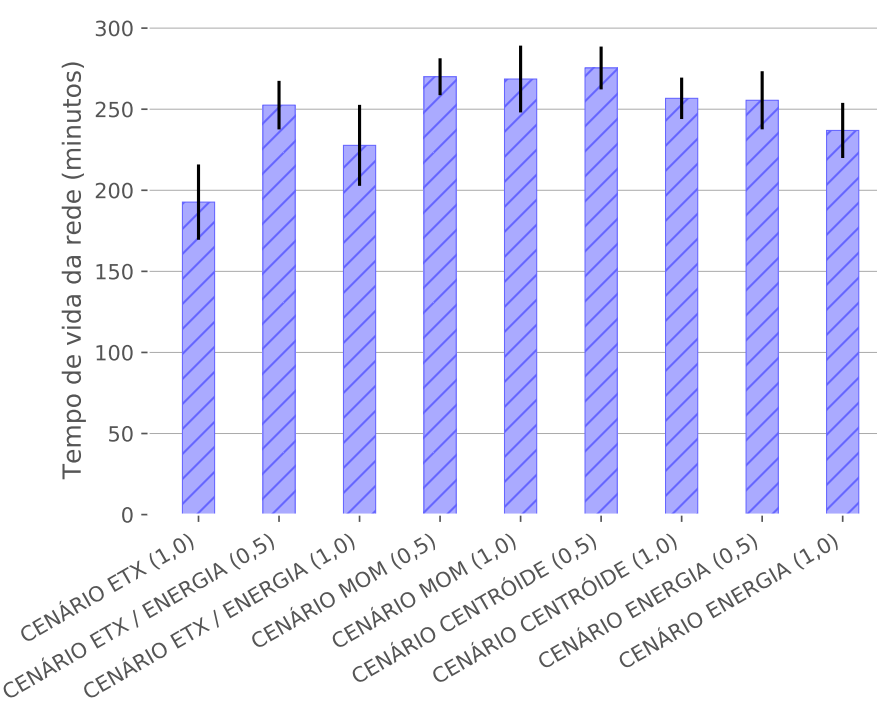

Figura 18 - Tempo médio de vida da rede por cenário com seus respectivos intervalos de confiança.

Fonte: autor.

O CENÁRIO CENTROIDE $(0,5)$ apresenta o maior tempo médio de vida da rede seguido do CenÁrio mom $(0,5)$ e o cenÁRIo mom $(1,0)$. Por outro lado, o cENÁRIo etx $(1,0)$ apresenta o menor tempo médio de vida da rede entre os cenários analisados, apresentando a mesma tendência para a métrica ETX observada na Seção 5.1.

Todos os cenários apresentam uma boa taxa de entrega de dados (PDR), com valores acima de 98\%, conforme exibido na Figura 19. Com isso, podemos concluir que os cenários analisados com suas respectivas configurações não geraram sobrecarga de controle suficiente para aumentar o congestionamento e impactar na taxa de entrega de dados. Uma taxa de entrega de dados elevada é um dos objetivos a se alcançar em redes de sensores sem fio.

A Figura 20 apresenta a sobrecarga média de controle por hora/nó de cada cenário com seu respectivo intervalo de confiança.

O CENÁRIo MOM $(1,0)$ apresenta a maior sobrecarga média de controle com aproxi- 


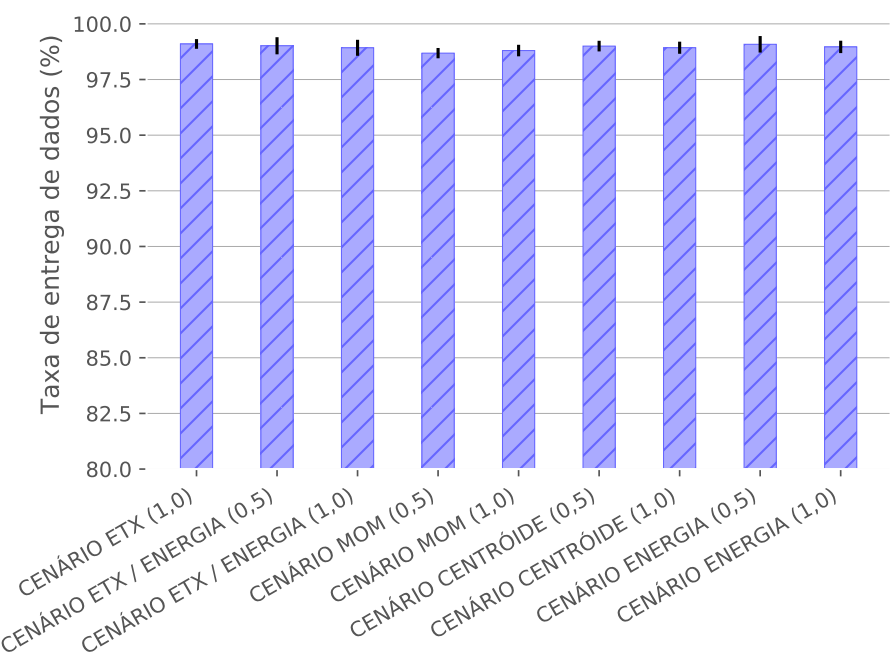

Figura 19 - Taxa média de entrega de dados por cenário com seus respectivos intervalos de confiança.

Fonte: autor.

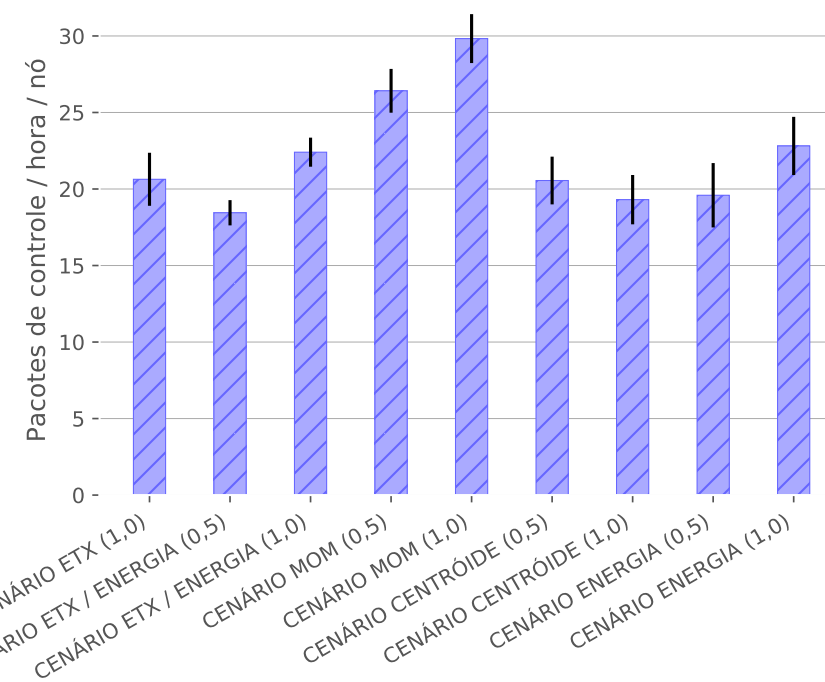

Figura 20 - Média das sobrecargas de controle por cenário com seus respectivos intervalos de confiança.

Fonte: autor.

madamente 30 pacotes de controle por hora/nó. Na outra ponta, o CENÁRIO ETX/ENERGIA $(0,5)$ apresenta a menor sobrecarga média de controle com aproximadamente 19 pacotes de controle por hora/nó. Apesar do CENÁRIo ETX/ENERGIA $(0,5)$ apresentar a menor taxa média de sobrecarga de controle, o mesmo cenário apresenta o sexto maior tempo médio de vida da rede com diferença de 23 minutos (aproximadamente 8\%) do cENÁRIO CENTROIDE $(0,5)$ que apresenta o maior tempo médio de vida da rede. Com isso, 
concluímos que a estratégia por equação de média ponderada com $\alpha=0,5$ contribui para uma menor sobrecarga de controle.

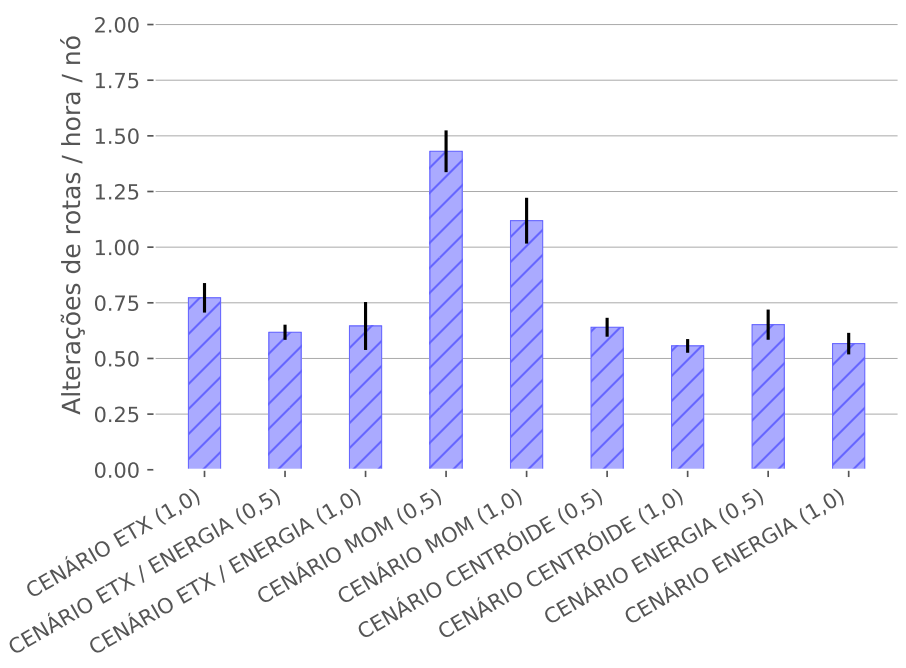

Figura 21 - Média do número de alterações de rotas por cenário com seus respectivos intervalos de confiança.

Fonte: autor.

Analisando as alterações de rotas entre os cenários, apresentadas na Figura 21, observamos que o CENÁRIO MOM $(0,5)$ e o cenário CENÁRIO MOM $(1,0)$ apresentam os maiores números em alterações de rotas e, como consequência, os maiores valores para sobrecarga de controle, conforme visualizado na Figura 20. Por outro lado, o cENÁRIo CENTROIDE $(1,0)$ e o CENÁRIO ENERGIA $(1,0)$ apresentam os menores número de alterações de rotas e a segunda e terceira menor sobrecarga de controle, respectivamente. Com isso, podemos concluir que o uso da energia como métrica contribui na redução de alterações de rotas conforme observado na Seção 5.1.

Na Figura 22 podemos visualizar o consumo de energia da rede em porcentagem, que é a relação entre o total de energia consumida da rede e o total de energia inicial da rede. $\mathrm{O}$ consumo de energia da rede está relacionado diretamente com o tempo de vida da rede, desta forma, o cenário que permitir um maior tempo de vida da rede irá consumir mais energia da rede. O CENÁRIO ETX $(1,0)$ apresenta o menor consumo de energia da rede exibindo o menor uso entre os cenários analisados. O CENÁRIo ETX/ENERGIA $(1,0)$ apresenta o segundo menor consumo de energia da rede. O CENÁRIo MOM (0,5), o CENÁRIO MOM $(1,0)$ e o CENÁRIo CENTROIDE $(0,5)$ apresentam os maiores consumo de energia da rede e, consequentemente, os melhores aproveitamentos de energia da rede. Não podemos esquecer que o melhor aproveitamento, neste caso, está somente relacionado 


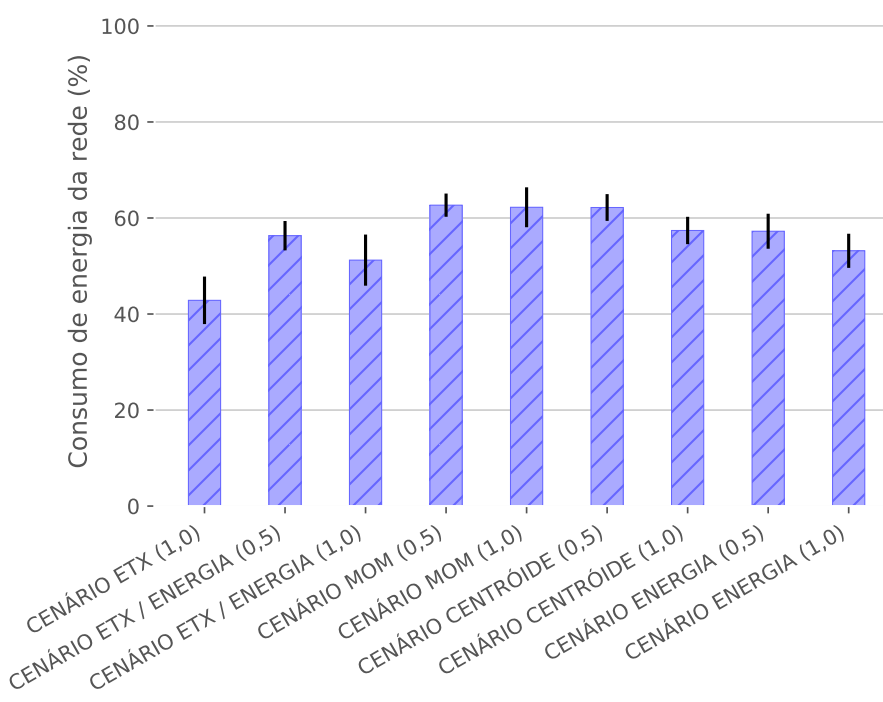

Figura 22 - Consumo médio de energia da rede por cenário com seus respectivos intervalos de confiança.

Fonte: autor.

ao consumo de energia da rede. Desta forma, não podemos afirmar que foi realmente o melhor aproveitamento sem antes relacionar o uso da energia com outros fatores como taxa de entrega de dados e sobrecarga de controle, por exemplo.

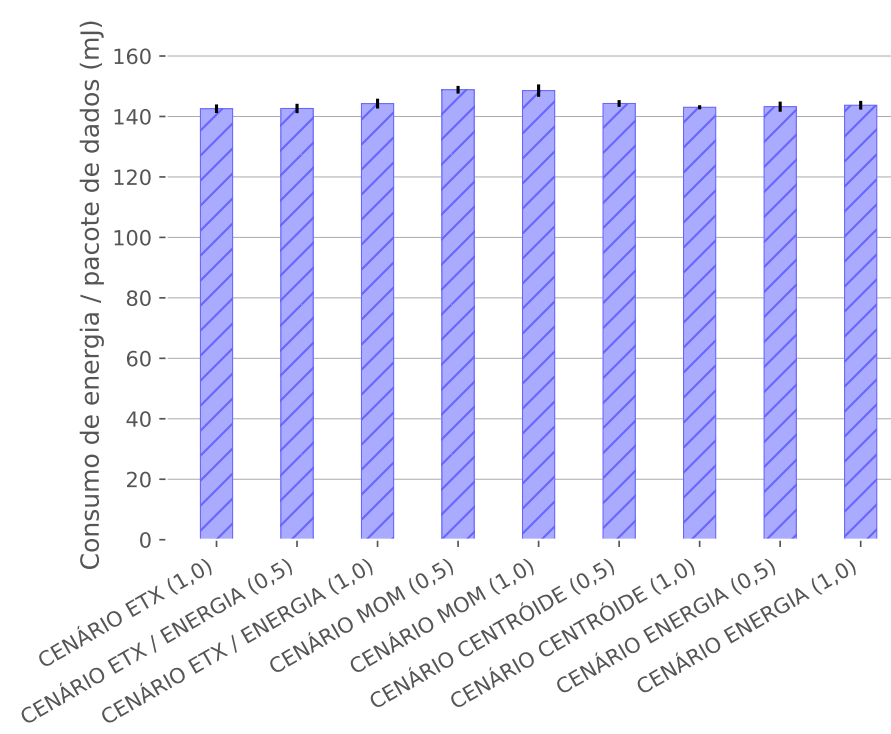

Figura 23 - Consumo médio de energia por pacote de dados entregue por cenário com seus respectivos intervalos de confiança.

Fonte: autor.

Para analisar melhor o consumo, podemos conferir na Figura 23 o consumo de energia por pacote de dados entregue na rede. Podemos observar que o CENÁRIO ETX $(1,0)$ emitiu o menor número de pacotes de controle por pacote de dados entregue 
apresentando o menor consumo de energia por pacote de dados entregue. Em contrapartida, apresentou o menor consumo de energia da rede observado na Figura 22 sendo consequência do esgotamento prematuro das baterias de alguns nós. O cENÁrio ETX/ENERGIA $(0,5)$ apresenta o segundo menor consumo de energia por pacotes de dados entregue, mas apresenta um maior consumo de energia da rede, se comparado ao cENÁRIO ETX $(1,0)$. O CENÁRIO MOM $(0,5)$ apresenta o maior consumo de energia por pacotes de dados entregue, mas apresenta o maior consumo de energia da rede. O cENÁRIo ETX/ENERGIA $(1,0)$ aparece como segundo menor consumidor de energia por pacote de dados entregue e como sexto maior consumidor de energia da rede. O CENÁRIo CENTROIDE $(1,0)$ aparece como terceiro menor consumidor de energia por pacote de dados entregue e o como quarto maior consumidor de energia da rede. O CENÁRIO ENERGIA $(0,5)$ aparece como quarto menor consumidor de energia por pacote de dados entregue e como quinto maior consumidor de energia da rede. Assim, estes três últimos cenários apresentam melhor equilíbrio entre pacote de dados entregue e consumo de energia da rede.

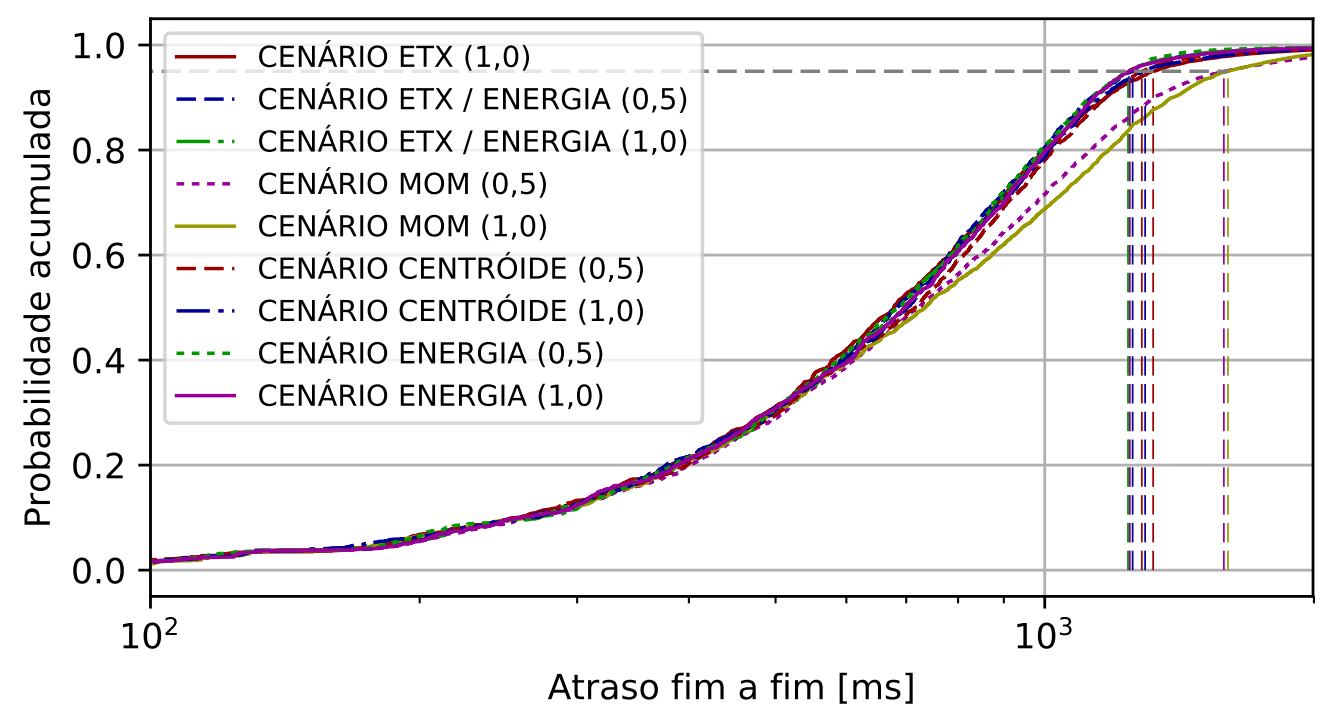

Figura 24 - Probabilidade acumulada de atraso fim a fim para pacote de dados de 10 simulações por cenário com percentil em $95 \%$.

Fonte: autor.

Na Figura 24 podemos verificar o atraso fim a fim com percentil em 95\%. Ordenando os cenários do menor atraso fim a fim para o maior, obtemos: CENÁRIO ETX/ENERGIA

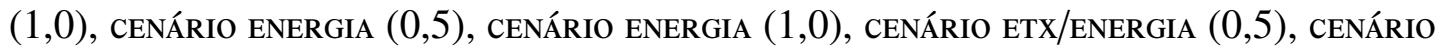
CENTROIDE $(0,5)$, CENÁRIo CENTROIDE $(1,0)$, CENÁRIO ETX $(1,0)$, CENÁRIO MOM $(0,5)$ e CENÁRIo мом $(1,0)$. 
Observando a Figura 24 podemos verificar que os dois CENÁRIOS MOM apresentam os maiores atrasos fim a fim, destacando-se dos outros cenários. Isto ocorre, principalmente, devido ao aumento no número de alterações de rotas que ocasiona no aumento do tráfego de pacotes de controle e no aumento do atraso fim a fim. O cENÁrio ETX/ENERGIa $(1,0)$ apresenta o menor atraso fim a fim através da combinação de métricas dada pela Equação 4.1 de média ponderada, e os dois cenários seguintes apresentam os menores atraso fim a fim através do uso da energia remanescente como métrica no algoritmo de definição de rotas. Dados os resultados observados na Figura 24 podemos afirmar que a estratégia da equação de média ponderada e o uso da energia remanescente no algoritmo de definição de rotas contribuem para redução do atraso fim a fim.

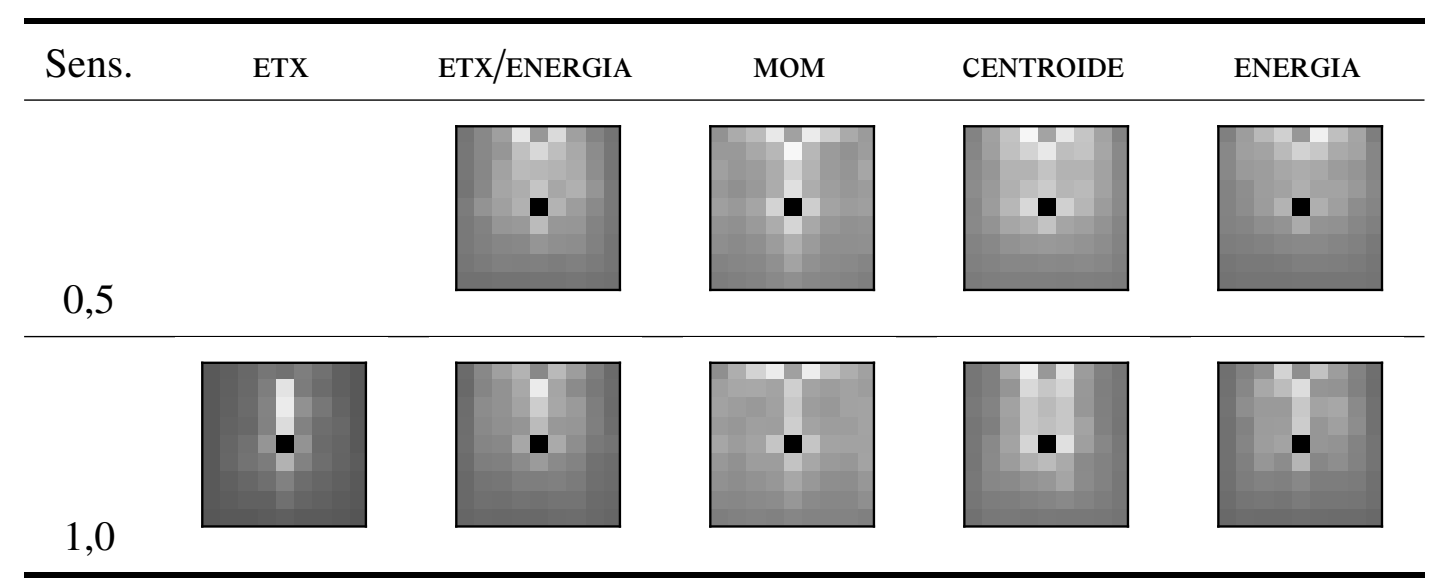

Tabela 15 - Mapas de média da energia remanescente dos nós da rede por cenário para análise da distribuição no consumo de energia entre os nós.

Fonte: Autor.

Para entender o balanceamento no consumo de energia entre os nós na rede analisamos os mapas de energia extraídos ao fim de cada simulação, exibidos na Tabela 15. Lembramos que cada ponto no mapa representa um nó e sua respectiva posição na rede. O ponto central (preto) representa o controlador que não possui limitação de energia. Quanto mais próximo de branco for o ponto maior será o consumo de energia naquele nó. Observamos que os cenários com sensibilidade 0,5 apresentam melhor distribuição no consumo de energia se comparado diretamente com seu respectivo cenário com sensibilidade 1,0. O CENÁRIO ETX $(1,0)$ apresenta a maior concentração no consumo de energia dos nós entre o controlador e o sorvedouro seguindo a mesma tendência para o uso da métrica ETX, conforme observado na Seção 5.1 .

Abordando a classificação dos cenários para as métricas avaliadas podemos observar na Tabela 16 a classificação geral dos cenários através da soma das pontuações 
obtidas em cada métrica. Observe que a pontuação para cada métrica avaliada varia entre 1 e 9 dado que os cenários avaliados totalizam nove.

\begin{tabular}{|c|c|c|c|c|c|c|c|c|}
\hline Cenário & 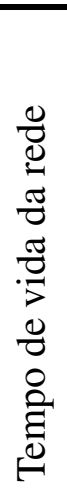 & 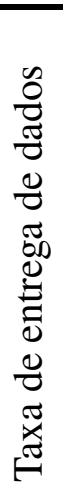 & 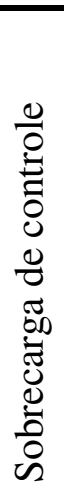 & 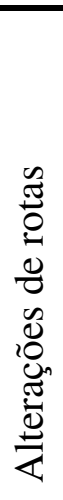 & 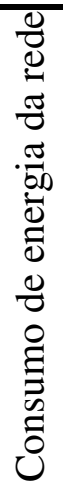 & 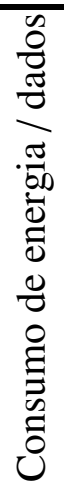 & 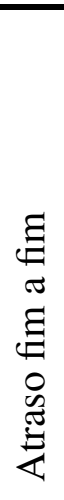 & 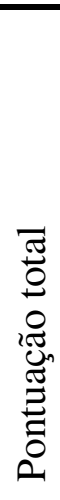 \\
\hline ETX/ENERGIA $(0,5)$ & 4 & 7 & 9 & 7 & 4 & 8 & 6 & 45 \\
\hline CENTROIDE $(1,0)$ & 6 & 3 & 8 & 9 & 6 & 7 & 4 & 43 \\
\hline ENERGIA $(0,5)$ & 5 & 8 & 7 & 4 & 5 & 6 & 8 & 43 \\
\hline CENTROIDE $(0,5)$ & 9 & 6 & 6 & 6 & 7 & 3 & 5 & 42 \\
\hline ENERGIA $(1,0)$ & 3 & 5 & 3 & 8 & 3 & 5 & 7 & 34 \\
\hline ETX $(1,0)$ & 1 & 9 & 5 & 3 & 1 & 9 & 3 & 31 \\
\hline ETX/ENERGIA $(1,0)$ & 2 & 4 & 4 & 5 & 2 & 4 & 9 & 30 \\
\hline мом $(0,5)$ & 8 & 1 & 2 & 1 & 9 & 1 & 2 & 24 \\
\hline мом $(1,0)$ & 7 & 2 & 1 & 2 & 8 & 2 & 1 & 23 \\
\hline
\end{tabular}

Tabela 16 - Classificação geral dos cenários ordenados pela pontuação obtida através da soma das classificações das métricas avaliadas.

Fonte: autor.

O CENÁRIO ETX/ENERGIA $(0,5)$ apresenta maior pontuação para a métrica sobrecarga de controle e consumo de energia/dados indicando que esta combinação de métricas reduz o tráfego de controle reduzindo o consumo de energia por pacote de dados entregue.

O CENÁRIO CENTROIDE $(1,0)$ apresenta maior pontuação para sobrecarga de controle e alterações de rotas indicando que este cenário obteve um bom equilíbrio na sobrecarga de controle através de um baixo número de alterações de rotas.

O CENÁrio ENERGIa $(0,5)$ apresenta uma boa pontuação para o atraso fim a fim e taxa de entrega de dados indicando que a métrica energia consegue uma melhor distribuição de rotas reduzindo assim o congestionamento e o atraso na entrega de pacote de dados. 
O CENÁRIO CENTROIDE ( 0,5 apresenta uma boa pontuação para o tempo de vida da rede indicando um bom equilíbrio entre taxa de entrega de dados, sobrecarga de controle e alterações de rotas permitindo que a rede fique ativa por mais tempo.

O CENÁRIO ETX $(1,0)$ apresenta uma boa pontuação para taxa de entrega de dados e consumo de energia por pacote de dados. Esta é uma característica do uso da métrica ETX no algoritmo de definição de rotas que mantém as rotas de forma estática por mais tempo reduzindo o congestionamento e aumentando a taxa de entrega de dados.

A partir da análise da combinação da classificação das métricas avaliadas, representada na Tabela 16, podemos visualizar os quatro cenários melhores classificados e com pontuações próximas: o CENÁRIO ETX/ENERGIA (0,5), o CENÁRIO CENTROIDE $(1,0)$, o CENÁRIO ENERGIA $(0,5)$ e o CENÁRIO CENTROIDE $(0,5)$.

\subsubsection{Considerações}

Nesta seção avaliamos o uso da combinação de métricas no algoritmo de roteamento através da estratégia de equação de média ponderada e a estratégia da lógica difusa avaliando dois métodos de defuzificação (centroide e média dos máximos). A partir dos resultados obtidos na Seção 5.1 extraímos os três melhores cenários e observamos que todos os cenários usam o algoritmo de roteamento SP e, desta forma optamos por usar esse algoritmo como padrão. Também avaliamos as duas sensibilidades $(0,5$ e 1,0) uma vez que ambas aparecem entre os melhores cenários na Seção 5.1 .

De acordo com os resultados analisados extraímos os quatro melhores cenários classificados conforme Tabela 16. O CENÁRIo ETX/ENERGIA $(0,5)$ obtém a maior pontuação demonstrando que a combinação das métricas apresenta melhores resultados se comparado aos resultados do uso de métricas individuais. Isto também fica claro ao observar que o CENÁrio CENTROIDE $(1,0)$ aparece em segundo lugar. Com isso, podemos afirmar que a combinação de métricas pode melhorar, de fato, o roteamento nas redes de sensores sem fio definidas por software, uma vez que a combinação aparece em três dos quatro melhores cenários. A variação de sensibilidade nos cenários que usam centroide como método de defuzificação no uso do algoritmo de lógica difusa não demonstram afetar o roteamento já que aparecem com pontuações próximas. $\mathrm{O}$ CENÁRIO ENERGIA $(0,5)$ foi o único cenário usando métrica individual classificado entre os melhores cenários. Desta forma, a energia remanescente apresenta ser uma métrica 
de grande impacto no algoritmo de definição de rotas.

\subsection{Análise de escalabilidade das estratégias}

Na Seção 5.2 avaliamos o uso da combinação de métricas no algoritmo de roteamento e extraímos os quatro melhores cenários: o CENÁRIO ETX/ENERGIA (0,5), o CENÁRIO CENTROIDE $(1,0)$, o CENÁRIO ENERGIA $(0,5)$ e o CENÁRIo CENTROIDE $(0,5)$.

A análise de escalabilidade é um fator crucial em SDWSN devido as características de centralização de controle e coleta de dados. Desta forma, os nós centralizadores sofrem uma carga maior de tráfego aumentando o congestionamento e por consequência a perda de pacotes por colisão, por exemplo. Com isso, o aumento no número de nós na rede irá aumentar o congestionamento nestes nós centralizadores mais rapidamente do que o restante da rede causando um grande impacto negativo em toda a rede.

Nesta seção analisamos a escalabilidade da rede através da variação do tamanho da topologia para verificarmos se o comportamento da rede observado nos quatro melhores cenários persistem, e se o aumento do congestionamento no controlador e no sorvedouro impactam drasticamente no comportamento da rede.

\subsubsection{Cenários e configurações dos experimentos}

Os tamanhos de rede usados para escalabilidade podem ser conferidos na Tabela 17. Escolhemos usar raízes ímpares no número de nós da topologia para manter o controlador e o sorvedouro centralizados conforme visualizado na Figura 25. O círculo verde apresenta o alcance do rádio configurado nos sensores.

As simulações são executadas no COOJA (simulador de redes de sensores sem fio e emulador de nós sensores) e são configuradas para finalizarem ao identificar o primeiro nó sem energia remanescente na rede. Desta forma, o tempo da simulação passa a ser o tempo de vida da rede. Os resultados apresentados exibem intervalo de confiança de $95 \%$ considerando a distribuição t de Student (HAVERKORT; WILEY, 1998) para a média de 10 simulações por cenário (com sementes aleatórias). 


\begin{tabular}{ll}
\hline Topologia & $\begin{array}{l}\text { grade }(5 \times 5,7 \times 7,9 \times 9,11 \times 11, \\
13 \times 13,15 \times 15 \text { e } 17 \times 17 \text { nós })\end{array}$ \\
\hline Tamanho da rede & $25,49,81,121,169,225$ e 289 nós \\
\hline Controlador & centro \\
\hline Sorvedouro & centro superior \\
\hline Nós sensores & Tamanho da rede subtraído 2 nós \\
\hline Anúncio de vizinhos & frequência máxima: 1 pacote por minuto \\
\hline Algoritmo de roteamento & SP \\
\hline Sensibilidade do roteamento & $0,5 / 1,0$ \\
\hline Sensoriamento de dados & a cada 1 minuto \\
\hline Ciclo de trabalho do rádio & $16 \mathrm{~Hz}$ \\
\hline Energia inicial & 62.000 mJ \\
\hline Tempo de simulação & primeiro nó sem energia \\
\hline Ambiente do rádio & UDGM (do inglês Unit Disk Graph Medium) \\
\hline Distância entre os nós & 45 metros vertical/horizontal \\
\hline Raio de alcance do rádio & 50 metros \\
\hline Raio de interferência & 50 metros \\
\hline
\end{tabular}

Tabela 17 - Configurações das simulações.

Fonte: autor.

\subsubsection{Análise dos resultados}

Seguindo a sequência das seções anteriores, iniciamos a análise do tempo de vida da rede exibido na Figura 26. O cenÁrio centroIde $(0,5)$ apresenta o maior tempo médio de vida da rede para todos os tamanhos de rede analisados. O CENÁRIO ETX/ENERGIA $(0,5)$ em redes com até 81 nós apresenta o menor tempo médio de vida da rede e a partir de 121 nós apresenta ganhos de tempo médio em relação ao CENÁRIo CENTROIDE $(1,0)$ e ao cenário entergia $(0,5)$. Em redes com 289 nós o cenÁrio etX/ENERgia $(0,5)$ volta a apresentar o menor tempo médio de vida da rede. Analisando apenas o tempo médio de vida da rede e ignorando os outros resultados podemos concluir que o CENÁRIO CENTROIDE $(0,5)$ obtém o melhor resultado, apresentando o maior tempo médio de vida da rede entre os tamanhos de rede analisados, enquanto o CENÁRIO ETX/ENERGIA 


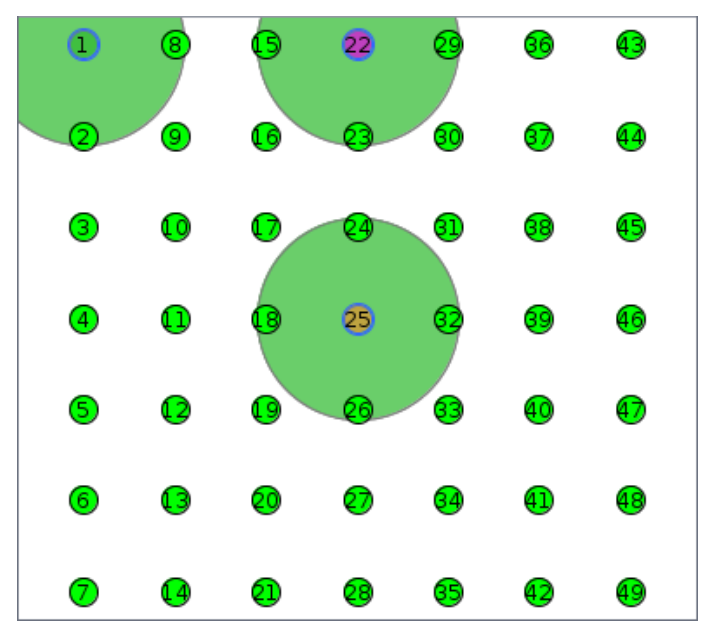

Figura 25 - Topologia em grade (7x7) com controlador no centro (\#25) e sorvedouro no centro superior (\#22).

Fonte: autor.

$(0,5)$ apresenta o pior resultado exibindo uma tendência para o menor tempo médio de vida da rede.

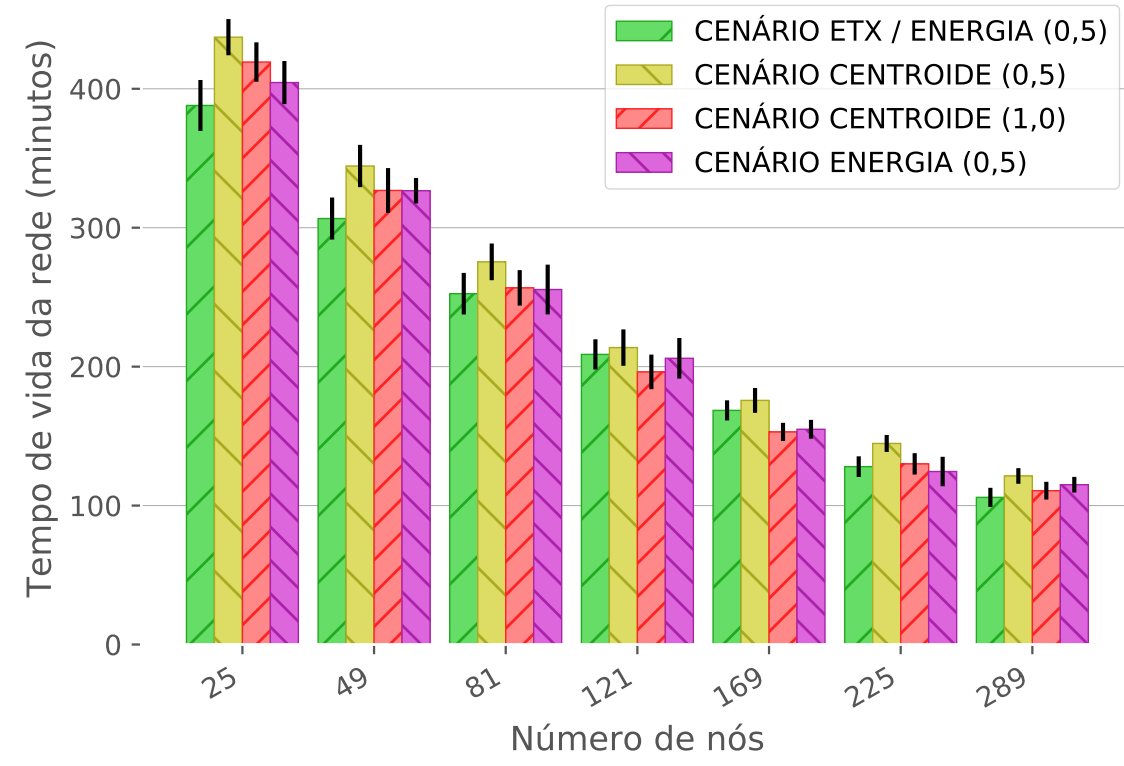

Figura 26 - Tempo médio de vida da rede por cenário com seus respectivos intervalos de confiança.

Fonte: autor.

Analisando a taxa média de entrega de dados (PDR), exibido na Figura 27, observamos uma taxa superior a $98 \%$ para redes com até 81 nós. Também podemos observar uma queda gradativa do PDR médio entre os cenários para redes acima de 81 nós. As redes com 225 e 289 nós apresentam uma queda drástica no PDR médio e isso ocorre 


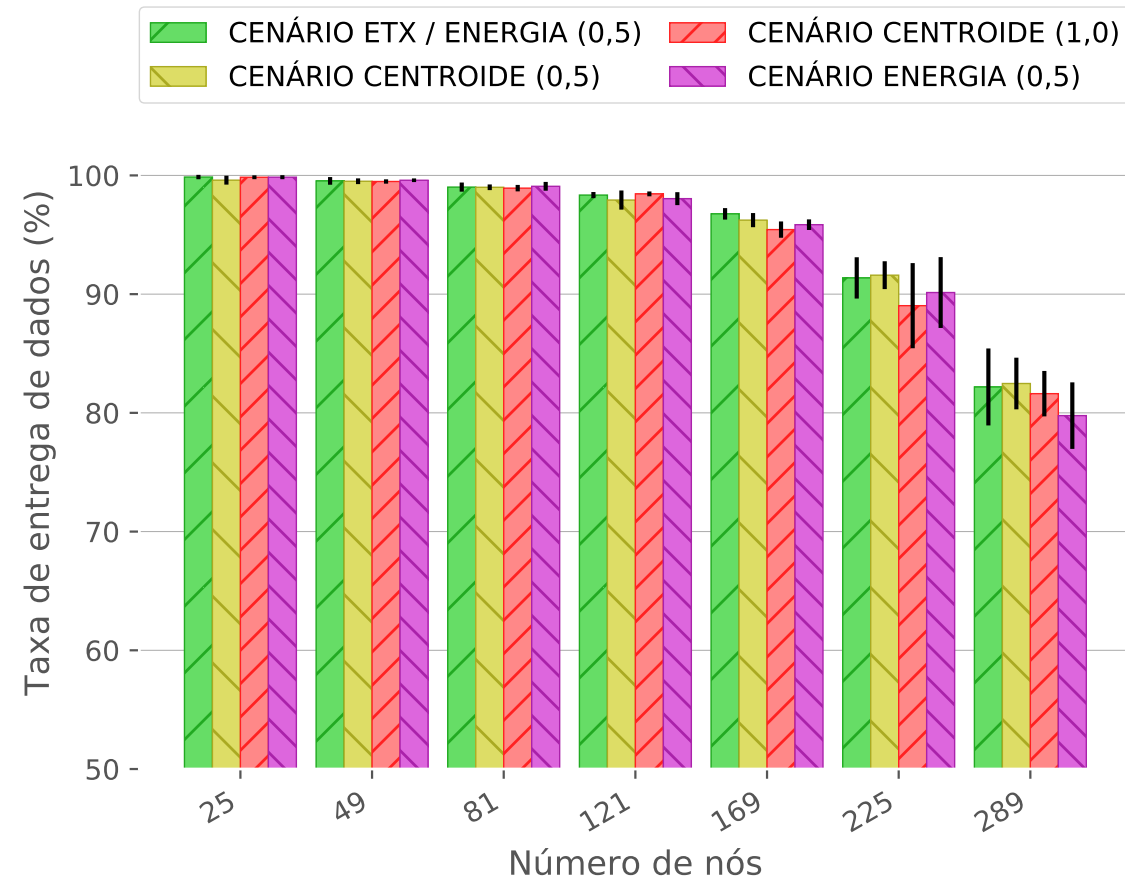

Figura 27 - Taxa média de entrega de dados por cenário com seus respectivos intervalos de confiança.

Fonte: autor.

devido ao aumento no tráfego de pacotes de controle e como consequência as perdas de pacotes por colisão. Podemos conferir a sobrecarga de controle na Figura 28.

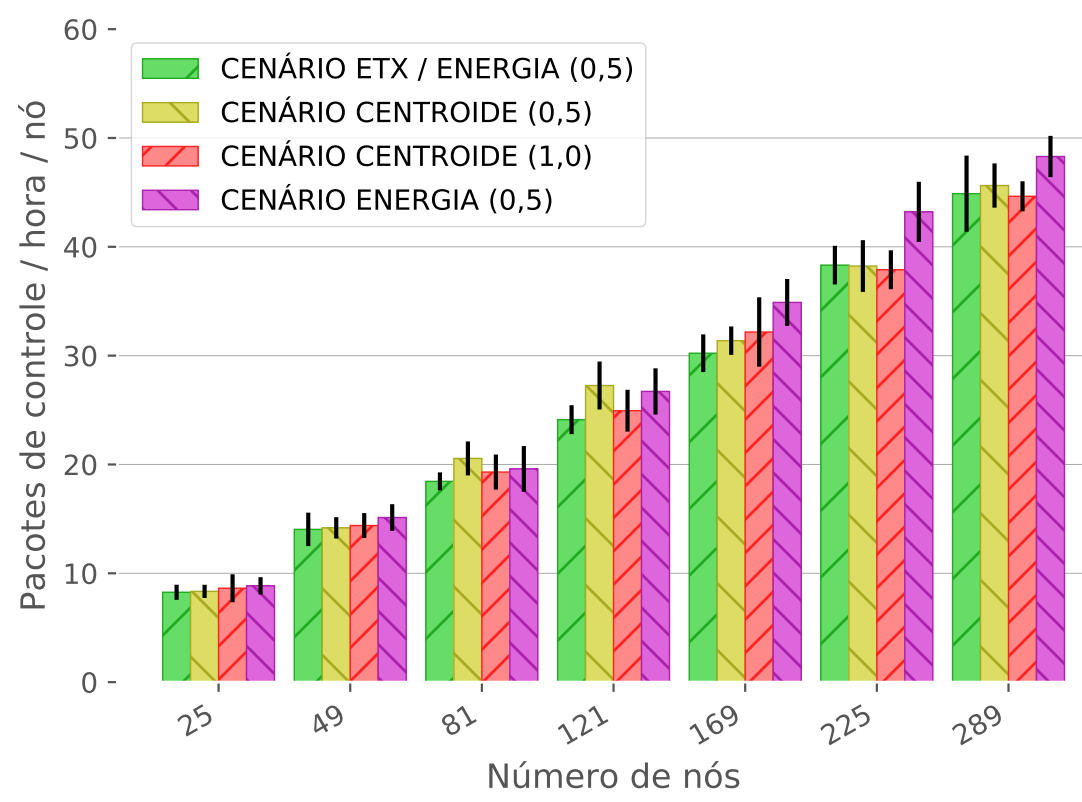

Figura 28 - Média das sobrecargas de controle por cenário com seus respectivos intervalo de confiança.

Fonte: autor. 
Na Figura 28 podemos observar um crescimento na sobrecarga média de controle relacionado diretamente ao número de nós na rede. Esse aumento na sobrecarga média de controle evidencia o problema do controle centralizado na definição de rotas e gerenciamento da rede em SDWSN (Kobo; Hancke; Abu-Mahfouz, 2017). Uma possível solução para esse problema é a descentralização em múltiplos controladores (OLIVEIRA; GABRIEL; MARGI, 2015). O aumento no tráfego de pacotes de controle aumenta o congestionamento na rede e as colisões de pacotes. Consequentemente, observamos uma redução na taxa média de entrega de dados conforme visualizado na Figura 27. O CENÁRIo enERgIa $(0,5)$ apresenta a maior média no envio de pacotes de controle por hora/nó em cinco das sete redes avaliadas (redes com 25, 49, 121, 169, 225 e 289 nós). Com isso, o cENÁRIo ENERgia $(0,5)$ é o menos qualificado para a sobrecarga média de controle. O CENÁRIO ETX/ENERGIA $(0,5)$ apresenta a menor média no envio de pacotes de controle por hora/nó em cinco das sete redes avaliadas (redes com 25, 49, 81, 121 e 169 nós). Enquanto o CENÁrIo CENTROIDE $(1,0)$ apresenta a menor média nas duas redes maiores (225 e 289 nós) apresentando uma melhora em comparação ao CENÁRIo ETX/ENERgia (0,5). Com isso, o CENÁRIo ETX/ENERGia $(0,5)$ e o CENÁRIo CENTROIDE $(1,0)$ se apresentam como os mais qualificados para uma melhor sobrecarga média de controle.

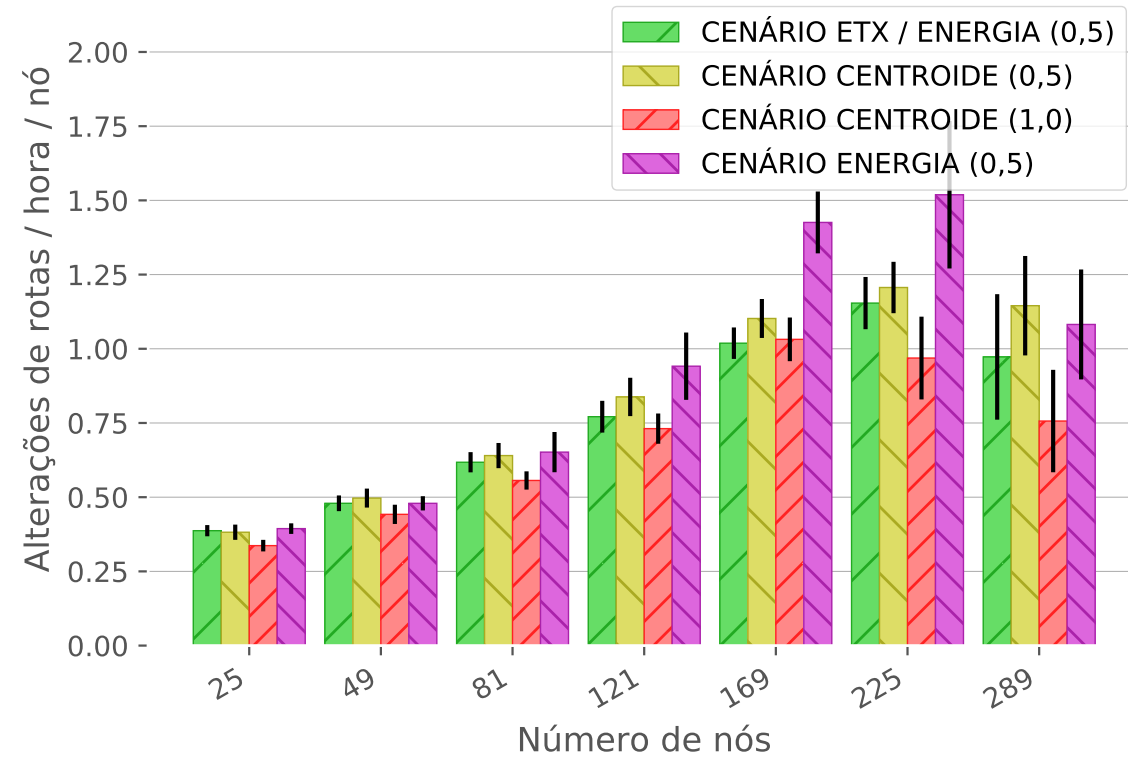

Figura 29 - Média do número de alterações de rotas por hora/nó por cenário com seus respectivos intervalos de confiança.

Fonte: autor.

Na Figura 29 podemos observar o número médio de alterações de rotas por hora/nó. 
O CENÁRIO CENTROIDE $(1,0)$ apresenta o menor número médio de alterações de rotas por hora/nó em seis dos setes tamanhos de redes avaliadas ficando em segundo lugar somente na rede com 169 nós. Por outro lado, o cenário enERgia $(0,5)$ apresenta o maior número médio de alterações de rotas por hora/nó em cinco dos sete tamanhos de redes avaliadas. Se uma rede apresentar um grande número de alterações de rotas, isso aumentará o tráfego de pacotes de controle e o congestionamento causando a redução no PDR da rede. Se uma rede apresentar um baixo número de alterações de rotas, isto pode causar definição de rotas fixas por um grande período de tempo e esgotar a energia de alguns nós prematuramente reduzindo o tempo de vida da rede e, provavelmente, causar o particionamento da rede. O ideal é chegar a um equilíbrio no número de alterações de rotas para maximizar o tempo de vida da rede e minimizar a sobrecarga de controle.

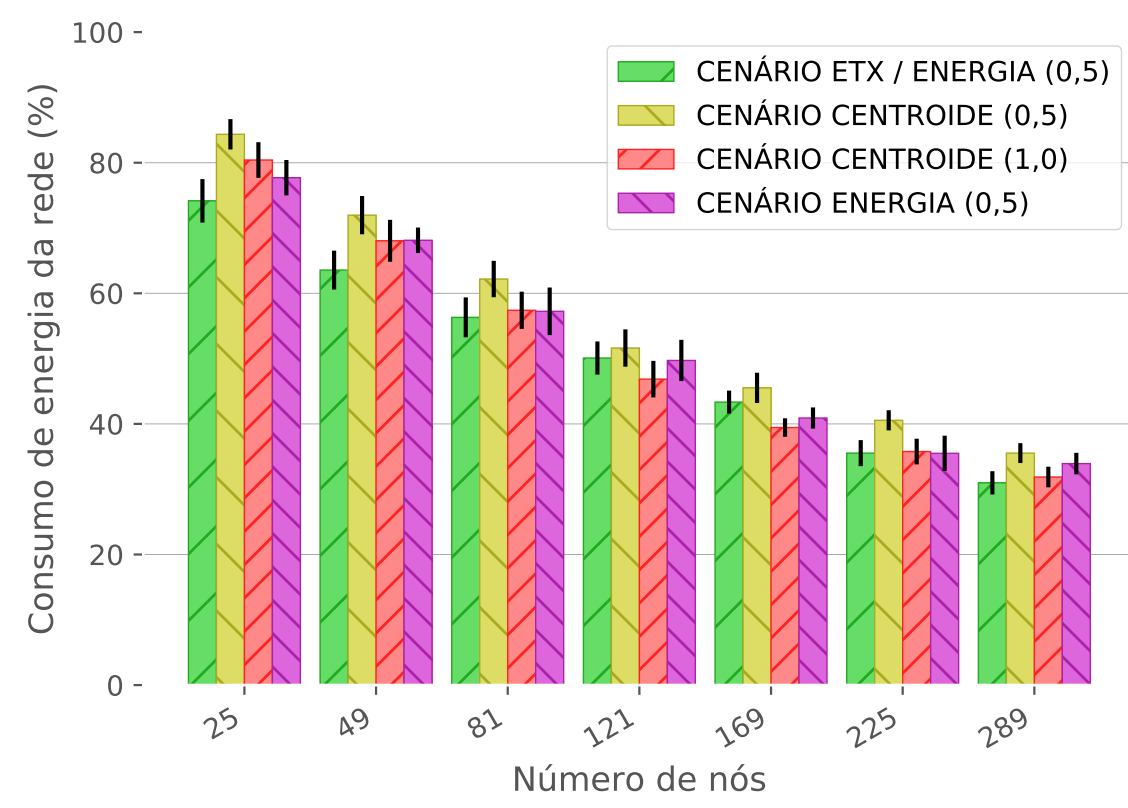

Figura 30 - Consumo médio de energia da rede por cenário com seus respectivos intervalos de confiança.

Fonte: autor.

O consumo de energia da rede é a relação entre o consumo total e o total de energia inicial da rede. Na Figura 30 podemos analisar o consumo médio de energia da rede com seus respectivos intervalos de confiança. O consumo médio indica o gasto de energia da rede enquanto todos os nós estão ativos e assim podemos avaliar se uma rede obteve um melhor balanceamento no consumo de energia entre os nós através do algoritmo de definição de rotas. O cENÁRIo CENTROIDE $(0,5)$ apresenta o maior consumo médio para todos os tamanhos de rede avaliados, demonstrando assim um maior 
aproveitamento da energia da rede. Porém, não podemos concluir que é o melhor aproveitamento de energia da rede sem antes correlacionar com o tempo de vida da rede e o PDR. Por outro lado, o cenário etx/Energia $(0,5)$ apresenta o menor consumo médio de energia em quatro dos sete tamanhos de rede avaliadas (25, 49, 81 e 289 nós) apresentando um menor aproveitamento da energia da rede.

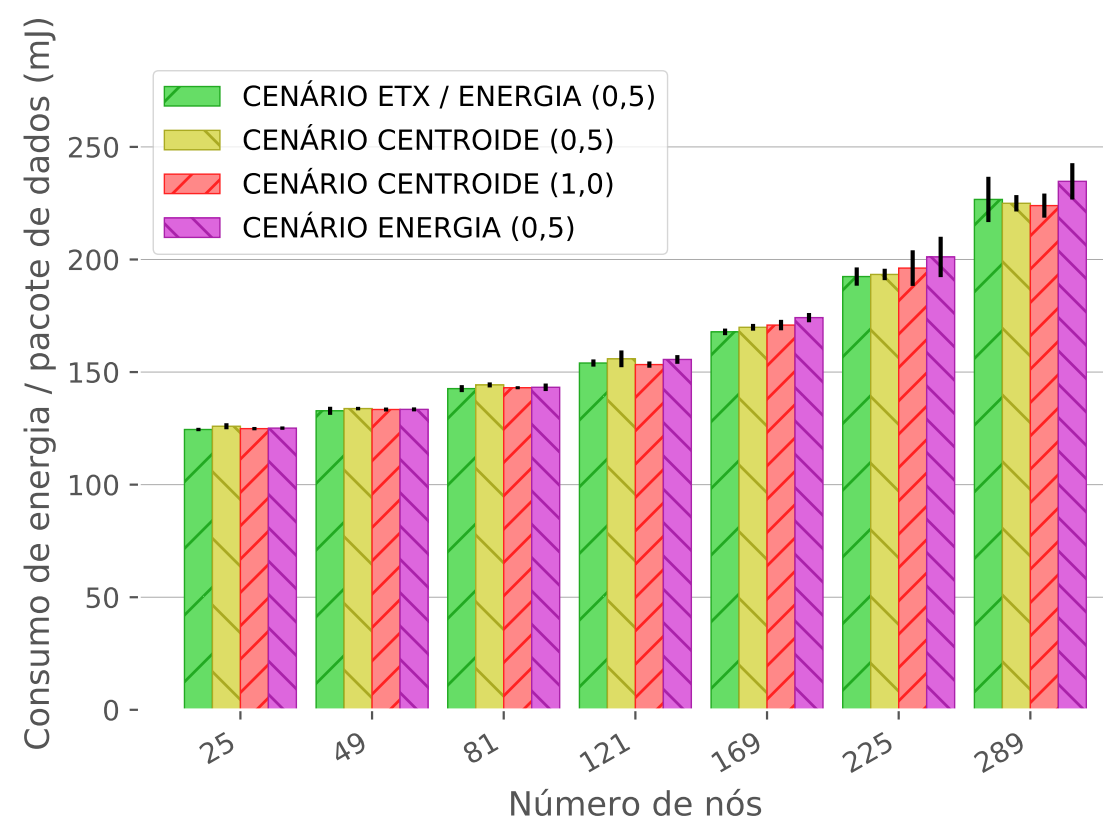

Figura 31 - Consumo médio de energia por pacote de dados entregue por cenário com seus respectivos intervalos de confiança.

Fonte: autor.

Após analisar o consumo médio de energia da rede, vamos analisar o consumo médio de energia da rede por pacotes de dados entregue que é a relação entre o consumo total de energia e o número total de pacotes de dados entregue. Desta forma, podemos medir a eficiência no consumo de energia uma vez que direcionamos todo o consumo para os pacotes de dados entregues. Esta relação pode ser visualizada na Figura 31. Redes até 81 nós apresentam consumos equivalentes de energia por pacotes de dados entregue. O CENÁRIO CENTROIDE $(1,0)$ apresenta o menor consumo para as redes de tamanho 121 e 289 nós. O CENÁRIO ETX/ENERGIA $(0,5)$ apresenta o menor consumo para as redes 25, 49, 81, 169 e 225 nós. O cENÁrio CENTROIDE (0,5) apresenta o maior consumo para redes até 121 nós e o CENÁRIO ENERGIA $(0,5)$ apresenta o maior consumo para as redes maiores que 121 nós.

Para analisar o atraso fim a fim dos pacotes de dados, elaboramos um gráfico para cada cenário para visualização da relação do ganho de atraso com o aumento no nú- 
mero de nós na rede. A Figura 32 exibe o atraso fim a fim para o CENÁRIo ETX/ENERGIA $(0,5)$. Observamos um aumento no atraso fim a fim relacionado diretamente ao número de nós na rede. Isto ocorre devido ao aumento no tráfego de pacotes de controle e congestionamento causado pela centralização de controle. Assim, quanto maior for o número de nós em uma rede maior será o congestionamento próximo ao controlador.

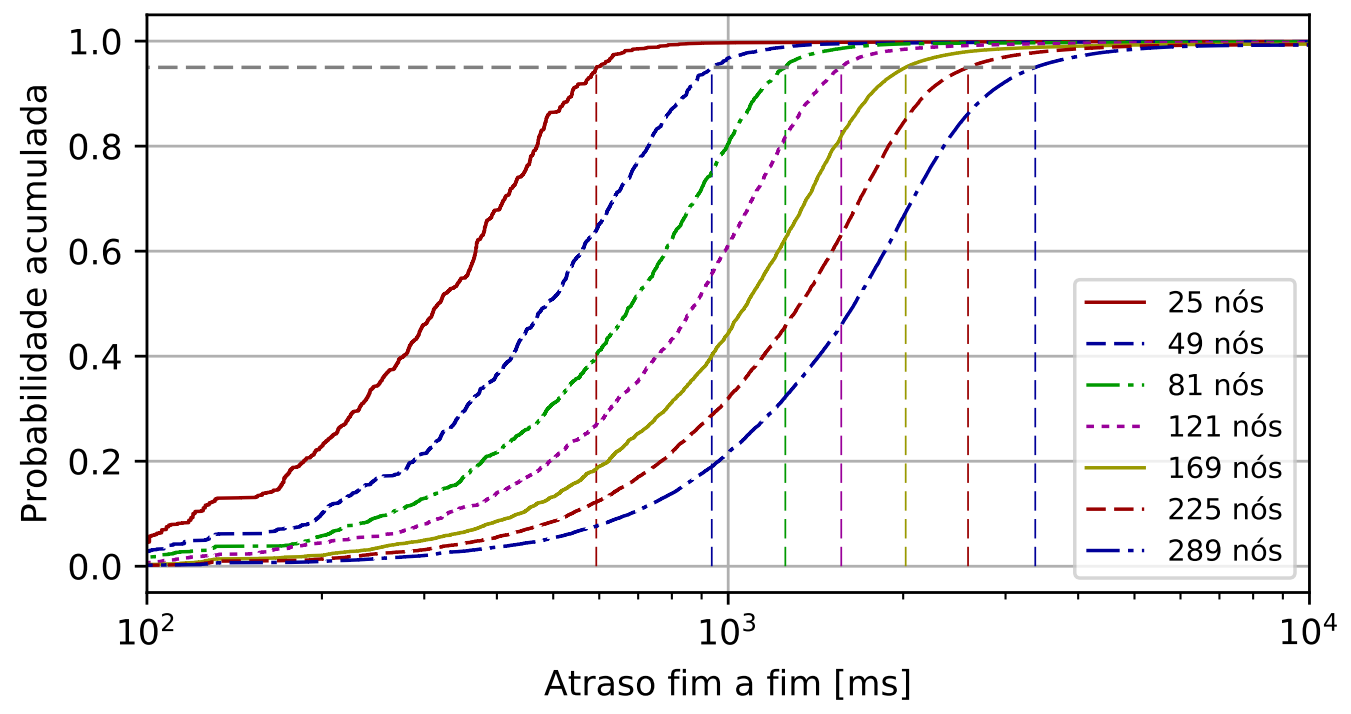

Figura 32 - Probabilidade acumulada de atraso fim a fim para os pacotes de dados de 10 simulações por cenário com percentil em $95 \%$ para o CENÁRIO ETX/ENERGIA $(0,5)$.

Fonte: autor.

A Figura 33 exibe o atraso fim a fim para o cenÁrio centroide $(0,5)$. Esta figura confirma a relação do aumento no atraso com o aumento no número de nós na rede observado na figura anterior.

A Figura 34 exibe o atraso fim a fim para o cENÁRIo CENTROIDE $(1,0)$ e a Figura 35 exibe o atraso fim a fim para o cenário enERgia $(0,5)$. Ambos gráficos de atraso fim a fim confirmam a relação do aumento do atraso com o aumento de número de nós na rede.

Na Tabela 18 organizamos os atrasos de cada cenário em ordem crescente por tamanho de rede. Nesta tabela observamos que para redes até 81 nós os atrasos entre os cenários ficam próximos para cada tamanho de rede. Em redes maiores de 81 nós o cENÁRIO ETX/ENERGIA $(0,5)$ lidera o primeiro lugar com o menor atraso fim a fim enquanto o CENÁRIO ENERGIA $(0,5)$ lidera o segundo lugar.

Através da Tabela 19 podemos analisar o balanceamento no consumo de energia através dos mapas de energia remanescente média de cada cenário separados por ta- 


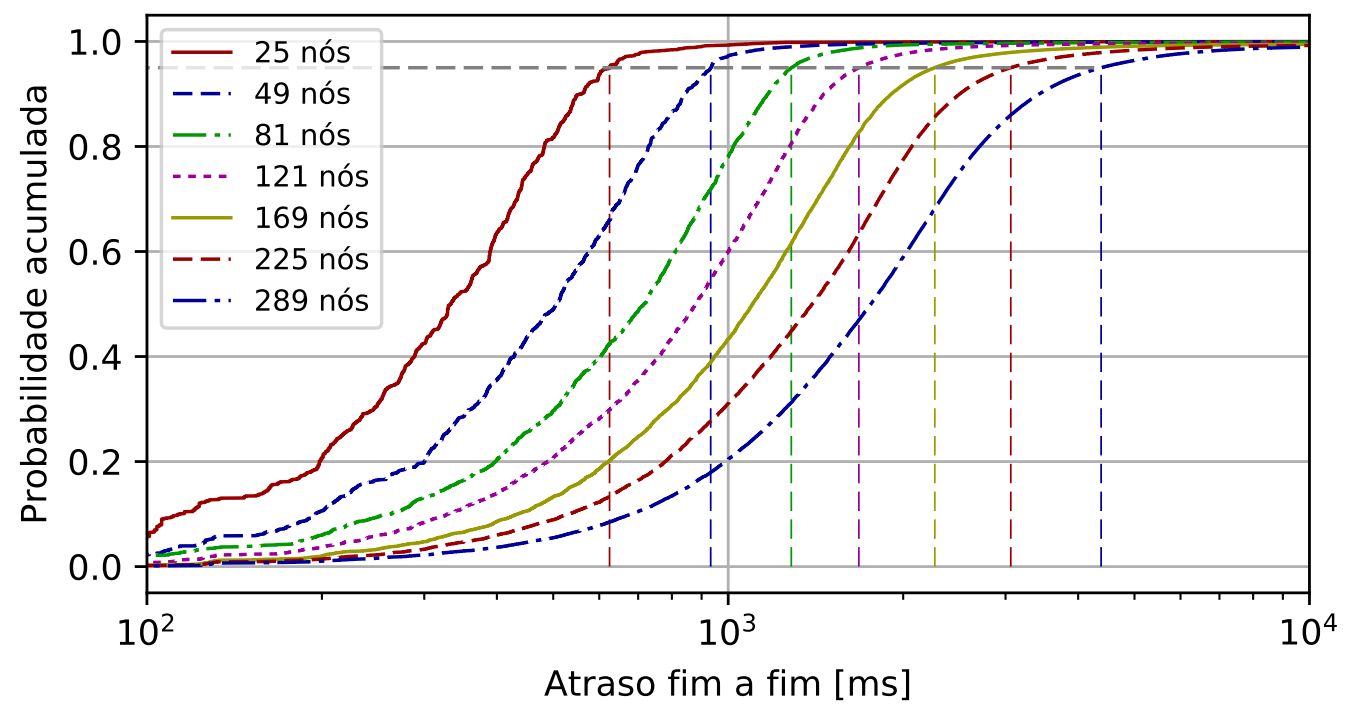

Figura 33 - Probabilidade acumulada de atraso fim a fim para os pacotes de dados de 10 simulações por cenário com percentil em 95\% para o CENÁRIO CENTROIDE $(0,5)$.

Fonte: autor.

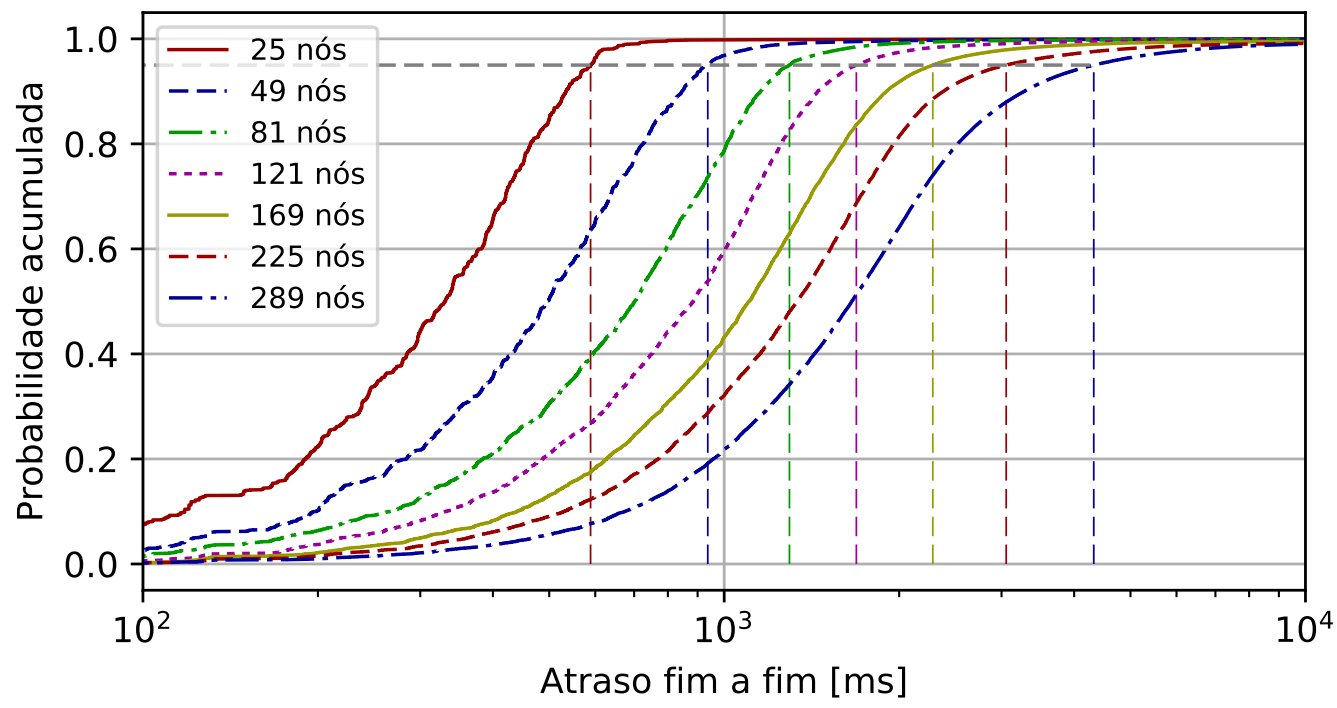

Figura 34 - Probabilidade acumulada de atraso fim a fim para os pacotes de dados de 10 simulações por cenário com percentil em 95\% para o CENÁRIO CENTROIDE $(1,0)$.

Fonte: autor.

manho da rede. Cada quadrado no mapa representa um sensor e sua respectiva posição na rede e a cor representa o nível de energia da bateria ao término da simulação. A cor preta representa uma bateria carregada e a cor branca representa um bateria totalmente descarregada. O ponto central (preto) representa o controlador ao qual não possui limitação de energia. Quanto mais próximo de branco for o ponto maior é o seu consumo 


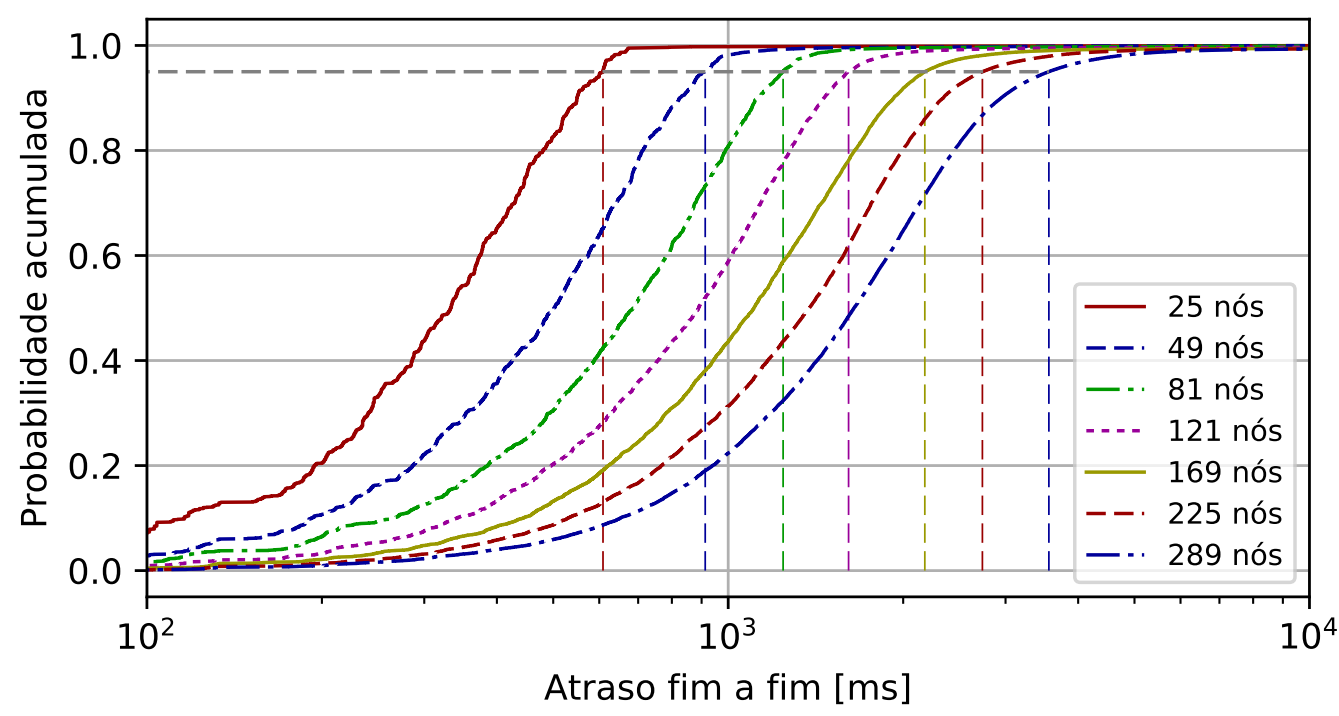

Figura 35 - Probabilidade acumulada de atraso fim a fim para os pacotes de dados de 10 simulações por cenário com percentil em $95 \%$ para o CENÁRIO ENERGIA $(0,5)$.

Fonte: autor.

e menor é sua energia remanescente. Analisando as linhas da tabela, que representam diferentes tamanhos de rede, observamos um escurecimento nos mapas para redes com mais sensores. Este escurecimento indica um menor tempo de vida da rede não permitindo que os nós consumam sua energia, conforme observado na Figura 26. Nestes mapas mais escuros podemos observar pontos claros próximos ao controlador e sorvedouro indicando um maior congestionamento nestes pontos. Este comportamento é esperado em SDWSN devido a centralização do tráfego de pacotes de controle e dados. O CENÁRIO CENTROIDE $(0,5)$ e o CENÁRIO ENERGIA $(0,5)$ apresentam melhor balanceamento no consumo de energia entre os tamanhos de rede avaliados uma vez que apresentam menos diferença de tonalidade entre os tons mais escuros e os mais claros.

Abordando a classificação dos cenários para as métricas avaliadas podemos observar na Tabela 20 a classificação geral dos cenários através da soma das pontuações obtidas em cada métrica. Observe que a pontuação para cada métrica avaliada varia entre 4 e 28 dado a avaliação de quatro cenários multiplicados por sete diferentes tamanhos de redes.

O CENÁRIO ETX/ENERGia $(0,5)$ apresenta pontuação alta para as métricas taxa de entrega de dados, sobrecarga de controle, consumo de energia por pacote de dados e atraso fim a fim demonstrando que o uso da combinação das métricas consegue equilibrar o congestionamento através da redução no envio de pacotes de controle e ao 


\begin{tabular}{ccccc}
\hline & menor atraso & $»$ & $»$ & maior atraso \\
\hline 25 & CENTROIDE $(1,0)$ & ETX/ENERGIA $(0,5)$ & ENERGIA $(0,5)$ & CENTROIDE $(0,5)$ \\
nós & $589.0 \mathrm{~ms}$ & $593.0 \mathrm{~ms}$ & $609.0 \mathrm{~ms}$ & $625.0 \mathrm{~ms}$ \\
\hline 49 & ENERGIA $(0,5)$ & CENTROIDE $(0,5)$ & ETX/ENERGIA $(0,5)$ & CENTROIDE $(1,0)$ \\
nós & $913.0 \mathrm{~ms}$ & $933.0 \mathrm{~ms}$ & $937.0 \mathrm{~ms}$ & $937.0 \mathrm{~ms}$ \\
\hline 81 & ENERGIA $(0,5)$ & ETX/ENERGIA $(0,5)$ & CENTROIDE $(0,5)$ & CENTROIDE $(1,0)$ \\
nós & $1243 \mathrm{~ms}$ & $1254 \mathrm{~ms}$ & $1284 \mathrm{~ms}$ & $1295 \mathrm{~ms}$ \\
\hline 121 & ETX/ENERGIA $(0,5)$ & ENERGIA $(0,5)$ & CENTROIDE $(0,5)$ & CENTROIDE $(1,0)$ \\
nós & $1565 \mathrm{~ms}$ & $1611 \mathrm{~ms}$ & $1678 \mathrm{~ms}$ & $1688 \mathrm{~ms}$ \\
\hline 169 & ETX/ENERGIA $(0,5)$ & ENERGIA $(0,5)$ & CENTROIDE $(0,5)$ & CENTROIDE $(1,0)$ \\
nós & $2020 \mathrm{~ms}$ & $2179 \mathrm{~ms}$ & $2267 \mathrm{~ms}$ & $2285 \mathrm{~ms}$ \\
\hline 225 & ETX/ENERGIA $(0,5)$ & ENERGIA $(0,5)$ & CENTROIDE $(1,0)$ & CENTROIDE $(0,5)$ \\
nós & $2586 \mathrm{~ms}$ & $2737 \mathrm{~ms}$ & $3056 \mathrm{~ms}$ & $3063 \mathrm{~ms}$ \\
\hline 289 & ETX/ENERGIA $(0,5)$ & ENERGIA $(0,5)$ & CENTROIDE $(1,0)$ & CENTROIDE $(0,5)$ \\
nós & $3375 \mathrm{~ms}$ & $3562 \mathrm{~ms}$ & $4323 \mathrm{~ms}$ & $4381 \mathrm{~ms}$ \\
\hline
\end{tabular}

Tabela 18 - Atraso fim a fim ordenado do menor para o maior por tamanho de rede para definição do melhor cenário.

Fonte: autor.

mesmo tempo balancear o tráfego através da distribuição de rotas.

O CENÁRIo CENTROIDE $(0,5)$ apresenta pontuação alta para o tempo de vida da rede e consumo de energia da rede, que apesar de apresentar um congestionamento maior que o CENÁRIO ETX/ENERGIA $(0,5)$ e consequentemente um aumento na energia consumida por pacote de dados entregue, demonstra conseguir uma melhor distribuição no congestionamento e assim no aumento do tempo de vida da rede.

Observamos que o CENÁRIO CENTROIDE $(1,0)$ apresenta pontuação alta para a métrica alterações de rotas indicando que a redução de sensibilidade (maior número igual a menor sensibilidade) no algoritmo de definição de rotas implica em uma redução no número de alterações de rotas. Em contrapartida, a redução na sensibilidade impacta na redução no tempo de vida da rede.

Através da análise da combinação da classificação das métricas observamos que o CENÁRIO ETX/ENERGIA $(0,5)$ apresentou a maior pontuação se classificando como melhor 


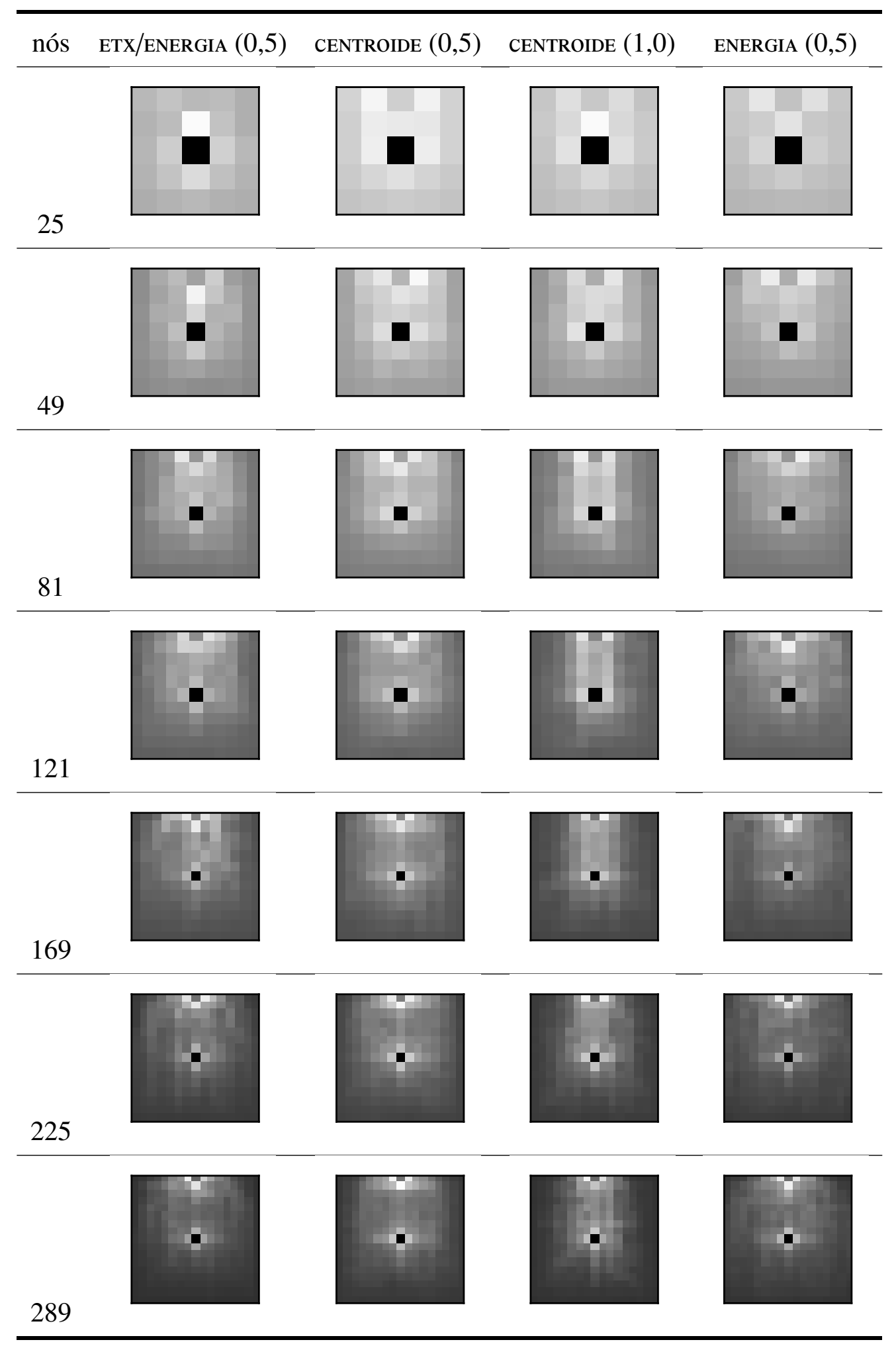

Tabela 19 - Mapas de média da energia remanescente dos nós da rede por cenário para análise da distribuição no consumo de energia entre os nós.

Fonte: Autor. 


\begin{tabular}{|c|c|c|c|c|c|c|c|c|}
\hline Cenário & 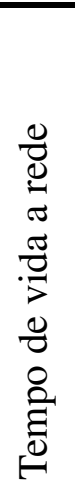 & 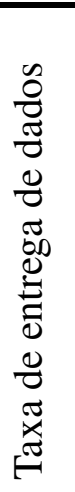 & 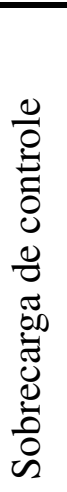 & 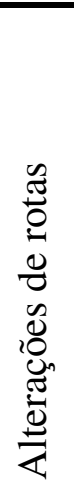 & 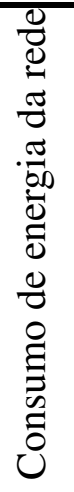 & 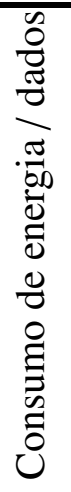 & 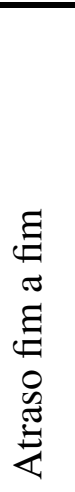 & 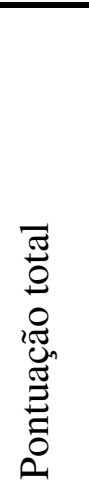 \\
\hline ETX/ENERGIA $(0,5)$ & 12 & 23 & 25 & 20 & 12 & 25 & 24 & 141 \\
\hline CENTROIDE $(0,5)$ & 28 & 17 & 16 & 13 & 28 & 13 & 12 & 127 \\
\hline CENTROIDE $(1,0)$ & 16 & 12 & 20 & 27 & 15 & 21 & 12 & 123 \\
\hline ENERGIA $(0,5)$ & 14 & 18 & 9 & 10 & 15 & 11 & 22 & 99 \\
\hline
\end{tabular}

Tabela 20 - Classificação dos cenários.

Fonte: autor.

cenário entre os avaliados.

\subsubsection{Considerações}

Nesta seção avaliamos a escalabilidade da rede $(25,49,81,121,169,225$ e 289 nós) para os melhores cenários observados na Seção 5.2. Os cenários selecionados por ordem de classificação foram: o cENÁRIo ETX/ENERGIA (0,5), o CENÁRIo CENTROIDE $(0,5)$, o CENÁrio CENTROIDE $(1,0)$ e o CENÁrio ENERgIA $(0,5)$. Na avaliação de escalabilidade, o CENÁRIO ETX/ENERGIA $(0,5)$ apresenta a maior pontuação destacando-se dos outros cenários e, assim, demonstrando ser uma boa configuração de combinação de métricas para o algoritmo de definição de rotas em redes de sensores definidas por software. $\mathrm{O}$ CENÁRIO CENTROIDE $(0,5)$ e o CENÁRIO CENTROIDE $(1,0)$ ficaram com pontuações próximas. Com isso, estes cenários se apresentam como alternativas de uso de combinação de métricas no algoritmo de definição de rotas. O cENÁRIo ENERGIA $(0,5)$ obteve a pontuação mais baixa demonstrando que a combinação de métricas é uma alternativa melhor do que o uso de métrica individual no algoritmo de definição de rotas. 


\subsection{Impacto dos pesos de métricas para seleção de es- tratégias}

Nesta seção analisamos os resultados das estratégias através do uso de diferentes pesos nas métricas avaliadas. Os pesos são aplicados com objetivo de priorizar alguma característica necessária ao ambiente da rede implantada. Para esta análise utilizamos os resultados apresentados na Tabela 20 da Seção 5.3 de análise de escalabilidade e aplicamos os pesos de acordo com a prioridade do ambiente da rede. Para isto, definimos dois ambientes distintos: o primeiro ambiente exige o menor atraso fim a fim possível para entrega de dados, como aplicações para semáforos inteligentes e dispositivos de monitoramento da saúde pessoal; o segundo ambiente exige que os nós fiquem ativos o máximo de tempo possível na rede como um todo, como em fazendas inteligentes e monitoramento de florestas.

\begin{tabular}{|c|c|c|c|c|c|c|c|c|}
\hline Cenário & 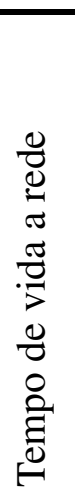 & 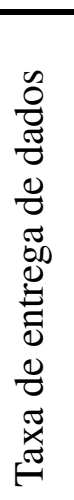 & 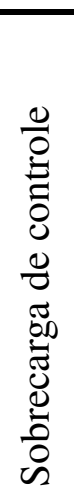 & 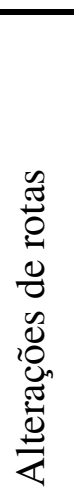 & 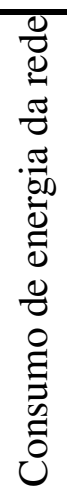 & 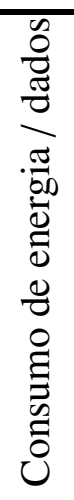 & 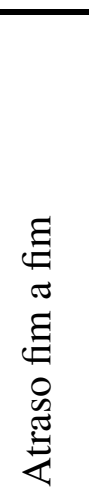 & 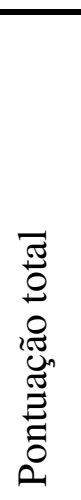 \\
\hline ETX/ENERGIA $(0,5)$ & 12 & 23 & 50 & 20 & 12 & 25 & 48 & 190 \\
\hline CENTROIDE $(0,5)$ & 28 & 17 & 32 & 13 & 28 & 13 & 24 & 155 \\
\hline CENTROIDE $(1,0)$ & 16 & 12 & 40 & 27 & 15 & 21 & 24 & 155 \\
\hline ENERGIA $(0,5)$ & 14 & 18 & 18 & 10 & 15 & 11 & 44 & 130 \\
\hline
\end{tabular}

Tabela 21 - Classificação dos cenários com aplicação de pesos priorizando a redução no atraso fim a fim.

Fonte: autor.

No primeiro ambiente, priorizando o menor atraso fim a fim, aplicamos peso 2 para as métricas sobrecarga de controle e atraso fim a fim, e mantivemos a pontuação original para as outras métricas. Escolhemos a métrica sobrecarga de controle por que através da redução na sobrecarga de controle conseguimos reduzir o congestionamento e consequentemente reduzir as colisões e o atraso fim a fim. Na Tabela 21 podemos conferir as pontuações corrigidas com os respectivos pesos. Observamos que a única 
mudança foi o empate entre o CENÁRIO CENTROIDE $(1,0)$ e o CENÁRIO CENTROIDE $(0,5)$. Porém o CENÁRIO ETX/ENERGIA $(0,5)$ continua em primeiro lugar como melhor cenário para ambientes com prioridade em reduzir o atraso fim a fim.

No segundo ambiente, priorizando o tempo de vida da rede, aplicamos peso 2 para as seguinte métricas: tempo de vida da rede que é a métrica que queremos priorizar; consumo de energia da rede por que quanto mais tempo a rede ficar ativa mais energia será consumida; e consumo de energia por pacote de dados por que um menor consumo de energia por pacote de dados entregue implica em um maior tempo de vida para rede. Na Tabela 22 podemos conferir as pontuações corrigidas com os respectivos pesos. Observamos que o cenário centroide $(0,5)$ assumiu o primeiro lugar indicando ser uma boa estratégia para conseguir um maior tempo de vida da rede. O cENÁRIo ETX/ENERGIA $(0,5)$ assume a segunda posição com uma diferença de 6 pontos indicando ainda ser uma boa estratégia para obtenção de um maior tempo de vida da rede. Os outros cenários mantiveram suas posições.

\begin{tabular}{|c|c|c|c|c|c|c|c|c|}
\hline Cenário & 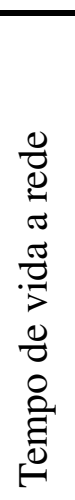 & 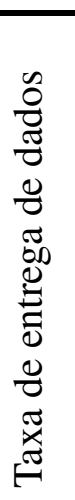 & 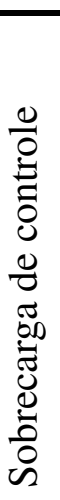 & 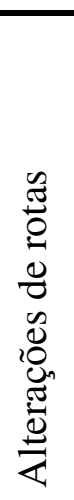 & 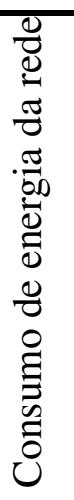 & 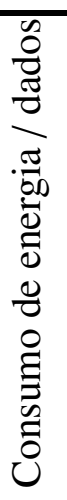 & 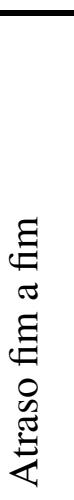 & 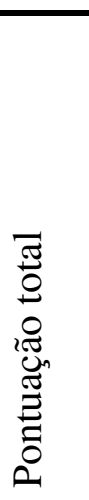 \\
\hline CENTROIDE $(0,5)$ & 56 & 17 & 16 & 13 & 56 & 26 & 12 & 196 \\
\hline ETX/ENERGIA $(0,5)$ & 24 & 23 & 25 & 20 & 24 & 50 & 24 & 190 \\
\hline CENTROIDE $(1,0)$ & 32 & 12 & 20 & 27 & 30 & 42 & 12 & 175 \\
\hline ENERGIA $(0,5)$ & 28 & 18 & 9 & 10 & 30 & 22 & 22 & 139 \\
\hline
\end{tabular}

Tabela 22 - Classificação dos cenários com aplicação de pesos priorizando o aumento no tempo de vida da rede.

Fonte: autor.

Aplicando pesos priorizamos algumas métricas e, em contrapartida, penalizamos outras. Com isso, observamos que as estratégias de combinações indicadas apresentam diferentes qualidades de acordo com a prioridade do ambiente da rede. Desta forma, concluímos que estratégias diferentes podem apresentar bons resultados de acordo com a prioridade do ambiente da rede. 


\section{CONCLUSÃO}

Esta pesquisa propôs o uso de múltiplas métricas no algoritmo de definição de rotas em SDWSN e avaliou o impacto destas combinações na rede. Inicialmente realizamos uma análise de correlação das métricas ETX e energia remanescente e concluímos que não há relação entre estas duas métricas. Desta forma, podemos combinar as duas métricas e possivelmente observar uma combinação das propriedades de ambas para redes de sensores sem fio definidas por software.

Toda a pesquisa foi divida em três etapas. Na primeira etapa analisamos dois algoritmos de definição de rotas (SP shortest path e WSP widest shortest path) com duas sensibilidades $(0,5$ e 1,0$)$ usando as métricas de forma individual. O algoritmo SP se mostrou mais promissor aparecendo nos melhores resultados obtidos. Já as duas sensibilidades aparecem entre os melhores resultados e foram usadas na segunda etapa junto ao uso do algoritmo SP.

$\mathrm{Na}$ segunda etapa avaliamos duas estratégias de combinações de métricas junto ao uso individual das métricas. Uma estratégia combinou as métricas através de uma equação de média ponderada aplicando um peso de $50 \%$ para cada métrica. A outra estratégia combinou as métricas através da lógica difusa avaliando dois métodos para defuzificação da métrica resultante (centroide e média dos máximos). A combinação por equação de média ponderada com sensibilidade 0,5 apresentou o melhor resultado na classificação de combinações dos resultados demonstrando que as propriedades da combinação de métricas se sobressai ao uso individual das métricas. A combinação através da lógica difusa com defuzificação por centroide e sensibilidade 1,0 conseguiu o segundo melhor resultado iterando a afirmação anterior. O uso da energia remanescente como métrica individual com sensibilidade 0,5 obteve a terceira melhor classificação, apresentando ser uma métrica com propriedades de impacto relevante em redes de sensores sem fio definidas por software.

Na terceira etapa avaliamos a escalabilidade para os melhores cenários classifica- 
dos nas etapas anteriores. A escalabilidade consistiu em avaliar redes entre 25 e 289 nós. A combinação através da equação de média ponderada obteve o melhor resultado geral, configurando assim a melhor estratégia entre as abordadas. A combinação através da lógica difusa com defuzificação por centroide ficou em segundo e terceiro lugar. O uso da energia remanescente ficou em quarto lugar mostrando sua relevância conforme observado na segunda etapa. Com isso, concluímos que as combinações de métricas no algoritmo de definição de rotas alavancam as propriedades da rede combinando as propriedades das métricas. Assim, o uso da combinação de métricas apresentam melhores resultados do que o uso de métricas individuais.

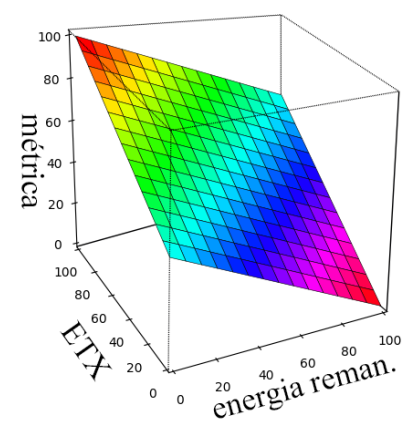

(a) MÉDIA PONDERADA $(\alpha=0,5)$

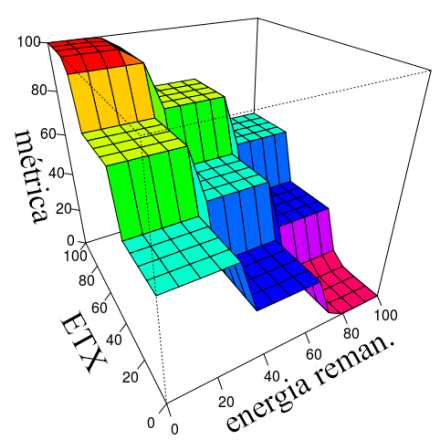

(b) MÉDIA DOS MÁXIMOS

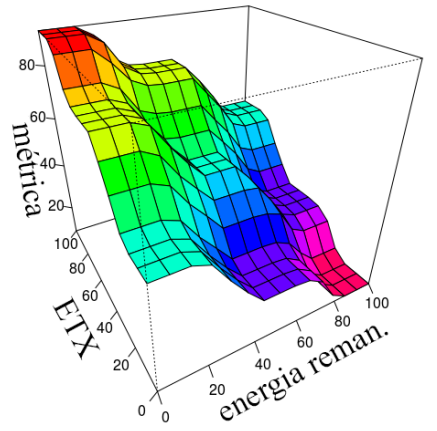

(c) CENTROIDE

Figura 36 - Superfície 3D demonstrando a relação entre os valores das métricas de entrada e os valores da métrica resultante da combinação que cada método de defuzificação provê. As cores da superfície são meramente ilustrativas não representando informação relevante.

Fonte: autor.

Por fim, realizamos uma análise de escalabilidade através da aplicação de pesos diferenciados às métricas avaliadas de acordo com a necessidade do ambiente da rede. Observamos que diferentes estratégias apresentaram bons resultados para prioridades distintas, como o aumento no tempo de vida da rede ou redução no atraso fim a fim. Desta forma, podemos definir diferentes estratégias de acordo com a necessidade do ambiente da rede.

Através da análise dos resultados das combinações das métricas e análise da superfície de relação entre as métricas de entrada e a métrica de saída que cada método provê, exibido na Figura 36, podemos concluir que um método de combinação de métricas que resulte em uma superfície plana e linear, como a apresentada na Figura 36a, tem grandes chances de obter melhores resultados em SDWSN comparado a outras superfícies desde que não haja prioridade entre as métricas. 
Deixamos como trabalhos futuros a análise de outros métodos e algoritmos para a combinação de métricas incluindo a possibilidade da variação do peso das métricas de forma dinâmica em resposta ao estado atual da rede. Também é interessante analisar outras métricas para a combinação como atraso fim a fim no intuito de reduzir o atraso na entrega de pacotes e taxa de transferência (throughtput) com a finalidade de dividir o congestionamento em rotas alternativas. 


\section{REFERÊNCIAS ${ }^{1}$}

ALVES, R. C. et al. IT-SDN: Improved architecture for SDWSN. In BRAZILIAN SYMPOSIUM ON COMPUTER NETWORKS AND DISTRIBUTED SYSTEMS. Proceedings... [S.1.], 2017.

Alves, R. C. A. et al. The cost of software-defining things: A scalability study of software-defined sensor networks. IEEE Access, vol. 7, p. 115093-115108, 2019.

BOSLAUGH, S. Statistics in a Nutshell, 2nd Edition. O'Reilly Media, Incorporated, 2012. ISBN 9781449361129. Available from Internet: < https://www.oreilly.com/ library/view/statistics-in-a/9781449361129>.

CAMILO, T. et al. An energy-efficient ant-based routing algorithm for wireless sensor networks. In DORIGO, M. et al. (Ed.). Proceedings... Berlin, Heidelberg: Springer Berlin Heidelberg, 2006. p. 49-59. ISBN 978-3-540-38483-0.

CHANG, L. H. et al. Energy-efficient oriented routing algorithm in wireless sensor networks. In IEEE INTERNATIONAL CONFERENCE ON SYSTEMS, MAN, AND CYBERNETICS. Proceedings... [S.1.], 2013. p. 3813-3818. ISSN 1062-922X.

COUTO, D. S. D. et al. A high-throughput path metric for multi-hop wireless routing. Wireless networks, Springer-Verlag New York, Inc., vol. 11, no. 4, p. 419-434, 2005.

CULLER, D.; ESTRIN, D.; SRIVASTAVA, M. Guest editors' introduction: Overview of sensor networks. Computer, vol. 37, no. 8, p. 41-49, Aug 2004. ISSN 0018-9162.

DERNONCOURT, F. Introduction to fuzzy logic. Massachusetts Institute of Technology, vol. 21, 2013.

DUNKELS, A. The contikimac radio duty cycling protocol. Swedish Institute of Computer Science, 2011.

DUNKELS, A.; GRONVALL, B.; VOIGT, T. Contiki - a lightweight and flexible operating system for tiny networked sensors. In IEEE INTERNATIONAL CONFERENCE ON LOCAL COMPUTER NETWORKS. Proceedings... [S.1.], 2004. p. 455-462. ISSN 0742-1303.

GALLUCCIO, L. et al. Sdn-wise: Design, prototyping and experimentation of a stateful sdn solution for wireless sensor networks. In IEEE CONFERENCE ON COMPUTER COMMUNICATIONS. Proceedings. [S.1.], 2015. p. 513-521. ISSN 0743-166X.

\footnotetext{
${ }^{1}$ De acordo com a Associação Brasileira de Normas Técnicas (ABNT NBR 6023)
} 
GHAFFARI, A. An energy efficient routing protocol for wireless sensor networks using a-star algorithm. Journal of Applied Research and Technology, vol. 12, no. 4, p. 815 - 822, 2014. ISSN 1665-6423. Available from Internet: $<$ http://www.sciencedirect.com/science/article/pii/S1665642314700975>.

HAVERKORT, B.; WILEY, J. Performance of computer communication systems: a model-based approach. [s.n.], 1998. 432 p. ISBN 0470841923. Available from Internet: <http://www.getcited.org/pub/100340325>.

HILL, J. et al. System architecture directions for networked sensors. ACM SIGOPS operating systems review, ACM, vol. 34, no. 5, p. 93-104, 2000.

IANCU, I. A mamdani type fuzzy logic controller. In Fuzzy logic-controls, concepts, theories and applications. [S.1.]: IntechOpen, 2012.

JUNLI, F.; YAWEN, W.; HAIBIN, S. An improved energy-efficient routing algorithm in software define wireless sensor network. In IEEE INTERNATIONAL CONFERENCE ON SIGNAL PROCESSING, COMMUNICATIONS AND COMPUTING. Proceddings... [S.1.], 2017. p. 1-5.

KAMGUEU, P. O.; NATAF, E.; DJOTIO, T. N. On design and deployment of fuzzy-based metric for routing in low-power and lossy networks. In IEEE LOCAL COMPUTER NETWORKS CONFERENCE WORKSHOPS. Proceedings... [S.1.], 2015. p. 789-795.

Kobo, H. I.; Hancke, G. P.; Abu-Mahfouz, A. M. Towards a distributed control system for software defined wireless sensor networks. In IECON 2017 - 43rd Annual Conference of the IEEE Industrial Electronics Society. [S.1.: s.n.], 2017. p. 6125-6130.

LAMAAZI, H.; BENAMAR, N. RPL enhancement using a new objective function based on combined metrics. In INTERNATIONAL WIRELESS COMMUNICATIONS AND MOBILE COMPUTING CONFERENCE. Proceedings... [S.1.], 2017. p. 1459-1464.

LEE, T. H.; XIE, X. S.; CHANG, L. H. RSSI-based IPv6 routing metrics for RPL in low-power and lossy networks. In Proceedings... [S.1.: s.n.], 2014. p. 1714-1719. ISSN 1062-922X.

LEVIS, P. et al. TinyOS: An operating system for sensor networks. Ambient Intelligence, p. 115-148, 2005. ISSN 01681699. Available from Internet: $<$ http://www.springerlink.com/index/10.1007/b138670>.

LUO, T.; TAN, H.-P.; QUEK, T. Q. Sensor openflow: Enabling software-defined wireless sensor networks. IEEE Communications letters, IEEE, vol. 16, no. 11, p. 1896-1899, 2012.

MAHMUD, A.; RAHMANI, R. Exploitation of openflow in wireless sensor networks. In IEEE COMPUTER SCIENCE AND NETWORK TECHNOLOGY. Proceedings... [S.1.], 2011. vol. 1, p. 594-600. 
MARGI, C.; OLIVEIRA, D. Roteamento ciente de energia em redes de sensores sem fio definidas por software. In Proceedings... São Pedro, SP: XXXV SIMPOSIO BRASILEIRO DE TELECOMUNICAÇÕES E PROCESSAMENTO DE SINAIS, 2017. Available from Internet: < http://www.sbrt.org.br/sbrt2017/anais/1570361214. pdf $>$.

MODIEGINYANE, K. M. et al. Software defined wireless sensor networks application opportunities for efficient network management: A survey. Computers $\mathcal{F}$ Electrical Engineering, 2017. ISSN 0045-7906. Available from Internet: $<$ http://www.sciencedirect.com/science/article/pii/S0045790617304159>.

MOTEIV, tmote sky for Low Power Wireless Sensor Module. [S.1.], 2006. 2 p. Último acesso em 03 de Abril, 2018. Available from Internet: < http://www.eecs.harvard.edu/ $\sim$ konrad/projects/shimmer/references/tmote-sky-datasheet.pdf $>$.

OLIVEIRA, B. T. D.; GABRIEL, L. B.; MARGI, C. B. TinySDN: Enabling multiple controllers for software-defined wireless sensor networks. IEEE Latin America Transactions, IEEE, vol. 13, no. 11, p. 3690-3696, 2015.

OLIVEIRA, B. T. D.; MARGI, B. Distributed Control Plane Architecture for Software-Defined Wireless Sensor Networks. p. 1-2, 2016.

OLIVEIRA, B. T. de; ALVES, R. C. A.; MARGI, C. B. Software-defined wireless sensor networks and internet of things standardization synergism. In IEEE CONFERENCE ON STANDARDS FOR COMMUNICATIONS AND NETWORKING. Proceedings... [S.1.], 2015. p. 60-65.

Oliveira, D. A. G.; Margi, C. B. Combining metrics for route selection in sdwsn: Static and dynamic approaches evaluation. In IEEE LATIN-AMERICAN CONFERENCE ON COMMUNICATIONS. Proceedings... [S.1.], 2018. p. 1-6.

OSTERLIND, F. et al. Cross-level sensor network simulation with COOJA. In IEEE CONFERENCE ON LOCAL COMPUTER NETWORKS. Proceedings... [S.1.], 2006. p. 641-648. ISSN 0742-1303.

Pantazis, N. A.; Nikolidakis, S. A.; Vergados, D. D. Energy-efficient routing protocols in wireless sensor networks: A survey. IEEE Communications Surveys Tutorials, vol. 15, no. 2, p. 551-591, Second 2013. ISSN 2373-745X.

QASEM, M. et al. A new efficient objective function for routing in internet of things paradigm. In IEEE CONFERENCE ON STANDARDS FOR COMMUNICATIONS AND NETWORKING. Proceedings... [S.1.], 2016. p. 1-6.

SANDRI, S.; CORREA, C. Lógica nebulosa. Instituto Tecnológico da AeronáuticaITA, V Escola de Redes Neurais, pp. C073-c090, São José dos Campos, 1999.

WENXING, L.; MUQING, W.; YUEWEI, W. Energy-efficient algorithm based on multi-dimensional energy space for software-defined wireless sensor networks. In INTERNATIONAL SYMPOSIUM ON WIRELESS COMMUNICATION SYSTEMS. Proceedings... [S.1.], 2016. p. 309-314. 
WINTER P. THUBERT, E. A. B. J. H. R. K. P. L. K. P. R. S. J. V. R. A. E. T. RPL: IPv6 Routing Protocol for Low-Power and Lossy Networks. [S.1.], 2012. Available from Internet: <https://www.rfc-editor.org/info/rfc6550>.

XIANG, W.; WANG, N.; ZHOU, Y. An energy-efficient routing algorithm for software-defined wireless sensor networks. IEEE Sensors Journal, vol. 16, no. 20, p. 7393-7400, Oct 2016. ISSN 1530-437X. 